\title{
A new light on dipyridamole (Persantin) and polyurethane biomaterials
}

Citation for published version (APA):

Aldenhoff, Y. B. J. (2001). A new light on dipyridamole (Persantin) and polyurethane biomaterials.

[Doctoral Thesis, Maastricht University]. Universiteit Maastricht. https://doi.org/10.26481/dis.20011128ya

Document status and date:

Published: 01/01/2001

DOI:

10.26481/dis.20011128ya

Document Version:

Publisher's PDF, also known as Version of record

\section{Please check the document version of this publication:}

- A submitted manuscript is the version of the article upon submission and before peer-review. There can be important differences between the submitted version and the official published version of record.

People interested in the research are advised to contact the author for the final version of the publication, or visit the DOI to the publisher's website.

- The final author version and the galley proof are versions of the publication after peer review.

- The final published version features the final layout of the paper including the volume, issue and page numbers.

Link to publication

\footnotetext{
General rights rights.

- You may freely distribute the URL identifying the publication in the public portal. please follow below link for the End User Agreement:

www.umlib.nl/taverne-license

Take down policy

If you believe that this document breaches copyright please contact us at:

repository@maastrichtuniversity.nl

providing details and we will investigate your claim.
}

Copyright and moral rights for the publications made accessible in the public portal are retained by the authors and/or other copyright owners and it is a condition of accessing publications that users recognise and abide by the legal requirements associated with these

- Users may download and print one copy of any publication from the public portal for the purpose of private study or research.

- You may not further distribute the material or use it for any profit-making activity or commercial gain

If the publication is distributed under the terms of Article $25 \mathrm{fa}$ of the Dutch Copyright Act, indicated by the "Taverne" license above, 
A new light on dipyridamole (Persantin ${ }^{\circledR}$ ) and polyurethane biomaterials 
Aldenhoff, Yvette B.J.

A new light on dipyridamole (Persantin ${ }^{8}$ ) and polyurethane biomaterials Thesis Maastricht, 2001

ISBN 90-9015173-7

Druk: Datawyse, Maastricht

OY.B.J. Aldenhoff, Maastricht 2001 


\section{A new light on dipyridamole (Persantin ${ }^{\circledR}$ ) and polyurethane biomaterials.}

\section{PROEFSCHRIFT}

ter verkrijging van de graad van doctor aan de

Universiteit Maastricht, op gezag van

de Rector Magnificus, Prof. Dr. A.C. Nieuwenhuizen Kruseman

volgens het besluit van het College van Decanen, in het openbaar te verdedigen op woensdag 28 november 2001 om 14:00 uur

door

Yvette Barbara Johanna Aldenhoff 


\section{Promotor:}

Prof. dr. L.H. Koole

\section{Beoordelingscommissie:}

Prof. dr. F.W. Bär (voorzitter)

Prof. dr. J. Ottenheim

Prof. dr. J. Rosing

Prof. dr. E. Schacht (Universiteit Gent)

Het verschijnen van dit proefschrift werd mede mogelijk gemaakt door de steun van de Nederlandse Vereniging voor Biomaterialen. 


\section{Contents}

\section{Chapter 1 Introduction}

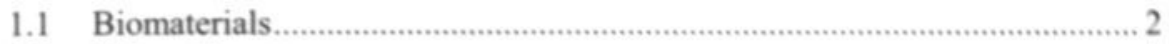

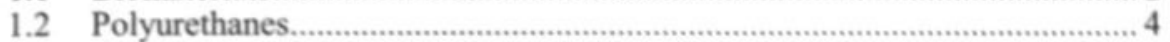

1.3 Role of bloodplatelets in blood-material interaction.................................. 6

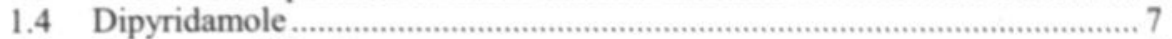

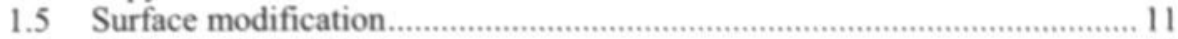

1.6 Outline of this thesis. ........................................................................... 14

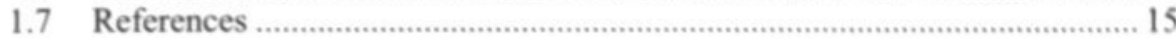

Chapter 2 Studies on a new strategy for surface modification of polymeric biomaterials

$2.1 \quad$ Abstract.

2.2 Introduction ..................................... 22

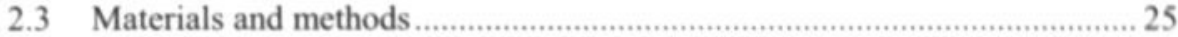

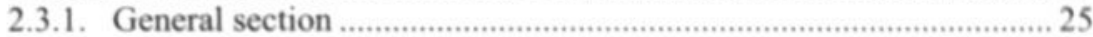

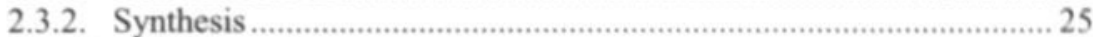

2.4 Results and Discussion ................................................................... 29

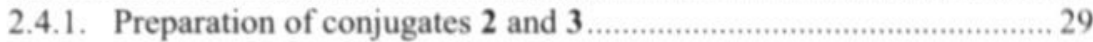

2.4.2. Photochemistry of $p$-azidophenyl compounds ............................... 34

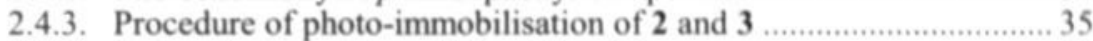

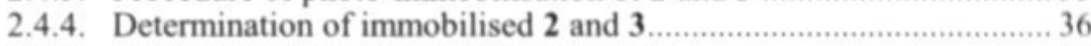

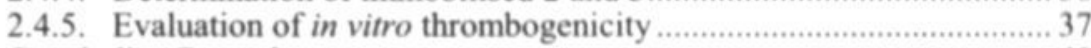

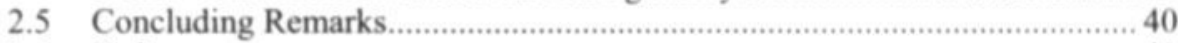

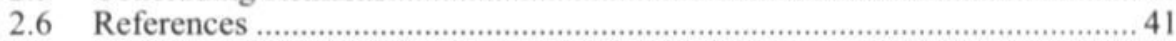

Chapter 3 Photo-immobilisation of dipyridamole (Persantin ${ }^{\star}$ ) at the surface of polyurethane biomaterials. Reduction of thrombogenicity

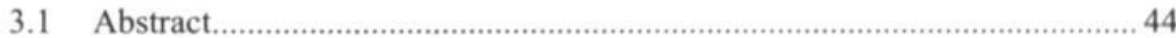

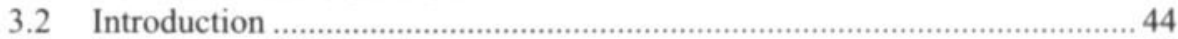

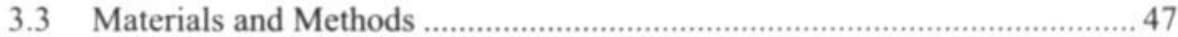

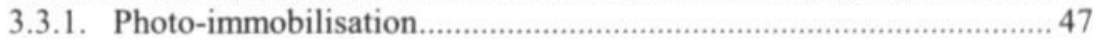

3.3.2. Physico-chemical characterisation .............................................. 48

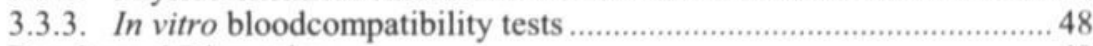

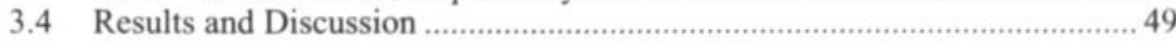

3.4.1. Physico-chemical characterisation ................................................. 49

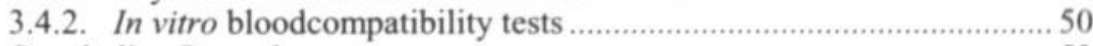

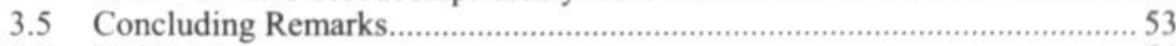

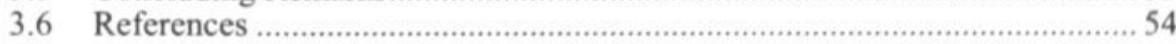


Chapter 4 Synthesis of a new photoreactive derivative of dipyridamole and its use in the manufacture of artificial surfaces with low thrombogenicity

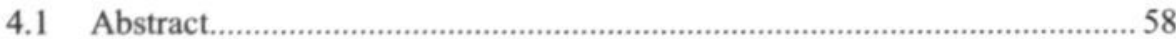

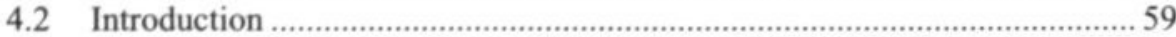

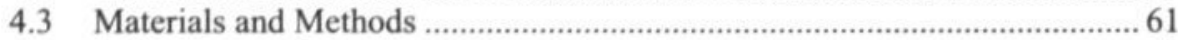

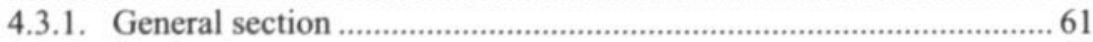

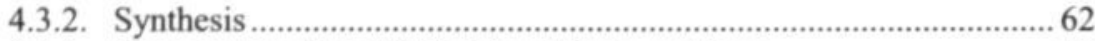

4.3.3. Preparation of modified polyurethane surfaces...................................... 64

4.3.4. Physico-chemical characterisation .................................................64 64

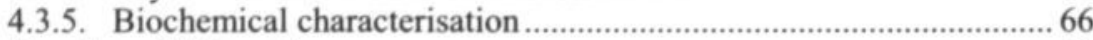

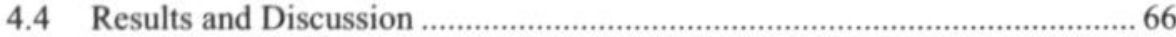

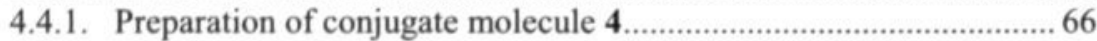

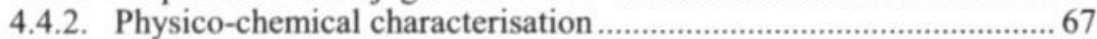

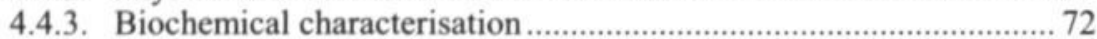

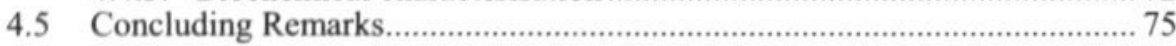

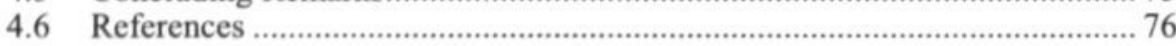

Chapter 5 Platelet adhesion studies on dipyridamole coated polyurethane surfaces

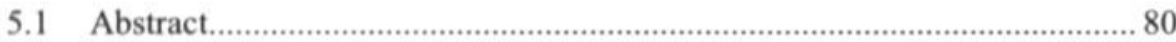

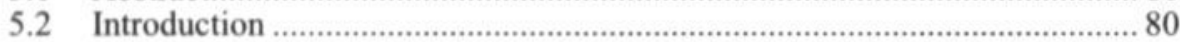

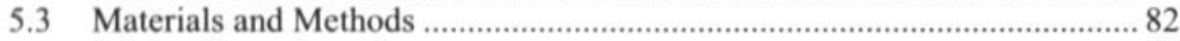

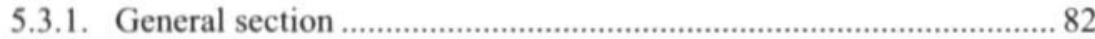

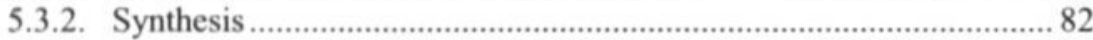

5.3.3. Preparation of modified polyurethane surfaces.................................. 84

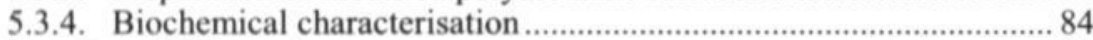

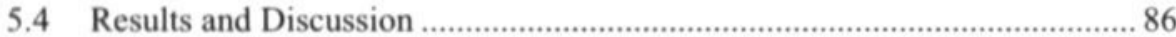

5.4.1. Preparation of conjugate molecule 26 .......................................... 86

5.4.2. Preparation of modified polyurethane surfaces................................. 86

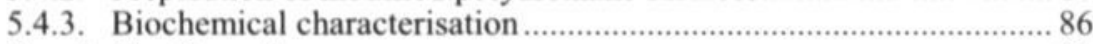

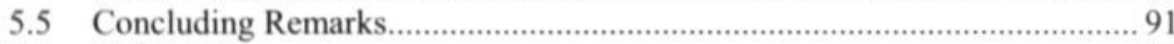

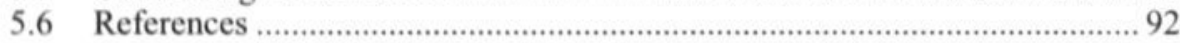

Chapter 6 Performance of a polyurethane vascular prosthesis carrying a dipyridamole (Persantin ${ }^{\star}$ ) coating on its lumenal surface

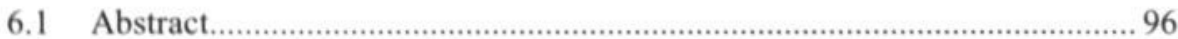

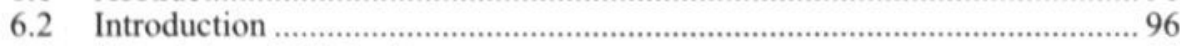

6.3 Materials and Methods .................................................................... 98

6.3.1. Immobilisation of dipyridamole onto the lumen of the Chronoflex ${ }^{*}$ vascular prosthesis ................................................ 98

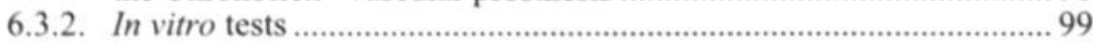

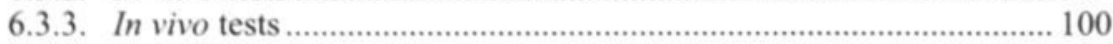

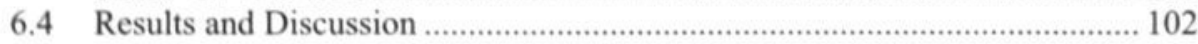

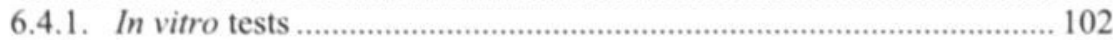

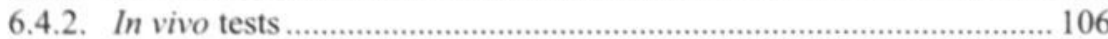

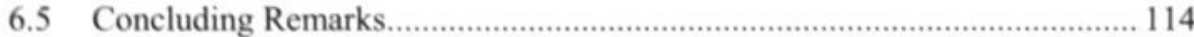

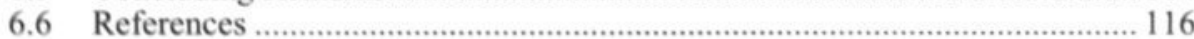


Summary and Concluding Remarks......................................................... 119

Samenvatting en Conclusie ........................................................................ 124

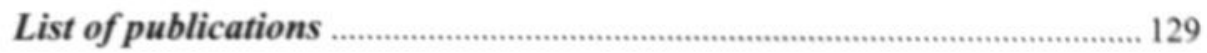

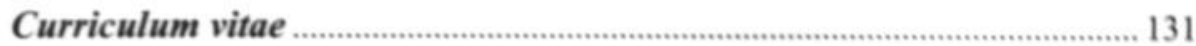

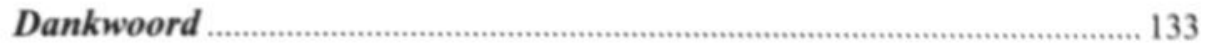


xas 


\section{CHAPTER 1}

A general introduction to this thesis 


\subsection{Biomaterials}

Biomaterials are defined as substances, other than food or drugs, contained in therapeutic or diagnostic systems that are used in contact with tissue or biological fluids. ${ }^{1}$ Biomaterials can be classified in many different ways, e.g., with respect to their composition: polymers, metals, and ceramics (Table 1). ${ }^{2,3}$ The applications for biomaterials (medical implants) can be found in many disciplines of modern medicine such as orthopaedic surgery, ophthalmology, cardiovascular surgery, facial surgery, dentistry etc.(Table 2). The development of biomaterials used in medical devices has

Table 1. Classification of biomaterials.

\begin{tabular}{c}
\hline Polymers \\
Polyethylene \\
Poly(ethylene terephtalate) \\
Poly(lactic acid) \\
Poly(methyl methacrylate) \\
Polyurethanes \\
Poly(tetrafluoro ethylene) \\
Poly(vinyl chloride) \\
Silicone rubber \\
Metals \\
Ceramics \\
Citainless steel \\
Titanium alloys \\
Cobalt chromium alloys \\
Alumina \\
Hydroxyapatite \\
Carbon \\
\hline
\end{tabular}

occurred in response to the growing number of patients afflicted with traumatic and non-traumatic conditions. As the population grows older, there is an increased need for medical devices to replace damaged or worn-out tissue. ${ }^{3}$ The use of polymeric cardiovascular biomaterials will be outlined in more depth since this thesis is focussed on polymeric biomaterials in the use of vascular prostheses.

Approximately 850.000 vascular reconstructions are performed worldwide each year. ${ }^{4}$ In most cases, the conduit of choice is an autologous vessel, such as the saphenous vein or internal mammary artery. However, an increasing 
number of patients have limited autologous vein available because of removal for other reconstructive procedures or poor conditions due to preexisting conditions like diabetes mellitus, post-thrombotic syndrome, or hypoplasia of the superficial venous system. In these cases, the use of polymeric vascular prostheses is mandated. The most commonly used polymeric biomaterials in the field of artificial blood vessels are: Dacron (poly(ethylene terephtalate)) and ePTFE (poly(tetrafluoro ethylene)). Vascular prostheses can be classified in large diameter $(5-38 \mathrm{~mm})$ prostheses and small diameter $(<5 \mathrm{~mm})$ prostheses. The distinction between these two is based on the degree of blood compatibility.

Table 2. Examples of applications of biomaterials.

\begin{tabular}{|c|c|}
\hline Cardiovascular surgery & $\begin{array}{l}\text { Cardiac valves } \\
\text { Catheters } \\
\text { Pace makers } \\
\text { Shunts } \\
\text { Stents } \\
\text { Vascular grafts }\end{array}$ \\
\hline Dentistry & Denture bases \\
\hline Drug delivery devices & $\begin{array}{c}\text { Coatings for tablets or capsules } \\
\text { Osmotically controlled pumps } \\
\text { Transdermal patches }\end{array}$ \\
\hline Extracorporeal devices & $\begin{array}{l}\text { Blood pumps } \\
\text { Dialysers } \\
\text { Oxygenerators }\end{array}$ \\
\hline Ophthalmology & $\begin{array}{c}\text { Contact lenses } \\
\text { Intraocular lenses }\end{array}$ \\
\hline Orthopaedic surgery & $\begin{array}{c}\text { Bone cement } \\
\text { Fixation } \\
\text { Hip joints } \\
\text { Knee joints }\end{array}$ \\
\hline Plastic and reconstructive surgery & $\begin{array}{l}\text { Breast implants } \\
\text { Ear replacements } \\
\text { Nose prostheses } \\
\text { Tendon prostheses }\end{array}$ \\
\hline
\end{tabular}


Clinical studies have demonstrated that Dacron ${ }^{8}$ leads to thrombosis and neo-intimal thickening under low-flow conditions, meaning its use should be limited to large diameter vessel replacement, such as replacement of the aorta, carotid arteries andfemoral arteries. ${ }^{3,5,6}$ ePTFE is currently the only alternative to autologous materials in small diameter vessel replacements. Their biocompatibility and long-term patency, however, is not optimal. ${ }^{7,8}$ Clinical studies have shown a long-term patency of approximately $75 \%$ for autologous vein replacement at 2 years after implantation, while ePTFE small-diameter prostheses show a long-term patency of approximately $30 \% .{ }^{4.8}$ These long-term patency rates of currently available synthetic vascular prostheses are very disappointing, and there is an urgent need for new polymeric small-diameter vascular prostheses.

\subsection{Polyurethanes}

Polyurethane is a generic term that refers to polymers containing the $-[\mathrm{NH}-$ COO-]- repeating linkage within the molecular chain. Polyurethane is considered as one of the most bio-and bloodcompatible materials known today due to their structure/property diversity. ${ }^{9}$ Polyurethanes differ in nature, some being linear thermoplastics and some cross-linked polymers. ${ }^{10.11}$ Polyurethane elastomers are block copolymers that consist of alternating blocks of "hard" and "soft" segments (segmented polymers). The structural properties of polyurethane elastomers can be characterised as follows:

- The hard and rigid urethane segments separate into glassy or semicristalline domains.

- The soft and flexible polyether segments form an amorphous or semicristalline matrix in which the hard domains are dispersed.

- The hard domains act as multifunctional cross linking sites and as reinforcing fillers which result in stiff and flexible materials.

- The driving force for the segregation into domains is provided by the chemical incompatibility of the hard and soft segments. 
By varying the constituents of hard and soft segments in the polymer chain a whole range of polyurethanes can be prepared forming hard and brittle to soft and tough materials. The main constituents of any polyurethane elastomer are diisocyanate, a long chain hydroxy-terminated macroglycol (e.g., ether or ester), and a chain extender (e.g., glycol or a diamine). Polyurethanes like Bionate $^{*}$, Chronoflex $^{*}$, Estane ${ }^{*}$, Pellethane ${ }^{*}$, Tecoflex $^{*}$, etc. are widely used for biomedical applications (see Table 3 for more information on their composition).

Table 3. (Bio)medical grade polyurethanes.

\begin{tabular}{|c|c|c|}
\hline Material & Composition & Source \\
\hline $\begin{array}{l}\text { Bionate } \\
\text { (formerly Corethane) }\end{array}$ & $\begin{array}{c}\text { MDI/BDO or } \\
\text { EG/polycarbonate }\end{array}$ & $\begin{array}{l}\text { Polymer Technology group, } \\
\text { Inc. }\end{array}$ \\
\hline Chronoflex ${ }^{*}$ & $\mathrm{HMDI} / \mathrm{BDO} /$ polycarbonate & Cardiotech International, Inc \\
\hline Estane $^{*}$ & $\mathrm{MDI} / \mathrm{BDO} /$ polyethers & B.F. Goodrich, Inc \\
\hline Pellethane $^{*} 2363$ series & MDI/BDO/PTMO & Dow Chemical, Inc \\
\hline Tecoflex ${ }^{8}$ & $\mathrm{HMDI} / \mathrm{BDO} / \mathrm{PTMO}$ & Thermedics, Inc \\
\hline
\end{tabular}

BDO=1,4-butanediol; EG-ethyleneglycol; $\mathrm{HMDI}=$ hydrogenated methylene disocyanate; $\mathrm{MDI}=$ methylene diisocyanate; PTMO=polytetramethylene oxide.

Nowadays, polyurethanes are used in cardiovascular applications, artificial organs, tissue replacement and many other applications. The use of polyurethanes in the cardiovascular surgery dominates the field and they gained popularity as a potential synthetic vascular reconstructive material. A clear advantage over Dacron ${ }^{\star}$ is that the physical properties of polyurethane can be tuned accurately which provides a means to minimize the risk of complications due to compliance mismatch, whereas Dacron ${ }^{*}$ tends to be rather stiff. An advantage of polyurethanes over ePTFE is that polyurethanes expose reactive functional groups at their surface, whereas ePTFE is chemically inert. Polyurethanes, however, have one important drawback; they have a moderate blood compatibility, but the reactive functional groups exposed at the surface of polyurethanes can be used in surface modification reactions, aimed at the manufacture of a more blood compatible surface.

Two kinds of polyurethanes have been used in the course of the work described in this thesis: (1) Pellethane ${ }^{\star}$ 2363-D55 (polyether-based 
polyurethane), transparent foil, to study the surface modification and the in vitro experiments, and (2) Chronoflex ${ }^{*}$ (polycarbonate polyurethane), porous tubing, to perform the in vivo experiments. The ultimate goal of this study was to optimize the bloodcompatibility of these polyurethanes.

\subsection{Role of bloodplatelets in blood-material interactions}

Bloodplatelets (thrombocytes) are disc shaped fragments of bone marrow megakaryotes circulating in blood $(250.000 \pm 80.000$ per $\mu \mathrm{l})$. They have a life span of approximately 8 to 10 days and play a key role in the recognition of vascular injury, formation of hemostatic plugs, and wound healing. ${ }^{12}$ The platelet plasma membrane contains glycoproteins as well as transmembrane proteins (integrins and nonintegrin domains). The glycoproteins serve as receptors for agonist/surface-mediated stimuli initiating platelet activation. The integrins participate in cell-cell and cell-matrix interactions, while the nonintegrins interact with macromolecules such as von Willebrand factor and collagen. When platelets are activated they can initiate severe clinical complications associated with cardiovascular and cerebrovascular diseases. There are four stages of activation: ( i) development of stickiness, (ii) changes in cell shape, (iii) contraction and release of granula contents, and (iv) irreversible aggregation.

When platelets interact with the subendothelial matrix their shape will change from their normal disc shape to a more round form, extend pseudopods, and become adherent to the surface. ${ }^{13,14}$ Then, they may release their granula contents into the surrounding media, which include ADP, ATP, calcium, platelet factors, fibrinogen etc. ${ }^{15}$

When a biomaterial surface comes in contact with blood, a variety of blood components interact with the surface. The activation of platelets by contact with an artificial surface is a key event in the thromboembolic complications of prosthetic devices in contact with blood. ${ }^{16}$ It is known that a plasma protein layer will absorb on the biomaterial surface first, leading to interaction of the surface with blood cells. ${ }^{17}$ Proteins like fibrinogen globulins and albumin are rapidly deposited and are partially replaced over by time by high-molecular weight kininogen and Hageman factor. ${ }^{18}$ Fibronectin, hemoglobin and von Willebrand factor are also deposited on artificial surfaces. ${ }^{19}$ Platelet adhesion to 
the biomaterial surface, which is called surface-induced platelet activation, occurs in the same way as to the subendothelial matrix. Difazio described platelet-surface interactions as follows: first, platelet-surface adhesion occurs between platelet surface receptors and the adsorbed matrix proteins. ${ }^{20}$ The matrix proteins dictate the degree of activation, for instance fibronectin promotes spreading and collagen supports aggregation and secretion. Secondly, the platelet-surface adhesion results in platelet activation, with subsequent degranulation and the release of platelet activating factors. Finally, a thrombus will be formed due to the deposition of blood elements and recruitment of platelets.

The research on blood-compatible biomaterials must evolve from fundamental studies on the interplay between: $(i)$ the physicochemical properties of the surface (surface chemistry, surface morphology and surface energy); (ii) adsorption of plasma components and their exchange with other plasma proteins in the course of time (Vroman effect); and (iii) thrombogenicity of the surface, both in the initial phase after blood-material contact, and after prolonged time.

\subsection{Dipyridamole}

In 1951, Fisher and Roch were the first who described the synthesis of chemical structures containing two conjugated pyrimidine systems. ${ }^{21}$ These structures were classified as pyrimido(-5,4-d)pyrimidines. The similarity of the

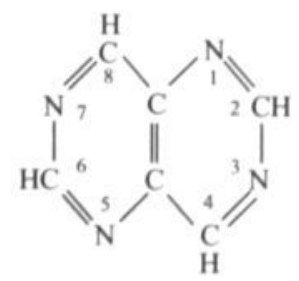

\section{Pyrimido(-5,4-d)pyrimidine}

chemical structure of the pyrimido(-5,4-d)pyrimidine and the purines, synthesizing derivatives of these compounds became very challenging. In the following years the research group of Dr. Karl Thomae GmbH synthesized a large number of these pyrimido(-5,4-d)pyrimidine derivatives and tested those 
compounds on their pharmacological properties. Among all the synthesized derivatives especially one was found to be of great interest, namely 2,6-Bis (diethanolamino)-4,8-dipiperino-pyrimido(5,4-d)pyrimidine. ${ }^{22}$ This compound, which was named dipyridamole (1) and marketed as Persantin ${ }^{*}$, is a yellow

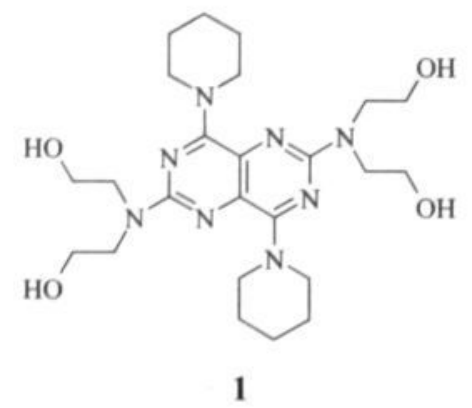

crystalline powder with a molecular weight of 504,6 and a melting point of 163 ${ }^{\circ} \mathrm{C}$. It is hardly soluble in water but easy soluble in aqueous acids, methanol and alcohol. The dipyridamole solutions are yellow and show an extensive bluegreen fluorescence which is due to the conjugated system in the molecular core.

The pharmacological properties of dipyridamole were first described in $19599^{22}$ It was found that dipyridamole had coronary vasodilating properties, without marked influence on the blood-pressure, heart-beat frequency, myocardial oxygen consumption and heart action. ${ }^{23-25}$ The acute toxicity of the drug was studied in mice, and the chronic toxicity in dogs what resulted in a remarkably low toxicity $\left(\mathrm{LD}_{50}\right.$ i.v. $0.15 \mathrm{~g} / \mathrm{kg}$; $\mathrm{LD}_{50}$ s.c. $2.7 \mathrm{~g} / \mathrm{kg}$ ). Beisenherz et al. studied the metabolism of dipyridamole and concluded that: (i) dipyridamole is rapidly adsorbed by the stomach and the small intestine, (ii) dipyridamole was eliminated from the blood in the liver by transformation into glucuronide (characterised as dipyridamole-monoglucuronide which also showed carotic activity), which is secreted with the bile into the small intestine, (iii) no dipyridamole was administered in the urine and only $1-3 \%$ of the dipyridamolemonoglucuronide, (iv) after intravenous and oral administration $50 \%$ of the applied dose was found in the faeces after 72 hours, and $(v)$ no evidence of accumulation of dipyridamole in the body was found. ${ }^{26}$

Dipyridamole was primarily introduced as an antianginal medication and originally marketed in $1959 .{ }^{22-26}$ In the following years it has been shown that dipyridamole has more pharmacological properties. Some of the most interesting studies will be discussed below. 
Emmons showed in 1965 that dipyridamole inhibited both platelet aggregation in humans and thrombus formation in the injured artery of rabbits. ${ }^{27.28}$ Reduction of thromboembolism by dipyridamole in patients with prosthetic vascular devices was demonstrated by Sullivan, ${ }^{29}$ and the reduction of reocclusion and development of artherosclerosis after coronary artery bypass grafting has been shown by Chesebro. ${ }^{30}$

In a rabbit model of restenosis dipyridamole (high dose) was found to prevent lumen narrowing after balloon injury, ${ }^{31}$ and to reduce intimal thickening in the baboon after arterial injury. ${ }^{32}$ Dipyridamole did however not reduce restenosis after coronary angioplasty in human clinical trials. ${ }^{33,34}$ An explanation for this could be that dipyridamole has shown to bind to serum proteins; after intraveneous administration as much as $99 \%$ of the dipyridamole in serum remains bound to serum proteins. ${ }^{35}$ Niewiarowski hypothesized that a direct application at the site of injury may inhibit restenosis. This was demonstrated by Singh, he showed that locally delivered dipyridamole resulted in a significant reduction in intimal thickening in an animal model of vascular smooth muscle cell proliferation. ${ }^{36}$

Antiplatelet agents like dipyridamole, and dipyridamole derivatives like mopidamol, RA-233 etc, are capable of preventing tumor cell-platelet interactions in vitro and in vivo. ${ }^{37-39}$ Several studies have shown blood platelets play an important role in tumor metastasis. Recently, it was demonstrated that when dipyridamole is combined with the dipyridamole derivative RA-233, synergistic actions are seen in the blockade of tumor cell-induced platelet aggregation and liver metastasis. The synergistic action of dipyridamole and RA-233 could be attributed to the biochemical effects on intracellular cAMP levels. The increase of intracellular cAMP levels in tumor cells can inhibit cell proliferation. ${ }^{40}$

More recently, many research groups investigated the effect of dipyridamole and inhaled nitric oxide (iNO) on pulmonary hypertension/vasodilation. iNO is a new therapy for persistent pulmonary hypertension of the newborn (PPHN) that improves oxygenation and decreases the need for extracorporeal membrane oxygenation (ECMO). iNO is believed to diffuse into pulmonary vascular smooth muscle cells where it stimulates soluble guanylate cyclase to produce the second messenger cGMP, which then mediates vascular relaxation of the pulmonary circulation. Phosphodiesterase V (PDE5) binds and hydrolyzes cGMP with high specificity relative to cAMP. 


\section{Chapter 1}

One strategy to enhance the pulmonary vascular effects of iNO could be to inhibit cGMP inactivation by PDE5. Recent studies showed that dipyridamole, which is believed to be an inhibitor of PDE5, inhibits PDE5 resulting in inhibition of cGMP inactivation. ${ }^{41-44}$

The interaction of blood platelets with subendothelium plays a key role in the early stages of arterial thrombosis. Damage of the vascular endothelial cell layer will result in exposure of subendothelial structures to which circulating platelets adhere. In vitro studies showed that when cultured human umbilical vein endothelial cells were treated with dipyridamole, the extracellular matrix which is produced by the endothelial cells, is less thrombogenic to circulating platelets. This could be attributed to the production of vascular prostacyclin by the endothelial cells in response to increased levels of cAMP. ${ }^{45}$

Ever since the introduction of dipyridamole as a drug, its exact mechanism of action has been the subject of many controversy. ${ }^{46}$ There are several postulated mechanisms of action of dipyridamole:

- Dipyridamole could inhibit the phosphodiesterase enzyme in blood platelets which will results in (i) an increase in intracellular cyclic AMP (cAMP), and (ii) the consequent potentiation of the platelet-inhibiting actions of prostacyclin.

- Dipyridamole could directly stimulate the release of eicosanoid (such as prostacyclin) by the vascular endothelium.

- Dipyridamole could inhibit cellular uptake and metabolism of adenosine, which eventually will lead to an increase of its concentration at the plateletvascular interface.

Nowadays dipyridamole is one of the most prescribed drugs in general practice, and amongst cardiovascular physicians and surgeons. ${ }^{47,48}$ Dipyridamole is mostly prescribed in combination with aspirin after coronary artery bypass grafting and as an adjunct to oral anticoagulation following prosthetic heart valve replacement. Dipyridamole is also widely used for myocardial imaging due to the coronary vasodilating property of dipyridamole, which is particularly valuable in patients who are unable to perform an exercise test. $^{49,50}$ 


\subsection{Surface modification}

Work by Bamford and co-workers implied that dipyridamole could play a role in the development of new blood compatible materials. ${ }^{51-53}$ Dipyridamole was converted with methacrylic acid to a monomethacrylate ester of dipyridamole (DIMA), which was copolymerized with water-soluble polymers. These materials showed that the drug retained its platelet-inhibitory activity, in some cases these materials were even significantly more active than the drug itself. This work prompted us to couple dipyridamole covalently onto polyurethane, which is a non-soluble polymer.

While the mechanical properties of a medical device are determined by the bulk of the material, the haemocompatibility is determined by its surface. Surface modifications of biomaterials has become a very popular method of developing new biomaterials, since it is often more efficient than the development of a new biomedical material. ${ }^{54,55}$ Surface modification of surfaces can be divided in physical modifications and chemical modifications:

- Physical modifications include: (i) adsorption of compounds like albumin, ${ }^{56.57}$ heparin, ${ }^{58}$ or phospholipids ${ }^{59}$ to the surface, (ii) attachment of polymers physically to the surface of other polymers, ${ }^{58}$ (iii) seeding of endothelial cells onto the surface. ${ }^{60-63}$

- Chemical modifications include (i) plasma treatment of biomaterials for example to incorporate chemical groups such as hydroxyl and/or amino groups, ${ }^{64,65}$ (ii) covalently coupling of alkyl groups, PEO, heparin, phospholipids, prostaglandins, dipyridamole etc. ${ }^{51,66-69}$

Here a new method for chemical modification of polyurethanes is described. The approach we used rests upon the use of a new type of conjugate molecules that can be schematically drawn as follows: 


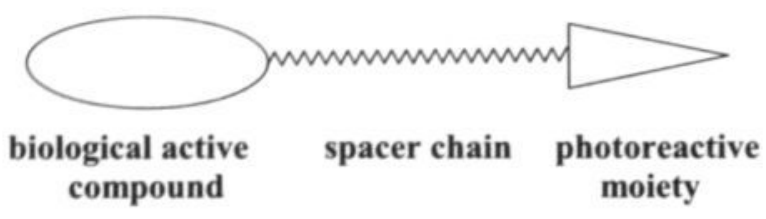

The photoreactive moiety, $p$-azidophenyl group, is used for the covalent coupling of the conjugate molecule onto the polyurethane surface. Irradiation with ultraviolet (UV) light transfers the $p$-azidophenyl group into a photochemically excited state from which reaction with nucleophiles occur easily.

The photoreactivity of arylazides has been studied in great depth. ${ }^{70}$ The first aryl azide (more familiarly known as phenyl azide) to be described was azidobenzene, which Peter Griess reported in 1864 after having obtained it from the reaction of benzenediazonium tribromide with ammonia. Although phenyl azides are colourless they absorb in the near ultraviolet $\left(\lambda_{\max } \sim 280,277\right.$, and $248 \mathrm{~nm}$ ). Like halogens, the azido substituent has a moderate electronwithdrawing effect on the benzene ring, and also interacts mesomerically with the benzene ring in such a way as to counteract the inductive effect. Electron release resulting from polarizability is still greater, such that the azido group actually activates the ring toward electrophilic attack. The most general and widely used method for the preparation of phenyl azides is diazotization of the corresponding aniline followed by addition of sodium azide. The method for generation of phenylnitrenes is thermolysis or photolysis. Thermolysis requires temperatures in the range of $130-180{ }^{\circ} \mathrm{C}$. Photolysis is effected by near-UV radiation; even sun light can be used. Thermolysis and photolysis results in

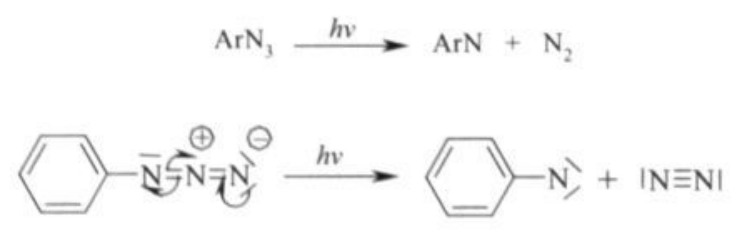

losing two of the three nitrogens as $\mathrm{N}_{2}$. The reactivity of the nitrene is related to the fact that the remaining nitrogen-atom, attached to the ring, is electron deficient (octet rule is not obeyed). Nitrenes posses only six valence electrons at the nitrogen. Two electronic configurations of reasonable low energies are 
important for the chemical reaction of the nitrenes. Singlet nitrenes have their valence electrons paired on nitrogen, two pairs occupy an orbital each and one

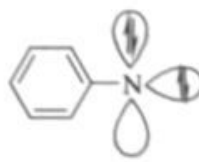

singlet state

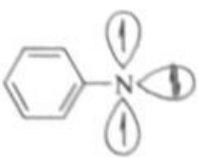

triplet state

orbital is empty and ready to accept an electron pair to complete the nitrogen octet. Triplet nitrenes have, in addition to four paired electrons, two of parallel spin, one each in an orbital on nitrogen. Photolysis of phenyl azides give rise to surprisingly varied group of products, whose identity and number are influenced by temperature, medium, substituents and nature of the initiating impulse. The reactions are seldom clean and modest yield of identifiable products are commonly accompanied by enigmatic, amorphous or polymeric tars or resins. Extensive experimental work on photoreactions of phenyl azides, in the presence of alcohols and primary/secondary amines, has shown that the reaction from the singlet state is usually the predominant reaction pathway. ${ }^{71,72}$ The phenyl azide $\mathbf{A}$ will transform to the singlet nitrene $\mathbf{B}$ under influence of UV (Scheme 1). An intramolecular rearrangement occurs, in which the singlet

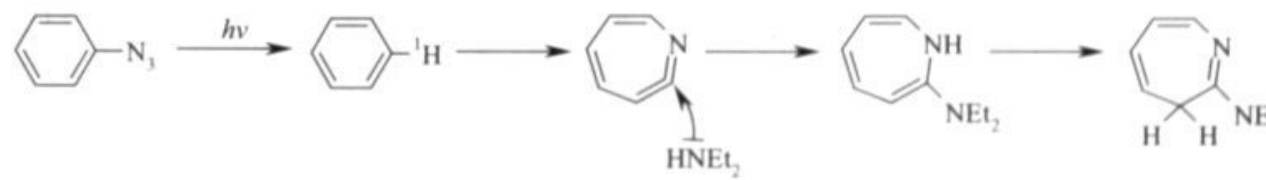

A

B

C

D

E

Scheme 1. Photochemistry of phenyl azides. ${ }^{70}$

state transforms to the dehydroazepine structure C. In the dehydroazepine structure it can be verified that all atoms obey the octet rule, i.e. this aspect provides the driving for the above rearrangement. Simultaneously, it is clear that the presence of an $s p$-hybridized carbon in the seven-membered ring is quite unfavourable. The molecular system can escape from this situation upon attack of a nucleophilic reagent, for example diethyl amine. Nucleophilic attack will occur at the $s p$-hybridized carbon leading to the $1 \mathrm{H}$-azepine structure $\mathbf{D}$ or the more stable form $\mathbf{E}$. 


\subsection{Outline of this thesis}

The aim of this study was to synthesize dipyridamole derivatives which could be effectively coupled covalently onto polyurethane surfaces in order to improve the blood compatibility of these surfaces. No attempt was made in this work to elucidate the mode of action of dipyridamole.

Chapter 2 describes the chemical synthesis of two new conjugate molecules (2 and 3), carrying the dipyridamole moiety at one end and a photoreactive moiety on the other end. Irradiation with UV light resulted in a covalent coupling of the two derivatives onto the polyurethane surface. The surface density of the derivatives could be calculated using UV spectroscopy. Preliminary in vitro bloodcompatibility tests, using the thrombin generation essay and platelet adhesion experiments, are described.

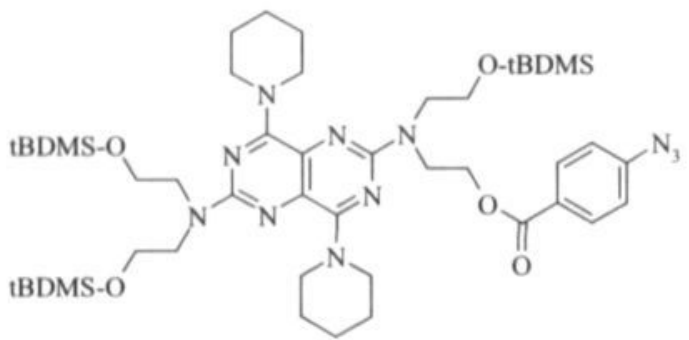

2

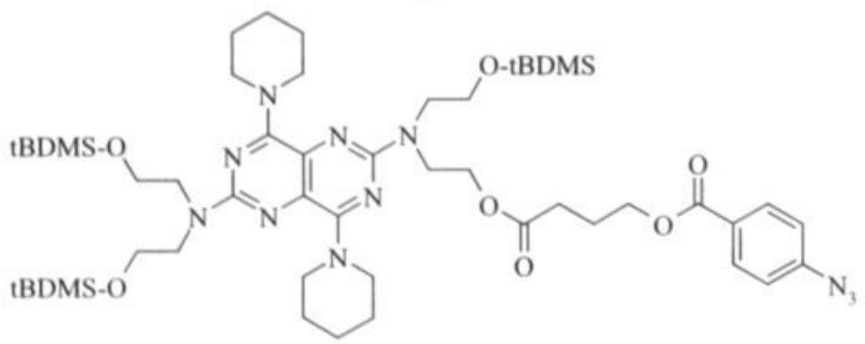

3

Chapter 3 describes a comparison between the dipyridamole-containing derivatives 2 and 3. Qualitative and quantitative biochemical experiments are performed in order to characterise the in vitro bloodcompatibility of a set of polyurethane surfaces onto which the two derivatives are immobilised.

Chapter 4 describes the synthesis of a new dipyridamole-containing derivative, 4 . Polyurethanes immobilised with this derivative are (i) physico- 


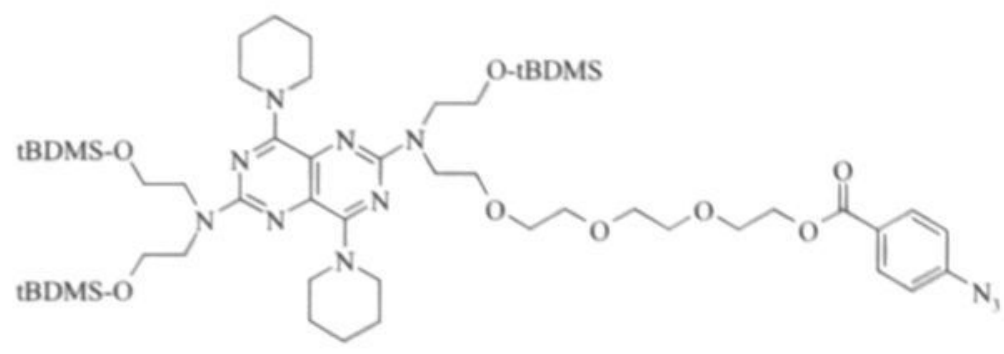

chemical characterised by UV spectroscopy, contact angle measurements, and XPS (X-ray photoelectron spectroscopy) experiments, and (ii) biochemical characterised by thrombin generation essay and platelet adhesion studies.

Chapter 5 describes a platelet adhesion study on dipyridamole coated polyurethane surfaces. The surfaces were characterised by platelet adhesion studies and by FIMS experiments.

Chapter 6 describes the immobilisation of the dipyridamole-containing derivative $\mathbf{4}$ onto the lumen of a polyurethane vascular graft (Chronoflex $\left.{ }^{*}\right)$. These vascular grafts have been investigated in vitro as well as in vivo.

\subsection{References}

1. N.A. Peppas and R. Langer, "New challenges in biomaterials," Science, 263, 1715-1720 (1994).

2. B.D. Ratner, "New ideas in biomaterials science - a path to engineered biomaterials," J. Biomed. Mater. Res., 27, 837-850 (1993).

3. F.H. Silver, In: "Biomaterials, medical devices and tissue engineering: an integrated approach," Chapman \& Hall, London, 1994.

4. A.D. Callow, "Current status of vascular grafts," Surg. Clin. North Am., 62, 501513 (1982).

5. M. Szycher and S.J. Lee, "Cardiovascular devices for the 1990s," J. Biomat. Appl., 8, 31-63 (1993).

6. J. Vollmar, In: "Rekonstruktive chirurgie der arterien," Thieme Verlag, Stuttgart, 39-71, 1982

7. M.G. Davies, "Vein graft adaption in the arterial circulation," J. Vasc. Surg., 6, 1099-1100 (1997).

8. C.O. Esquivel and W.F. Blaisdell, "Why small caliber graft fail: a review of clinical and experimental experience and the significance of the interaction with blood at the interface," J. Surg. Res., 41, 1-15 (1986). 
9. R.J. Zdrahala and I.J. Zdrahala, "Biomedical applications of polyurethanes: a review of past promises, present realities, and a vibrant future," J. Biomat. Appl., 14, 67-90 (1999).

10. J.W. Boretos, In: "Biocompatibility of clinical implant materials," Vol II, CRC Press, Boca Raton, Fl, and references herein (1981).

11. M.D. Lelah and S.L. Cooper, "Polyurethanes in medicine," CRC Press, Boca Raton, Fl, and references herein (1986).

12. G.H.R. Rao and T. Chandy, "Role of platelets in blood-material interactions," Bull. Mater. Sci., 22, 633-939 (1999).

13. H.R. Baumgartner, R. Muggli, T.B. Tschopp, and V.T. Turitto, "Platelet adhesion, release and aggregation in flowing blood: effects of surface properties and platelet function," Thromb. Haemost., 35, 124-138 (1976).

14. C.N. Chesterman and M.C. Berndt, "Platelet and vessel wall interaction and the gensis of artherosclerosis," Clin. Haemotol., 15, 323-353 (1986).

15. E.W. Salzman, J. Lindon, D. Brier, and E.W. Merril, "Surface-induced platelet adhesion, aggregation, and release," Ann. N. Y. Acad. Sci., 283, 114-127 (1977).

16. K. Park and H. Park, "Application of video-enhanced interference reflection microscopy to the study of platelet-surface interaction," Scan. Microscopy Suppl., 3, 137-145 (1989).

17. I.A. Feuerstein and J.I. Sheppard, "States in adherent platelet morphology and the processing of adsorbed protein on biomaterials," Biomaterials, 14, 137-147 (1993).

18. L. Vroman, A. L. Adams, G.C. Fischer, and P.C. Munoz, "Interaction of high molecular kininogen, factor XII, and fibrinogen in plasma at interfaces," Blood, 55, 156-159 (1980).

19. N.P. Ziats, D.A. Pankowsky, B.P. Tierney, O.D. Ratnoff, and J.M. Anderson, "Adsorption of Hageman factor (factor XII) and other human plasma proteins to biomedical polymers," J. Lab. Clin. Med., 116, 687-696 (1990).

20. L.T. Difazio, C. Stratoulias, R.S. Greco, and B. Haimovich, "Multiple platelet surface receptors mediate platelet adhesion to surfaces coated with plasma proteins, "J. Surg. Res., 57, 133-137 (1994).

21. F.G. Fischer and J. Roch, "Tetraoxy-homopurin und Trioxy-homopurin, Zwei Ringhomologe des Harnsäure bzw. des Xanthins (Über Pyrimidino-pyrimidine I)," Liebigs Ann. Chem., 572, 217-229 (1951).

22. R. Kadatz, "Die Pharmakologischen Eigenschaften der Neuen Coronarerweiternden Substanz 2,6-Bis(diaethanolamino)-4,8-dipiperidinopyrimido(5,4-d)pyrimidin," Arzneim. Forsch., 9, 39-45 (1959).

23. G. Grabner, F. Kaindl, and O. Kraupp, "Die Wirkung von 2,6Bis(diaethanolamino)-4,8-dipiperidino-pyrimido(5,4-d)pyrimidin auf Herztätig keit und Coronarkreislauf Narkotisierter Hunde," Arzneim. Forsch., 9 45-49 (1959).

24. H.J. Bretschneider, A. Frank, U. Bernard, K. Kochsiek, and F. Scheler, "Die wirkung eines pyrimidopyrimidine-derivatives af die sauerstoffversorgung des herzmuskels," Arzneim. Forsch., 9, 49-59 (1959).

25. H. Spitzbarth, "Kreislaufanalytische und Klinische Studien über 2,6Bis(diaethanolamino)-4,8-dipiperidino-pyrimido(5,4-d)pyrimidin," Arzneim. Forsch., 9, 59-63 (1959).

26. G. Beisenherz, F.W. Koss, A. Schüle, I. Genauer, R. Bärisch, and R. Fröde, "Das Schicksal des 2,6-Bis(diaethanolamino)-4,8-dipiperidino-pyrimido(5,4- 
d)pyrimidin im Menschlichen und Tierischen Organismus," Arzneim. Forsch., 10, 307-312 (1960).

27. P.R. Emmons, M.J.G. Harrison, A.J. Honour, and J.R.A. Mitchell, "Effect of dipyridamole on human platelet behavior," Lancet, ii, 603-606 (1965).

28. P.R. Emmons, M.J.G. Harrison, A.J. Honour, and J.R.A. Mitchell, "Effect of a pyrimidopyrimidine derivative on thrombus formation in the rabbit," Nature, 108, 255-257 (1965).

29. J.M. Sullivan, D.E. Harken, and R. Gorlin, "Pharmacologic control of embolic complications of cardiac valve replacement," N. Eng. J. Med., 284, 1391-1394 (1971).

30. J.H. Chesebro, V. Fuster, L.R. Elveback, I.P. Clements, H.C. Smith, D.R. Holmes Jr., W.T. Bradsley, J.R. Pluth, R.B. Wallace, F.J. Puga et al., "Effect of dipyridamole and aspirin on late vein-graft patency artery coronary bypass operations," N. Eng. J. Med., 310, 209-214 (1984).

31. D.P. Faxon, T.A. Sanborn, C.C. Haudenschild, and T.J. Ryan, "Effect of antiplatelet therapy on restenosis after experimental angioplasty," Am. $J$. Cardiol., 53, 72C-6C (1984).

32. L. Harker, R. Ross, J. Slichter, and C.R. Scott, "Homocystein-induced arteriosclerosis," J. Clin. Invest., 58, 731-741 (1976).

33. L. Schwartz, M.A. Bourassa, J. Lesperance H.E. Aldridge, F. Kazim, V.A. Salvatore, M. Henderson, R. Bonan, and P.R. David, "Aspirin and dipyridamole in the prevention of restenosis after PTCA," N. Eng. J. Med., 318, 1714-1719 (1988).

34. C.W. White, M. Knudson, D. Schmidt et al., "Neither ticlopine nor aspirindipyridamole prevent restenosis post PTCA: results from a randomized placebocontrolled multicenter trial [abstract]," Circulation, 76 suppl IV, IV-213 (1987).

35. S. Niewiarowski, H. Lukasiewicz, N. Nath, and A.T. Sha, "Inhibition of human platelet aggregation by dipyridamole and two related compounds and its modification by acid glycoproteins of human plasma," J. Lab. Clin. Med., 86, 6476 (1975).

36. J.P. Singh, K.J. Rothfuss, T.R. Wiernicki, W.B. Lacefield, W.L. Kurtz, R.F. Brown, K.A. Brune, D. Bailey, and G.P. Dubé, "Dipyridamole directly inhibits vascular smooth muscle cell proliferation in vitro and in vivo: implications in the treatment of restenosis after angioplasty," J. Am. Coll. Cardiol., 23, 665-671 (1995).

37. H. Gastpar, J.L. Ambrus, and C.M. Ambrus, In: "Interaction of platelets and tumor cells," Alan R Liss, New York, 63-82 (1982).

38. H. Gastpar, "Inhibition of cancer cell stickiness by anticoagulants, fibrinolytic drugs and pyrimido-pyrimidine compounds," Hematol. Rev., 3, 1-15 (1972).

39. J.L. Ambrus, C.M. Ambrus, and H. Gastpar, "Study of platelet aggregation in vivo: VI. Effect of pyrimido-pyrimidine derivative (RA-233) on tumor cell metastasis," J. Med., 9, 183-186 (1978).

40. G.N. Tzanakakis, K.C. Agarwal, and M.P. Vezeridis, "Prevention of human pancreatic cancer cell-induced hepatic metastasis in nude mice by dipyridamole and its derivative RA-233," Cancer, 71, 2466-2471 (1993).

41. D.A. Fullerton, J. Jaggers, F Piedalue, F.L. Grover, and R.C. McIntyre, "Effective control of refractory pulmonary hypertension after cardiac operations," J. Thorac. Cardiovasc. Surg, 113, 363-370 (1997).

42. R.C. Dukarm, F. C. Morin III, J.A. Russel, and R.H. Steinhorn, "Pulmonary and systemic effects of the phosphodiesterase inhibitor dipyridamole in newborn 
lambs with persistent pulmonary hypertension," Pediatr. Res., 44, 831-837 (1998).

43. J.W. Ziegler, D. Dunbar Ivy, J.J. Fox, J.P. Kinsella, W.R. Clarke, and S.H. Abman, "Dipyridamole potentiates pulmonary vasodilation induced by acetylcholine and nitric oxide in the ovine fetus," Am. J. Respir. Crit. Care Med., 157, 1104-1110 (1998).

44. J.W. Ziegler, D. Dunbar Ivy, J.W. Wiggins, J.P. Kinsella, W.R. Clarke, and S.H. Abman, "Effects of dipyridamole and inhaled nitric oxide in pediatric patients with pulmonary hypertension," Am. J. Respir. Crit. Care Med., 158, 1388-1395 (1998).

45. J. Aznar-Salatti, E. Bastida, G. Escolar, L. Almirall, M. Díaz-Ricart, P. Antón, R. Castillo, and A. Ordinas, "Dipyridamole induces changes in the thrombogenic properties of extracellular matrix generated by endothelial cells in culture," Thromb. Res., 64, 341-353 (1991).

46. G.A. Fitzgerald, "Dipyridamole," N. Eng. J. Med., 316, 1247-1257 (1987).

47. G.S. Hillis and K.P. Jennings, "Dipyridamole: an unfulfilled promise," Cardiovasc. Surg., 5, 350-353 (1997).

48. C.R. Gibbs and G.Y.H. Lip, "Do we still need dipyridamole," Br. J. Clin. Pharmacol., 45, 323-328 (1998).

49. Ranhosky and J. Rawson, "The safety of intraveneous dipyridamole thallium myocardial perfusion imaging," Circulation, 81, 1205 (1990).

50. S.K. Varma, D.D. Watson, and G.A. Beller, "Quantitative comparison of thallium-201 scintigraphy after exercise and dipyridamole in coronary artery disease," Am. J. Cardiol., 64, 871 (1989).

51. C.H. Bamford, K.G. Al-Lamee, I.P. Middelton, J. Paprotny, and R. Carr, "Chemical modification of polymers intended to increase blood compatibility," Bull. Soc. Chim. Belg., 99, 919-930 (1990).

52. C.H. Bamford, I.P. Middleton, and K.G. Al-Lamee, "Polymeric inhibitors of platelet aggregation. II. Copolymers of dipyridamole and related drugs with $\mathrm{N}$ vinylpyrrolidone," Biochim. Biophys. Acta, 924, 38-44 (1987).

53. C.H. Bamford, I.P. Middleton, Y. Satake, and K.G. Al-Lamee, In: "Advances in polymer synthesis," Plenum Press, New York and London, 291-320 (1985).

54. Y. Ikada, "Surface modification of polymers for medical applications," Biomaterials, 15, 725-736 (1994)

55. C.H. Bamford and K.G. Al-Lamee, "Chemical methods for improving the haemocompatibility of synthetic polymers," Clin. Mater., 10, 243-61 (1992).

56. T.G. Grasel, J.A. Pierce, and S.L. Cooper, "Effects of alkyl grafting on surface properties and blood compatibility of polyurethane block copolymers," $J$. Biomed. Mater. Res., 21, 815-842 (1987).

57. W.G. Pitt and S.L. Cooper, "Albumin adsorption an alkyl chain derivatized polyurethanes: I. The effect of C-18 alkylation," J. Biomed. Mater. Res., 22, 359382 (1988).

58. E.W. Merril, "Distinctions and correspondences among surface contacting blood," Ann. N. Y. Acad. Sci., 516, 196-203 (1987).

59. J.A. Hayward and D. Chapman, "Biomembrane surfaces as models for polymer design: the potential for haemocompatibiliy," Biomaterials, 5, 135-142 (1984).

60. D.C. McKenzie and J. Lowenthal, "Endothelium growth in nylon vascular grafts," Br. J. Surg., 48, 212-217 (1960). 
61. A.W. Clowes, A.M. Gown, S.R. Hanson, and M.A. Reidy, "Mechanisms of arterial graft failure. I. Role of cellular proliferation in early healing of ePTFE prostheses," Am. J. Pathol., 118, 43-54 (1985).

62. D.A. Mosquera and M. Goldman, "Endothelial cell seeding," Br. J. Surg., 78, 656-660 (1991).

63. G.B. Kövecker, L.M. Graham, W.E. Burkel, R. Sell, and J.C. Stanley, "Extracellular matrix preparation of ePTFE grafts seeded with endothelial cells: influence on early platelet deposition, cellular growth, and luminal prostacyclin release," Surgery, 109, 313-319 (1991).

64. B.D. Ratner B.J. Tyler, and A. Chilkoty, "Analysis of biomedical polymer surfaces: polyurethanes and plasma-deposited thin films," Clin. Mat., 13, 71-84 (1993).

65. T.Z. Ko, J.C. Lin, and S.L. Cooper, "Surface characterization and platelet adhesion studies of plasma-carboxylated polyethylene," J. Colloid Interface Sci., 156, 207-217 (1993)

66. O. Larm, R. Larsson, and P. Olsson, "A new non-thrombogenic surface prepared by selective covalent binding of heparin via a modified reducing terminal residue," Biomat. Med. Dev. Art. Org., 11, 161-173 (1983).

67. Y. Ito, "Antithrombogenic heparin-bound polyurethanes," J. Biomat. Appl., 2, 235-165 (1987).

68. R. Eloy, J. Belleville, M.C. Rissoan, and J. Baquet, "Heparinization of medical grade polyurethanes," J. Biomat. Appl., 2, $475-519$ (1988).

69. C.D. Ebert, E.S. Lee, and S.W. Kim, "The antiplatelet activity of immobilized prostacyclin" J. Biomed. Mater. Res., 16, 624-638 (1982).

70. P.A.S. Smith, In: "Azides and nitrenes; reactivity and utility," Academic Press, Orlando, Fl, 95-204, and references herein (1984).

71. E. Leyva, M.S. Platz, G. Persy, and J. Wirz, "Photochemistry of phenyl azide: the role of singlet and triplet phenylnitrene as transient intermediates," J. Am. Chem. Soc., 108, 3783-3790 (1986).

72. A.K. Schrock and G.B. Schuster, "Photochemistry of phenylazide: chemical properties of the transient intermediates," J. Am. Chem. Soc., 106, 5228-5234 (1984). 



\section{CHAPTER 2}

Studies on a New Strategy for Surface Modification of Polymeric Biomaterials ${ }^{*}$ 


\subsection{Abstract}

This chapter deals with a new methodology to improve bloodcompatibility of polyurethane (medical grade Pellethane D-55) surfaces. The approach is essentially based on a photochemical immobilisation reaction. Two new conjugate molecules, compounds $\mathbf{2}$ and $\mathbf{3}$, were prepared. They consist of (i) dipyridamole, a well-known inhibitor of platelet activation, and a vasodilating drug with clinical application, for instance before and during Percutaneous Transluminar Coronary Angioplasty (PTCA; also called dottering); (ii) an aryl azide, a moiety that exhibits marked photo-reactivity. In 2, the dipyridamole unit is directly linked to the aryl azide (via an ester bond), while a short spacer chain separates both units in $\mathbf{3}$. Upon irradiation of $\mathbf{2}$ or $\mathbf{3}$, adsorbed onto the polyurethane foil, the aryl azide is converted into a highly reactive species which reacts with a nucleophilic group on the polymer surface. In this way, the dipyridamole is covalently linked to the polymer. The underlying principle is also used in photo-affinity labeling, a well-known technique in biochemical studies on enzyme structure and function.

From UV extinction experiments it could be deduced that the surfacedensity of immobilised $\mathbf{2}$ is $4.9 \mathrm{nmol} / \mathrm{cm}^{2}$. The surface density for $\mathbf{3}$ was 14.6 $\mathrm{nmol} / \mathrm{cm}^{2}$. The surfaces were subjected to an in vitro thrombin generation assay. This assay gives a valuable impression about the bloodcompatibility of artificial surfaces. These experiments revealed that the clotting times were substantially prolonged as a result of the photo-immobilisation of dipyridamole. This was especially the case for immobilised $\mathbf{3}$.

In addition, the photo-modified surfaces were incubated with platelet-rich blood plasma $\left(37^{\circ} \mathrm{C}, 30 \mathrm{~min}\right.$.), and subsequently examined by scanning electron microscopy. The morphology of the blood platelets, adhered to the surface also showed that bloodcompatibility increases in the order untreated polyurethane < polyurethane with immobilised $\mathbf{2}<$ polyurethane with immobilised 3. 


\subsection{Introduction}

A substantial part of current research on biomaterials is focused on design and preparation of polymers with perfect or near-perfect bloodcompatibility.' The ultimate goal of that work is to find materials featuring complete absence of surface-induced thrombus formation, a phenomenon that poses serious problems in the functioning of implants and other medical devices. This holds true in particular for replacements in the cardiovascular system (heart valves, vascular protheses), and also for extracorporeal circulation devices (heart-lung machines or haemodialysis). ${ }^{2}$

Design of new bloodcompatible materials expands on existing knowledge about blood-coagulation and blood-material interactions. It is well known that contact of blood with an artificial surface first leads to adsorption of plasma components. Probably more than 200 different proteinaceous plasma molecules are prone to adsorption. ${ }^{3}$ It is important to realize that a least part of these molecules have the specific function to recognize foreign surfaces, complex to them, change structure and function (i.e. "become activated"), and call for reinforcement (e.g. via activation of blood platelets). This means that research on blood-compatible materials must evolve from fundamental studies on the interplay between: $(i)$ the physico-chemical properties of the surface (surface chemistry, surface morphology, surface energy); (ii) adsorption of plasma components and their exchange with other plasma proteins in the course of time (Vroman effect); (iii) thrombogenicity of the surface, both in the initial phase after blood-material contact, and after prolonged time.

Several different strategies have been followed in attempts to prepare bloodcompatible artificial surfaces. One promising approach is based on socalled amphiphilic block copolymers, composed of alternating hydrophilic and hydrophobic segments along the chain. In short, the principle is that hydrophilic and hydrophobic micro-domains are exposed at the surface (thermodynamic phase separation). A unique mode of protein adsorption results from this morphology, and surfaces with excellent bloodcompatibility are obtained. ${ }^{4} \mathrm{~A}$ second approach is based on attachment of heparin to polymeric surfaces. Heparin is a very powerful anticoagulant molecule as it potentiates the action of antithrombin-III, the enzyme that is responsible for inactivation and breakdown of thrombin. Recent reports on covalent end-point attachment of heparin to polymers describe surfaces with long-lasting passivity. ${ }^{4.5}$ 
A new strategy which is based on surface immobilisation of dipyridamole (1) is described. This compound finds extensive use in the clinic as a vasodilating drug (commercial name: Persantin $\left.{ }^{8}\right) .{ }^{6}$ Compound $\mathbf{1}$ is one of the most powerful inhibitors of platelet activation-aggregation known to date. Remarkably, the mechanism of action has not been clarified unambiguously. On one hand, it has been proposed that $\mathbf{1}$ has an intracellular mode of action via inhibition of phosphodiesterase activity (competitive inhibition). On the other hand, it has been shown by several groups that $\mathbf{1}$ blocks the uptake of adenosine

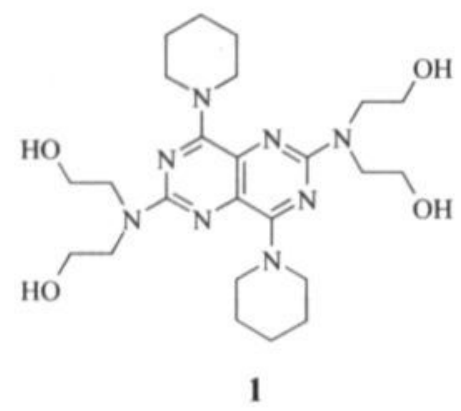

by platelets, probably by interaction with receptor sites on the surface of platelet membranes. Recent work by Bamford et al. has underlined the importance of extracellular mechanisms. ${ }^{7-9}$ It was found that dipyridamole, attached covalently to a water-soluble polymer such as poly-Nvinylpyrrolidone, still shows a marked platelet-inhibitory activity. Evidently, it is highly unlikely that such a macromolecular conjugate is transported across a cellular membrane. Remarkably, it was found in several cases that conjugates dipyridamole-soluble polymer are even more potent than dipyridamole itself. The literature data on $\mathbf{1}$ prompted us to prepare two new conjugate derivatives, i.e. compounds $\mathbf{2}$ and $\mathbf{3}$.

Note that $\mathbf{2}$ and $\mathbf{3}$ contain the $p$-azidophenyl group, which is a well-known photoreactive moiety. Irradiation of $\mathbf{2}$ and $\mathbf{3}$ with ultraviolet (UV) light transfers the $p$-azidophenyl group into a photochemically excited state from which reaction with nucleophiles occurs easily. Thus, if the irradiation is performed at the surface of a polymeric object, the electromagnetic energy of a UV quant $(h v)$ can be used to generate a new covalent bond linking the (protected) dipyridamole to the surface. 


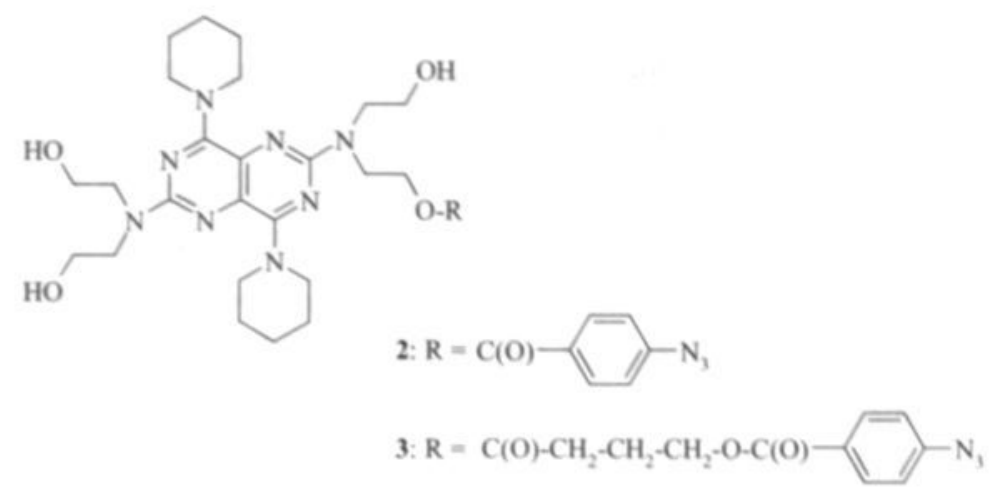

Here, the chemical synthesis of $\mathbf{2}$ and $\mathbf{3}$ as well as the first results of photoimmobilisation experiments with these molecules are reported. In our experiments, $\mathbf{2}$ or $\mathbf{3}$ was adsorbed onto a foil of medical grade Pellethane D-55. After deprotection (cleavage of the tBDMS protective groups) the surfaces were subjected to two in vitro bloodcompatibility tests. The results of these experiments are presented and discussed.

\subsection{Materials and Methods}

\subsubsection{General section}

All solvents and starting materials were of the highest available purity or they were purified as specified. Diethylether, pyridine, N,N-dimethylformamide (DMF) and dichloromethane were distilled from $\mathrm{LiAlH}_{4}$ or $\mathrm{CaH}_{2}$ and stored over Linde $3 \AA$ molecular sieves. Triethylamine (TEA) was distilled from $\mathrm{CaH}_{2}$ and stored over $\mathrm{KOH}$ pellets. Thin-layer chromatography was performed on precoated silicagel on glass plates $(3 \times 10 \mathrm{~cm})$ with UV-indicator. Silicagel 0.006-0.200 $\mathrm{mm}$ (pore diameter ca. $4 \mathrm{~nm}$ ) was used for column chromatography. IR spectroscopy was performed on a Mattson Polaris FT-IR spectrometer. Ultraviolet spectra were run on a Beckmann DU 7500 spectrophotometer. Mass spectra were run on a Kratos MS 80 RF instrument. ${ }^{1} \mathrm{H}$ NMR and ${ }^{13} \mathrm{C}$ NMR were recorded at 400 and $100 \mathrm{MHz}$, respectively on a Bruker AM 400 instrument. Solutions in $\mathrm{CDCl}_{3}$ or acetone- $\mathrm{d}_{6}$ were used. Tetramethylsilane was used as the internal standard $(\delta=0.00 \mathrm{ppm})$. 


\subsubsection{Synthesis}

$N$-(Benzyl)-4-hydroxy butanamide (9): This compound was prepared according to ref16. The synthesis was started with $4.00 \mathrm{~g}(104 \mathrm{mmol})$ of $\mathrm{LiAlH}_{4}, 55.64 \mathrm{~g}(520 \mathrm{mmol})$ of benzylamine, and $8.95 \mathrm{~g}(104 \mathrm{mmol})$ of $\gamma$ butyrolactone. The crude product was purified by flash column chromatography eluting with 2-butanone to give 9 as a white solid. Yield: $20.0 \mathrm{~g}(99.6 \%) . \mathrm{Mp}=$ $71.6^{\circ} \mathrm{C}$; IR ( $\left.\mathrm{KBr}\right), \mathrm{cm}^{-1}: 3300,1630,1540 ;{ }^{1} \mathrm{H} \mathrm{NMR}\left(\mathrm{CDCl}_{3}\right), \delta: 7.20-7.35(5 \mathrm{H}$, $\mathrm{m}$, aromate), $6.20(1 \mathrm{H}$, broad s, $\mathrm{NH}), 4.40\left(2 \mathrm{H}, \mathrm{d}, \mathrm{CH}_{2} \mathrm{~N}\right), 3.70\left(2 \mathrm{H}, \mathrm{t}, \mathrm{OCH}_{2}\right)$, $2.40\left(2 \mathrm{H}, \mathrm{t}, \mathrm{CH}_{2} \mathrm{C}(\mathrm{O})\right), 1.90\left(2 \mathrm{H}, \mathrm{m}, \mathrm{CH}_{2}\right) ;{ }^{13} \mathrm{C} \mathrm{NMR}\left(\mathrm{CDCl}_{3}\right), \delta: 139.10$, $128.73,127.79,127.56,62.28,43.73,33.87,28.09$. HRMS: calcd for $\mathrm{C}_{11} \mathrm{H}_{11} \mathrm{NO}_{2}(\mathrm{M}+)$ : 193.246 . Found: 193.110 .

$\mathrm{N}$-(Benzyl)-4-(triphenylmethoxy)-butanamide (10): To a solution of 9 (5.50 $\mathrm{g}, 28.96 \mathrm{mmol})$ in anhydrous pyridine was added triphenylchloromethane ( 8.24 $\mathrm{g}, 29.54 \mathrm{mmol}$ ). The solution was magnetically stirred for $24 \mathrm{~h}$ under exclusion of moisture. Then, all volatiles were removed under reduced pressure (last traces of pyridine were removed by coevaporation with toluene). The residue was taken up in toluene and washed with saturated aqueous $\mathrm{NaHCO}_{3}$ and water. The organic layer was dried over $\mathrm{MgSO}_{4}$ and evaporated to dryness under reduced pressure to give $\mathbf{1 0}$ as a white solid. Yield: $12.47 \mathrm{~g}(99.0 \%)$. ${ }^{1} \mathrm{H}$ NMR showed that the purity was $>98 \%$. IR $(\mathrm{KBr}) \mathrm{cm}^{-1}: 1630,1520 ;{ }^{1} \mathrm{H}$ NMR $\left(\mathrm{CDCl}_{3}\right), \delta: 7.20-7.40(20 \mathrm{H}, \mathrm{m}$, aromate), $5.85(1 \mathrm{H}$, broad s, $\mathrm{NH}), 4.35(2 \mathrm{H}, \mathrm{d}$, $\left.\mathrm{CH}_{2} \mathrm{~N}\right), 3.14\left(2 \mathrm{H}, \mathrm{t}, \mathrm{OCH}_{2}\right), 2.35(2 \mathrm{H}, \mathrm{t}, \mathrm{C}(\mathrm{O})), 1.95\left(2 \mathrm{H}, \mathrm{m}, \mathrm{CH}_{2}\right)$.

$\mathrm{N}$-(Benzyl)-N-(tert-butoxycarbonyl)-4-(triphenylmethoxy)-butanamide (11): Di-tert-butyldicarbonate (1.00 g, $4.60 \mathrm{mmol}), 4$-(dimethylamino)-pyridine (DMAP) $(0.28 \mathrm{~g}, 2.30 \mathrm{mmol})$, and TEA $(0.23 \mathrm{~g}, 2.30 \mathrm{mmol})$ were added to a $0.50 \mathrm{M}$ solution of $\mathbf{1 0}(1.0 \mathrm{~g}, 2.30 \mathrm{mmol})$ in anhydrous $\mathrm{CH}_{2} \mathrm{Cl}_{2}$. This solution was magnetically stirred overnight. All volatile matters were removed under reduced pressure. The crude product was recrystallized from 1:1 petroleumether/ether to give $\mathbf{1 1}$ as a white solid. Yield: $1.00 \mathrm{~g}(81.4 \%) \mathrm{Mp}$ $=127.5^{\circ} \mathrm{C}$; IR $(\mathrm{KBr}), \mathrm{cm}^{-1}: 1720,1600 ;{ }^{1} \mathrm{H}$ NMR $\left(\mathrm{CDCl}_{3}\right), \delta: 7.50-7.19(20 \mathrm{H}$, $\mathrm{m}$, aromate), $4.89\left(2 \mathrm{H}, \mathrm{s}, \mathrm{CH}_{2} \mathrm{~N}\right), 3.15\left(2 \mathrm{H}, \mathrm{t}, \mathrm{OCH}_{2}\right), 3.05\left(2 \mathrm{H}, \mathrm{t}, \mathrm{CH}_{2} \mathrm{C}(\mathrm{O})\right)$, $2.01\left(2 \mathrm{H}, \mathrm{m}, \mathrm{CH}_{2}\right), 1.42(9 \mathrm{H}, \mathrm{s}$, tert-butyl $) ;{ }^{13} \mathrm{C} \mathrm{NMR}\left(\mathrm{CDCl}_{3}\right), \delta: 175.80$, $153.05,144.32,138.32,128.66,128.25,127.68,127.52,127.02,126.80,86.35$, $83.11,62.87,42.31,35.27,27.88,25.67$; FABMS $m / z \mathrm{C}_{35} \mathrm{H}_{37} \mathrm{NO}_{4} 436(\mathrm{M}+$ $\mathrm{H})+$. 
4-Triphenylmethoxy-butyric acid (12): To a $0.20 \mathrm{M}$ solution of $11(1.0 \mathrm{~g}$, $1.87 \mathrm{mmol}$ ) in THF was added $5.61 \mathrm{~mL}$ of a $1.0 \mathrm{~N}$ solution of $\mathrm{LiOH}$. The solution was magnetically stirred for $3 \mathrm{~h}$ at $60{ }^{\circ} \mathrm{C}$. After removal of THF in vacuo, the basic aqueous residue was neutralized via careful addition of a $10 \%$ solution of acetic acid, and extracted with diethylether. The organic layer was dried on $\mathrm{MgSO}_{4}$ and evaporated to dryness under reduced pressure. The crude product was recrystallized from 1:1 petroleumether/ether to give $\mathbf{1 2}$ as a white solid. Yield: $0.58 \mathrm{~g}(89.6 \%) . \mathrm{Mp}=148.1{ }^{\circ} \mathrm{C}$; IR (KBr), $\mathrm{cm}^{-1}$ : 3300-2400, 1700; ${ }^{1} \mathrm{H}$ NMR $\left(\mathrm{CDCl}_{3}\right), \delta: 7.40-7.20(15 \mathrm{H}, \mathrm{m}$, aromate $), 2.92\left(2 \mathrm{H}, \mathrm{t}, \mathrm{OCH}_{2}\right), 1.97$ $\left(2 \mathrm{H}, \mathrm{t}, \mathrm{CH}_{2} \mathrm{C}(\mathrm{O})\right), 1.77\left(2 \mathrm{H}, \mathrm{m}, \mathrm{CH}_{2}\right) ;{ }^{13} \mathrm{C}$ NMR $\left(\mathrm{CDCl}_{3}\right), \delta: 144.12,128.61$, 127.74, 126.91, 86.51, 62.35, 31.20, 25.10. HRMS: calcd. for $\mathrm{C}_{23} \mathrm{H}_{22} \mathrm{O}_{3}(\mathrm{M}+)$ : 346.426. Found: 346.156 .

Mono-acetyl dipyridamole (6): Acetic acid anhydride (1.01 g, $9.91 \mathrm{mmol})$ was added dropwise to a solution of dipyridamole $(10.00 \mathrm{~g}, 19.82 \mathrm{mmol})$ in 150 $\mathrm{mL}$ of anhydrous pyridine. The yellow-green fluorescent solution was magnetically stirred at $20^{\circ} \mathrm{C}$ for $12 \mathrm{~h}$. The pyridine was evaporated under reduced pressure (last traces of pyridine were removed by coevaporation with toluene). The crude product was purified by flash column chromatography eluting with ethylacetate to give 6 as a yellow oil. Yield: $3.56 \mathrm{~g}(65.7 \%)$. ${ }^{1} \mathrm{H}$ NMR $\left(\mathrm{CDCl}_{3}\right) \delta: 4.62-4.42$ (br s, 3H, OH), 4.30 (t, $\left.2 \mathrm{H}, \mathrm{CH}_{2}-\mathrm{OAc}\right), 4.03-3.75$ (br s, $22 \mathrm{H}, \mathrm{CH}_{2}-\mathrm{O}$ and $\mathrm{CH}_{2}-\mathrm{N}$ ), $2.05(\mathrm{~s}, 3 \mathrm{H}, \mathrm{Ac}), 1.82-1.53$ (br s, $12 \mathrm{H}, \mathrm{CH}_{2}$ of piperidine rings). FABMS $m / z \mathrm{C}_{26} \mathrm{H}_{42} \mathrm{~N}_{8} \mathrm{O}_{5} 547(\mathrm{M}+\mathrm{H})+$.

Tri-(tert-butyl, dimethylsilyl)acetyl dipyridamole (7): To a solution of $\mathbf{6}$ (3.56 g, $6.51 \mathrm{mmol}$ ) in $20 \mathrm{~mL}$ of anhydrous DMF were added tbutyldimethylsilylchloride $(8.83 \mathrm{~g}, 58.57 \mathrm{mmol})$, anhydrous TEA $(5.93 \mathrm{~g}, 58.57$ mmol) and DMAP (7.16 g, $58.57 \mathrm{mmol})$. The solution was magnetically stirred for $2 \mathrm{~h}$. Then $20 \mathrm{~mL}$ of brine was added and the mixture was extracted with ether $(3 \times 20 \mathrm{~mL})$. The combined ether extracts were washed with saturated $\mathrm{NH}_{4} \mathrm{Cl}(3 \times 10 \mathrm{~mL})$, dried over $\mathrm{MgSO}_{4}$ and evaporated to dryness under reduced pressure to give 7 as a yellow oil. Yield: $5.79 \mathrm{~g} \mathrm{(100 \% ).}{ }^{1} \mathrm{H}$ NMR $\left(\mathrm{CDCl}_{3}\right) \delta: 4.25$ (t, 2H, $\mathrm{CH}_{2}-\mathrm{OAc}$ ), 4.13-3.91 (br s, 6H, $\mathrm{CH}_{2}-\mathrm{O}-\mathrm{Si}$ ), 3.80-3.73 (br, $16 \mathrm{H}, \mathrm{CH}_{2}-\mathrm{N}$ ), 2.02 (s, 3H, Ac), 1.73-1.60 (br s, $12 \mathrm{H}, \mathrm{CH}_{2}$ of piperidine rings), $0.90(\mathrm{~s}, 9 \mathrm{H}, t-\mathrm{Bu}), 0.88(\mathrm{~s}, 18 \mathrm{H}, t-\mathrm{Bu}), 0.09(\mathrm{~s}, 6 \mathrm{H}, \mathrm{Me}-\mathrm{Si}), 0.00(\mathrm{~s}, 12 \mathrm{H}$, $\mathrm{Me}-\mathrm{Si})$; FABMS $m / z \mathrm{C}_{44} \mathrm{H}_{84} \mathrm{~N}_{8} \mathrm{Si}_{3} \mathrm{O}_{5} 889(\mathrm{M}+\mathrm{H})+$ 
Tri-(tert-butyl, dimethylsilyl) dipyridamole (8): To a solution of $7(5.79 \mathrm{~g}$, $6.51 \mathrm{mmol}$ ) in $200 \mathrm{~mL}$ of anhydrous ethanol was added potassium carbonate $(3.15 \mathrm{~g}, 22.78 \mathrm{mmol})$. The solution was magnetically stirred for $5 \mathrm{~h}$. After filtration the reaction mixture was evaporated to dryness under reduced pressure. The crude product was purified by flash column chromatography eluting with petroleumether gradually increasing to $1: 1$ petroleumether/ether to give 8 as a yellow oil. Yield: $4.88 \mathrm{~g}(88.5 \%)$. ${ }^{1} \mathrm{H} \mathrm{NMR}\left(\mathrm{CDCl}_{3}\right) \delta: 4.28(\mathrm{t}, 2 \mathrm{H}$, $\mathrm{CH}_{2}-\mathrm{OH}$ ), 4.10-3.95 (br s, 6H, CH2-O-Si), 3.89-3.65 (br, $16 \mathrm{H}, \mathrm{CH}_{2}-\mathrm{N}$ ), 1.741.61 (br s, $12 \mathrm{H}, \mathrm{CH}_{2}$ of piperidine rings), $0.90(\mathrm{~s}, 27 \mathrm{H}, t-\mathrm{Bu}), 0.022(\mathrm{~s}, 6 \mathrm{H}, \mathrm{Me}-$ $\mathrm{Si}), 0.017$ (s, 12H, Me-Si); FABMS m/z $\mathrm{C}_{42} \mathrm{H}_{82} \mathrm{~N}_{8} \mathrm{Si}_{3} \mathrm{O}_{4} 847(\mathrm{M}+\mathrm{H})+$.

Tri-(tert-butyl, dimethylsilyl) 4'-hydroxy-butyryl dipyridamole (14): 4Triphenyl methoxy-butyric acid $(0.41 \mathrm{~g}, 1.19 \mathrm{mmol})$, BOP-Cl $(0.30 \mathrm{~g}, 1.19$ $\mathrm{mmol})$ and anhydrous TEA $(0.24 \mathrm{~g}, 2.37 \mathrm{mmol})$ were added to a solution of 8 $(0.67 \mathrm{~g}, 0.79 \mathrm{mmol})$ in $10 \mathrm{~mL}$ of anhydrous $\mathrm{CH}_{2} \mathrm{Cl}_{2}$. The solution was magnetically stirred for $14 \mathrm{~h}$. Then $10 \mathrm{~mL}$ water (made slightly basic with potassiumhydrogen carbonate) was added and the organic layer was separated and dried over $\mathrm{MgSO}_{4}$. After evaporation to dryness the material (crude 13) was taken up in $\mathrm{CH}_{2} \mathrm{Cl}_{2}$, and anhydrous $\mathrm{ZnBr}_{2}(1.78 \mathrm{~g}, 7.90 \mathrm{mmol})$ was added. The solution was magnetically stirred for $2 \mathrm{~h}$ at $20^{\circ} \mathrm{C}$ and isolated quantitavely by extraction into ethyl acetate and washing with phosphate buffer $(\mathrm{pH}=7.5)$, followed by water. The organic layer was evaporated to dryness under reduced pressure. The crude product was purified by flash column chromatography eluting with petroleumether gradually increasing to ethylacetate to give $\mathbf{1 4}$ as a yellow oil. Yield: $0.40 \mathrm{~g}(51.6 \%)$. ${ }^{1} \mathrm{H} \mathrm{NMR}\left(\mathrm{CDCl}_{3}\right) \delta: 4.40-4.20$ (br, $8 \mathrm{H}, \mathrm{CH}_{2}$ $\mathrm{O}$ of dipyridamole), 3.91-3.70 (br, $\left.16 \mathrm{H}, \mathrm{CH}_{2}-\mathrm{N}\right), 3.64\left(\mathrm{t}, 2 \mathrm{H}, \mathrm{CH}_{2}-\mathrm{OH}\right), 2.43$ (t, $2 \mathrm{H}, \mathrm{CH}_{2}-\mathrm{C}(\mathrm{O})$ ), 1.90-1.81 (m, $2 \mathrm{H}$, middle $\mathrm{CH}_{2}$ of spacer), 1.79-1.58 (br, $12 \mathrm{H}$, $\mathrm{CH}_{2}$ of piperidine rings), $0.86(\mathrm{~s}, 27 \mathrm{H}, t-\mathrm{Bu}), 0.01(\mathrm{~s}, 18 \mathrm{H}, \mathrm{Me}-\mathrm{Si}) ; \mathrm{FABMS} m / z$ $\mathrm{C}_{46} \mathrm{H}_{88} \mathrm{~N}_{8} \mathrm{Si}_{3} \mathrm{O}_{6} 933(\mathrm{M}+\mathrm{H})+$.

Tri-(tert-butyl, dimethylsilyl)4'-(p-azidobenzoyl) butyryl dipyridamole (3): p-Azidobenzoic acid $(0.084 \mathrm{~g}, 0.51 \mathrm{mmol}), \mathrm{BOP}-\mathrm{Cl}(0.13 \mathrm{~g}, 0.51 \mathrm{mmol})$ and anhydrous TEA $(0.10 \mathrm{~g}, 1,03 \mathrm{mmol})$ were added to a solution of $14(0.32 \mathrm{~g}$, $0.34 \mathrm{mmol}$ ) in $10 \mathrm{~mL}$ of anhydrous $\mathrm{CH}_{2} \mathrm{Cl}_{2}$. The solution was magnetically stirred for $26 \mathrm{~h}$ in darkness. Then $10 \mathrm{~mL}$ water (made slightly basic with potassiumhydrogen carbonate) was added and the organic layer was separated, dried over $\mathrm{MgSO}_{4}$ and evaporated to dryness under reduced pressure. The crude product was purified by flash column chromatography eluting with 
petroleumether gradually increasing to ethylacetate to give $\mathbf{3}$ as a yellow-brown oil. Yield: $0.05 \mathrm{~g}$ (13.6\%). 'H NMR $\left(\mathrm{CDCl}_{3}\right) \delta: 8.02$ (d, $2 \mathrm{H}$, aromatic $\left.\mathrm{H}\right), 7.05$ (d, $2 \mathrm{H}$, aromatic $\mathrm{H}), 4.34$ (t, $2 \mathrm{H}, \mathrm{CH}_{2}-\mathrm{O}$ spacer), $4.28\left(\mathrm{t}, 2 \mathrm{H}, \mathrm{CH}_{2}-\mathrm{O}-\mathrm{C}(\mathrm{O})\right.$ of dipyridamole), 4.10-3.95 (br s, $\left.6 \mathrm{H}, \mathrm{CH}_{2}-\mathrm{O}-\mathrm{Si}\right), 3.85-3.65\left(\mathrm{~m}, 16 \mathrm{H}, \mathrm{CH}_{2}-\mathrm{N}\right.$ ), 2.48 (t, $2 \mathrm{H}, \mathrm{CH}_{2}-\mathrm{C}(\mathrm{O})$ spacer), 2.13-2.07 (m, 2H, middle $\mathrm{CH}_{2}$ of spacer), 1.711.61 (br s, $12 \mathrm{H}, \mathrm{CH}_{2}$ of piperidine rings), $0.88(\mathrm{~s}, 27 \mathrm{H}, t-\mathrm{Bu}), 0.02(\mathrm{~s}, 18 \mathrm{H}, \mathrm{Me}-$ $\mathrm{Si})$; FABMS $m / z \mathrm{C}_{53} \mathrm{H}_{91} \mathrm{~N}_{11} \mathrm{Si}_{3} \mathrm{O}_{7} 1078(\mathrm{M}+\mathrm{H})+$.

Tri-(tert-butyl, dimethylsilyl)p-azidobenzoyl dipyridamole (2): pAzidobenzoic acid $(0.18 \mathrm{~g}, 1.07 \mathrm{mmol})$, DCC $(0.24 \mathrm{~g}, 1.18 \mathrm{mmol})$ and DMAP $(0.013 \mathrm{~g}, 0.11 \mathrm{mmol})$ were added to a solution of $8(1.0 \mathrm{~g}, 1.18 \mathrm{mmol})$ in $10 \mathrm{~mL}$ of anhydrous $\mathrm{CH}_{2} \mathrm{Cl}_{2}$. The solution was magnetically stirred for $12 \mathrm{~h}$ in darkness. Then $5 \mathrm{~mL}$ water was added, the dicyclohexylureum (DCU) was filtered and the filtrate washed with water $(3 \times 20 \mathrm{~mL}), 5 \%$ acetic acid solution $(3 \times 20 \mathrm{~mL})$ and again with water $(3 \times 20 \mathrm{~mL})$, dried over $\mathrm{MgSO}_{4}$ and evaporated to dryness under reduced pressure. This afforded a brown oil which was taken up in ice-cold acetone ( 3 times), during which the resting DCU precipitates and filtered off. The crude product was purified by column chromatography eluting with 95:5 petroleumether/ether to give $\mathbf{2}$ as a yellowbrown oil. Yield: $0.60 \mathrm{~g}(56.5 \%)$. ' $\mathrm{H}$ NMR $\left(\right.$ Acetone- $\left._{6}\right) \delta: 8.00(\mathrm{~d}, 2 \mathrm{H}$, aromatic $\mathrm{H}), 7.14$ (d, 2H, aromatic $\mathrm{H}), 4.58\left(\mathrm{t}, 2 \mathrm{H}, \mathrm{CH}_{2}-\mathrm{C}(\mathrm{O})\right), 4.25-3.65(\mathrm{~m}$, $22 \mathrm{H}, \mathrm{CH}_{2}-\mathrm{O}$ and $\mathrm{CH}_{2}-\mathrm{N}$ ), 1.77-1.60 (br s, $12 \mathrm{H}, \mathrm{CH}_{2}$ of piperidine rings), 0.90 (s, 18H, $t$-Bu), 0.87 (s, 9H, $t$-Bu), 0.05 (s, 12H, Me-Si), 0.02 (s, 6H, Me-Si); FABMS $m / z \mathrm{C}_{49} \mathrm{H}_{85} \mathrm{~N}_{11} \mathrm{Si}_{3} \mathrm{O}_{5} 992(\mathrm{M}+\mathrm{H})+$.

\subsection{Results and Discussion}

\subsubsection{Preparation of conjugates 2 and 3}

This work started out with defining which molecule would provide the best or easiest test system with respect to the efficacy of surface-immobilised dipyridamole. Initially, we reasoned that structure $\mathbf{5}$ would probably be the easiest conjugate system composed of $\mathbf{1}$ and a $p$-azidophenyl moiety. Evidently, 


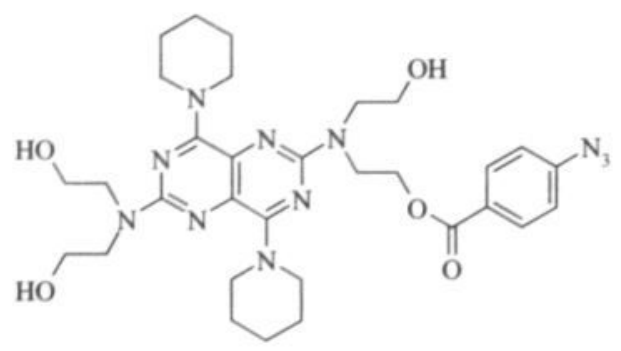

5 can be prepared directly from $\mathbf{1}$ and $p$-azidobenzoic acid via a standard esterification reaction. It was found, however, that use of $\mathbf{5}$ is associated with two major problems. The first one is that a complex mixture is obtained during synthesis; the mixture consists of unreacted 1, 5, disubstituted 1 (two isomers), and tri- and tetrasubstituted $\mathbf{1}$. Isolation of $\mathbf{5}$ proved to be a cumbersome lowyield operation. The second problem with $\mathbf{5}$ is that its irradiation will lead to unwanted products as reaction of the excited photosystem with a hydroxyl of $\mathbf{5}$ can occur. Note that this unwanted reaction can follow both an intramolecular and an intermolecular course. For these reasons compound $\mathbf{2}$ has been selected rather than compound $\mathbf{5}$. Note that structure $\mathbf{2}$ contains three tertbutyldimethylsilyl (tBDMS) groups to protect the hydroxyls during irradiation. The tBDMS group is orthogonal with respect to the ester function, i.e. the tBDMS group can be cleaved after irradiation without disrupting the covalent attachment of $\mathbf{1}$. Compound $\mathbf{2}$ was prepared according to Scheme I. In the first step, 1 was reacted with 1 equiv. of acetic anhydride in pyridine which afforded a mixture of $\mathbf{1}, \mathbf{5}$, di-acetylated $\mathbf{1}$ (two isomers), and tri- and tetra-acetylated $\mathbf{1}$. It was possible to isolate pure $\mathbf{6}$ from this mixture using routine column chromatography on silica gel. Then, 6 was converted into 7 through reaction with tBDMS-chloride. ${ }^{10-12}$ Treatment of 7 with $5 \% \mathrm{~K}_{2} \mathrm{CO}_{3}$ in EtOH afforded structure $\mathbf{8}$. In the last step, $\mathbf{8}$ was reacted with $p$ - azidobenzoic acid in the presence of $\mathrm{N}, \mathrm{N}^{\prime}$-dicyclohexyl carbodiimide (DCC). ${ }^{13-15}$ The target compound $\mathbf{2}$ was obtained in pure form after column chromatography. The structural features were verified by means of ${ }^{1} \mathrm{H} N \mathrm{NMR}$ at $400 \mathrm{MHz}$, infrared (IR) spectroscopy, and fast atom bombardment (FAB) mass spectrometry (see: Experimental Section for details). Purity of $\mathbf{2}$ was further established with analytical high performance liquid chromatography (HPLC). 
The ideas about the mode of action of surface-immobilised $\mathbf{1}$ are essentially based on complexation of dipyridamole with a putative receptor site on the platelet membrane. Evidently, this requires a favorable orientation of the dipyridamole heterocycle with respect to the receptor. We reasoned that such an orientation could be realized easier upon introduction of a spacer chain which allows greater physical separation of the dipyridamole moiety and the surface.

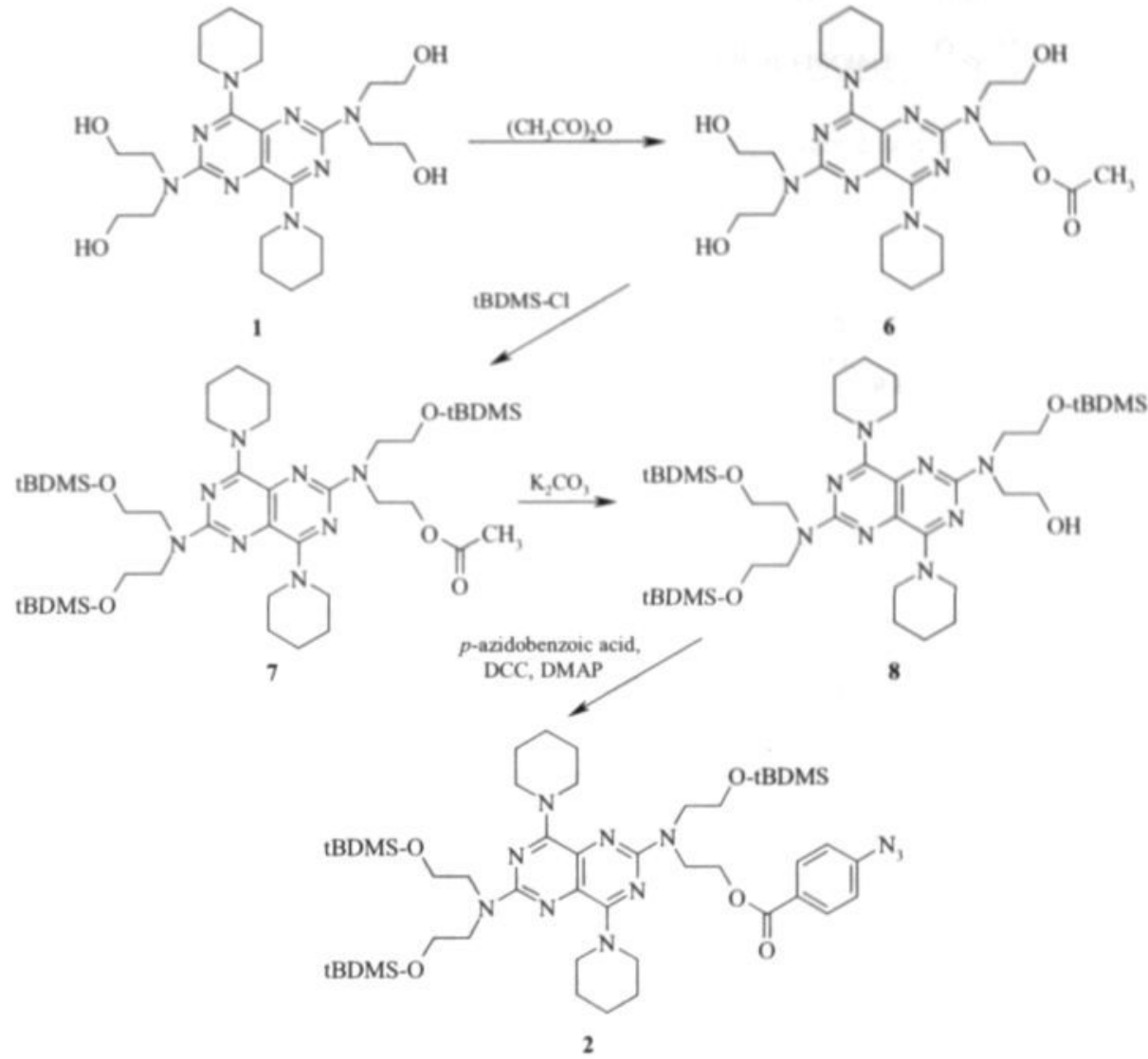

Scheme I. Preparation of compound 2.

For this reason, structure 3 was also prepared, which features $-\mathrm{C}(\mathrm{O})-\mathrm{CH}_{2}-$ $\mathrm{CH}_{2}-\mathrm{CH}_{2}-\mathrm{O}$ - as the spacer chain. Scheme II outlines our synthesis of the spacer molecule. This reaction sequence starts out with $\gamma$-butyrolactone which is reacted with the complex $\mathrm{LiAl}[\mathrm{HN}-\mathrm{Ph}]_{4}$ in the first step. ${ }^{16}$ After work-up compound $\mathbf{9}$ was obtained in pure form. The second step is a reaction of $\mathbf{9}$ with 
tritylchloride which affords the trityl ether $\mathbf{1 0}$. This compound was reacted with di-tert-butyldicarbonate affording $\mathbf{1 1}$, which was subsequently hydrolyzed with LiOH to afford the spacer chain $12 .{ }^{17}$ Note that structure $\mathbf{1 2}$ has a free carboxyl group on one end, and a protected primary alcohol function on the other end. The trityl protective group is orthogonal with respect to tBDMS and ester functions (vide infra).

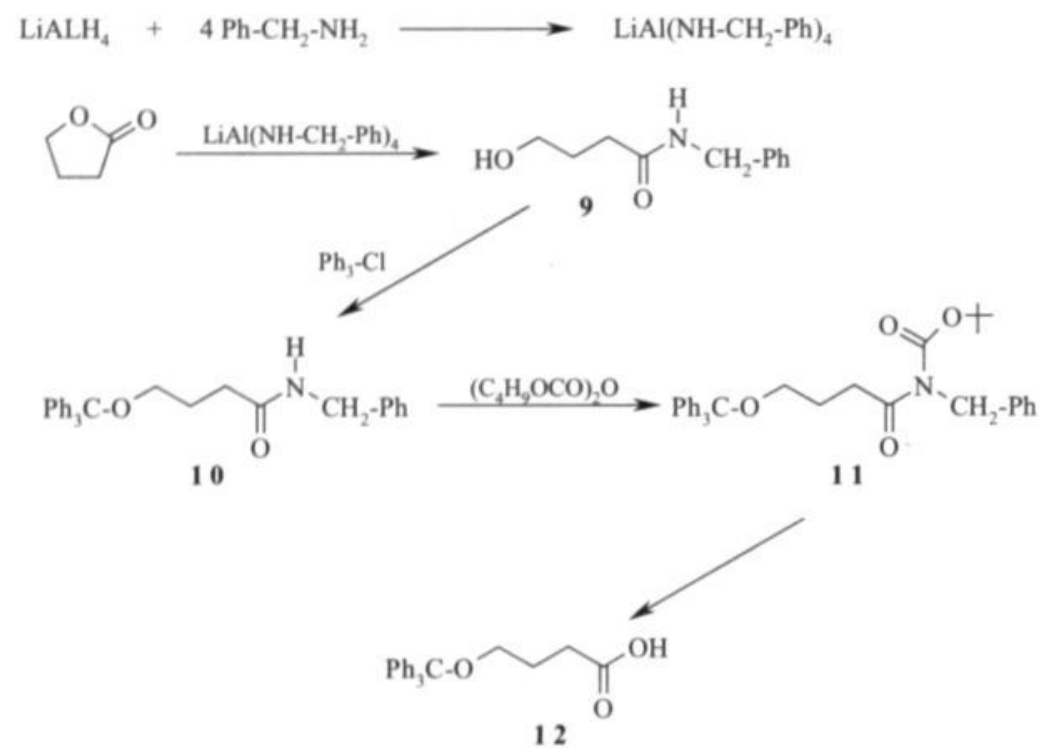

Scheme II. Preparation of compound 11.

Synthesis of $\mathbf{3}$ was accomplished according to Scheme III. The reaction sequence starts with coupling of $\mathbf{8}$ to $\mathbf{1 2}$, in the presence of DCC. This afforded structure 13. Detritylation with $\mathrm{ZnBr}_{2}$ in dichloromethane proceeded with complete preservation of the tBDMS protective groups and the ester function. ${ }^{18}$ This afforded structure 14 which was isolated in pure form after column chromatography. Finally, 14 was coupled to $p$-azidobenzoic acid in the presence of BOP-Cl. ${ }^{19}$ Compound 3 was obtained in pure form after column chromatography. Identity and purity of the product were established with 400 $\mathrm{MHz}{ }^{1} \mathrm{H}$ NMR spectroscopy, HPLC, IR spectroscopy and FAB mass spectrometry. 


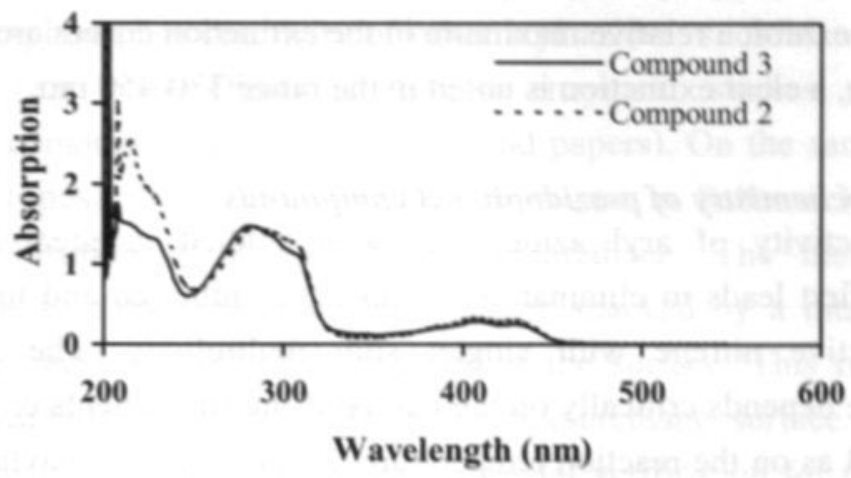

Figure 1. UV absorption spectra of compounds $\mathbf{2}$ and $\mathbf{3 .}$
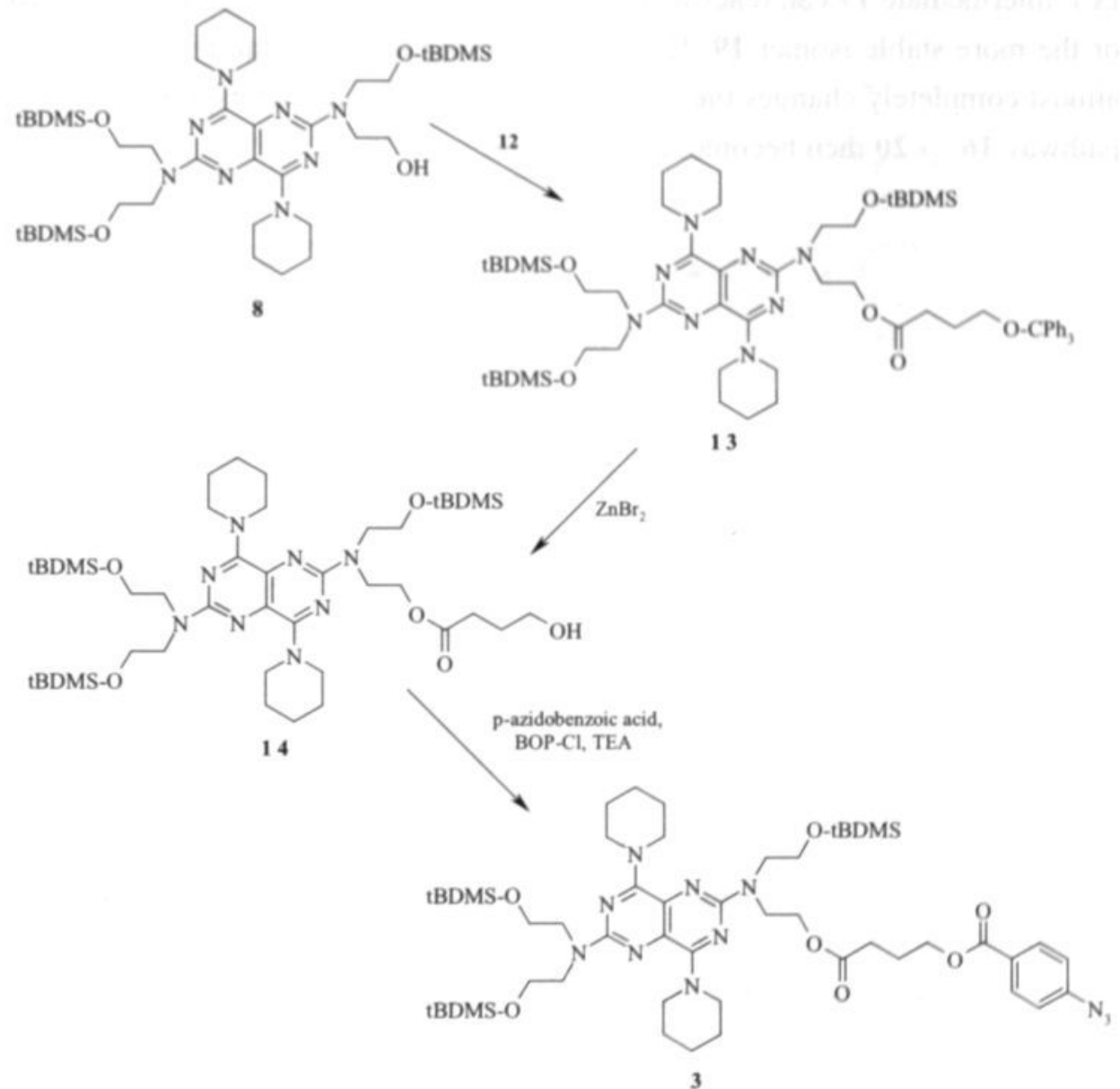

Scheme III. Preparation of compound 3. 
The UV extinction spectra of compounds $\mathbf{2}$ and $\mathbf{3}$ were shown in Figure 1. Both compounds exhibit a relative maximum in the extinction curves around $280 \mathrm{~nm}$. Furthermore, a clear extinction is noted in the range $370-450 \mathrm{~nm}$.

\subsubsection{Photochemistry of p-azidophenyl compounds}

Photoreactivity of aryl azides has been studied in great depth. ${ }^{20}$ UV irradiation first leads to elimination of molecular nitrogen and formation of a highly reactive nitrene with singlet spin multiplicity. The fate of this intermediate depends critically on the nature of the substituents on the aromatic ring, as well as on the reaction temperature. In the case of phenylazide $\mathbf{1 5}$, it is known that UV irradiation at ambient temperature leads to singlet phenylnitrene 16, and subsequently to the cyclic heterocumulene 17 (Scheme IV). Intermediate $\mathbf{1 7}$ can react with a nucleophile (e.g. diethylamine) to form $\mathbf{1 8}$ or the more stable isomer 19. However, lowering the temperature to e.g. $77 \mathrm{~K}$ almost completely changes the reaction mechanism, as the intersystem crossing pathway $\mathbf{1 6} \rightarrow \mathbf{2 0}$ then becomes predominant. ${ }^{21}$

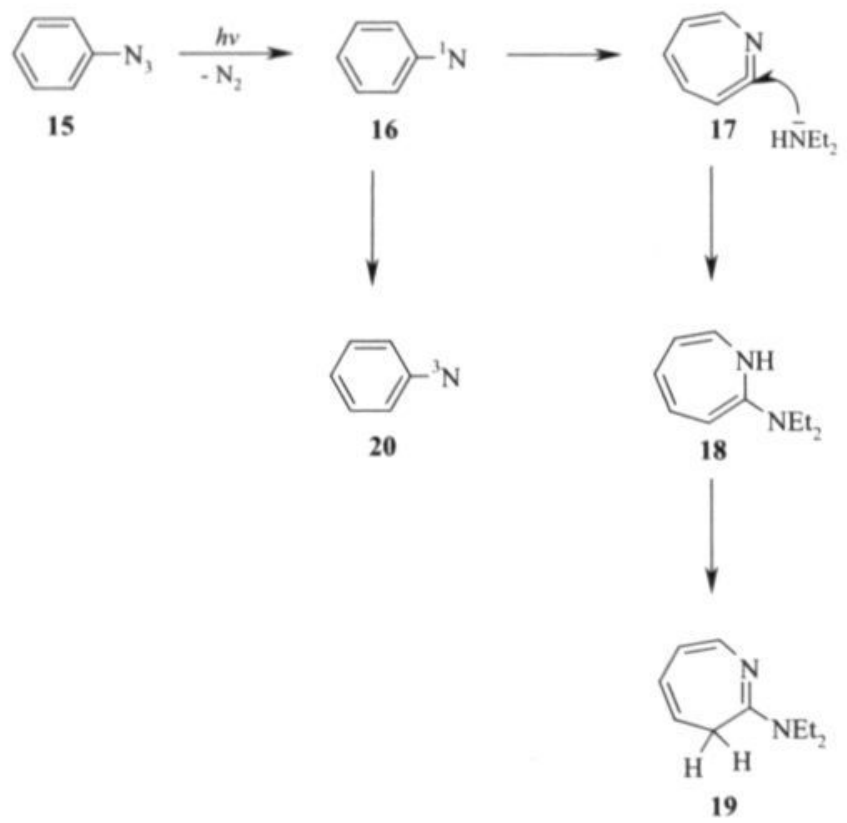

Scheme IV. Photochemistry of phenylazide (after ref. 21). 
Formation of a heterocumulene intermediate, analogous to 17 , has also been invoked to explain photoreactivity of other aryl azides, such as used in many applications (e.g. photoaffinity labeling in enzymatic studies, synthesis of heterocyclic compounds, dying of textiles and papers). On the same basis, we tentatively propose the reaction mechanism shown in Scheme $V$ to explain photo-immobilisation of $\mathbf{2}$ and $\mathbf{3}$ on polyurethane. The most plausible mechanism is that the heterocumulene ring is attacked by a nitrogen in the polyurethane backbone, which is exposed at the surface. This reaction then leads to covalent attachment of $\mathbf{R}$ to the polyurethane surface. It must be stressed, however, that we have no experimental verification for the proposed mechanism thus far.

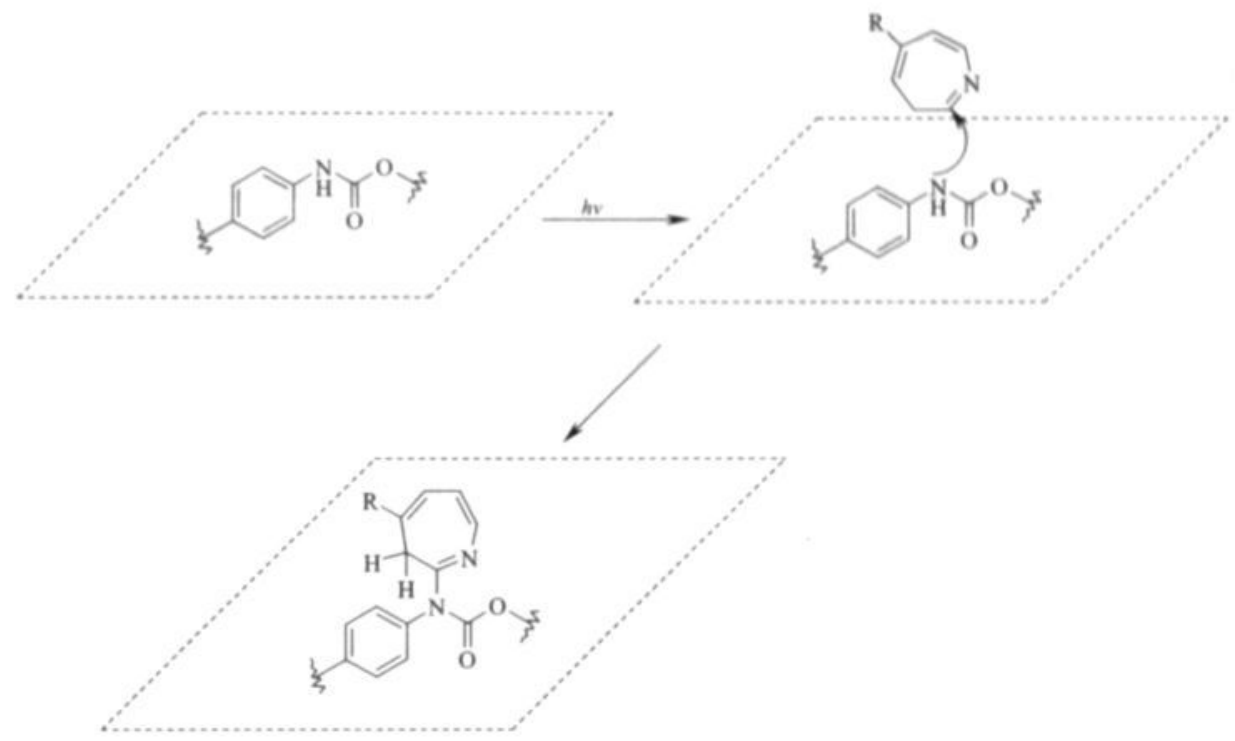

Scheme V. Tentative mechanism for the covalent photo-immobilisation of $\mathbf{2}$ and $\mathbf{3}$ to the polyurethane surface.

\subsubsection{Procedure of photo-immobilisation of 2 and 3}

Photo-immobilisation of $\mathbf{2}$ and $\mathbf{3}$ was carried out with a commercial foil (Pellethane D-55 medical grade, thickness $0.40 \mathrm{~mm}$ ). The experiments were performed with a simple device, consisting of a horizontal bottom glass plate $(80 \times 30 \times 3 \mathrm{~mm})$ and a horizontal top glass plate $(80 \times 30 \times 8 \mathrm{~mm})$, and two clamps. The top glass plate contains a circular hole with diameter $20 \mathrm{~mm}$. A 
piece of the polyurethane foil $(80 \times 30 \mathrm{~mm})$ was thoroughly cleaned with isopropanol, pressed between the glass plates and secured in position by means of the clamps. A solution of $\mathbf{2}$ or $\mathbf{3}$ in isopropanol $(250 \mu \mathrm{L}, 3.35 \mathrm{mM})$ was transferred into the hole of the top glass plate, and the solvent was thoroughly evaporated in vacuo at slightly elevated temperature. The device was then irradiated for 15 minutes with a Philips HPA 1000 high power UV lamp (Philips Lighting, PO Box 90059, 5600 PB Eindhoven The Netherlands). The foil was liberated, thoroughly washed with isopropanol and immersed for $24 \mathrm{~h}$ in a stirred solution of $\mathrm{Bu}_{4} \mathrm{NF}$ in nitromethane. This reagent is known to effectively cleave the t-BDMS groups. The foil was then thoroughly washed, first with isopropanol and then with water, and stored in dry form.

\subsubsection{Determination of immobilised 2 and 3}

The UV extinction of compound $\mathbf{2}$ and $\mathbf{3}$ provided a convenient means to obtain an estimate of the surface concentration after photo-immobilisation. We have focused on the spectral region between 370 and $480 \mathrm{~nm}$, since absorption in this region can be ascribed safely to the dipyridamole moiety exclusively. First, the molar extinction coefficients of $\mathbf{2}$ and $\mathbf{3}$ were determined at $\lambda=408 \mathrm{~nm}(\lambda=$ $89381 . \mathrm{mol}^{-1} \cdot \mathrm{cm}^{-1}$ for 2 and $76561 . \mathrm{mol}^{-1} \cdot \mathrm{cm}^{-1}$ for 3 ). These $\lambda$ values were measured in solution of $\mathbf{2}$ and $\mathbf{3}$ (both $3.72 \times 10^{-5} \mathrm{M}$ ) in isopropanol. Secondly, a blank solution was prepared, containing $42.14 \mathrm{~mm}^{2}$ of the polyurethane (untreated) in $5.62 \mathrm{~mL}$ of THF. The blanco UV spectrum was stored in the digital memory of the UV spectrometer. Thirdly, $56.82 \mathrm{~mm}^{2}$ of the polyurethane with immobilised 2 was dissolved in $7.58 \mathrm{~mL}$ of THF. Figure 2 shows the UV absorption spectra of this solution after substraction of the blank. Fourthly, $37.04 \mathrm{~mm}^{2}$ of the polyurethane with immobilised 3 was dissolved in $4.94 \mathrm{~mL}$ of THF. The resulting UV spectrum is also shown in Figure 2. Note that the spectral patterns between $\lambda=360 \mathrm{~nm}$ and $\lambda=480 \mathrm{~nm}$ of immobilised 2 and $\mathbf{3}$ are highly comparable. A close resemblance with the same spectral region in the UV spectra of $\mathbf{2}$ and $\mathbf{3}$ (Figure 1) is also noted, although its clear that the spectra in Figure 2 correspond with a much higher concentration. It could be calculated from the UV absorption at $\lambda=408 \mathrm{~nm}$ that the surface concentration of immobilised 2 is equal to $4.9 \mathrm{nmol} / \mathrm{cm}^{2}$, and $14.6 \mathrm{nmol} / \mathrm{cm}^{2}$ for 3. Taking into account the amount of $\mathbf{2}$ and $\mathbf{3}$ that was introduced in the hole of our irradiation device (vide supra; this amount is $266 \mathrm{nmol} / \mathrm{cm}^{2}$ ), it must be 
concluded that the yield of the photo-immobilisation is only in the range of 2 $5 \%$. Future work will be directed to improvement of this yield.

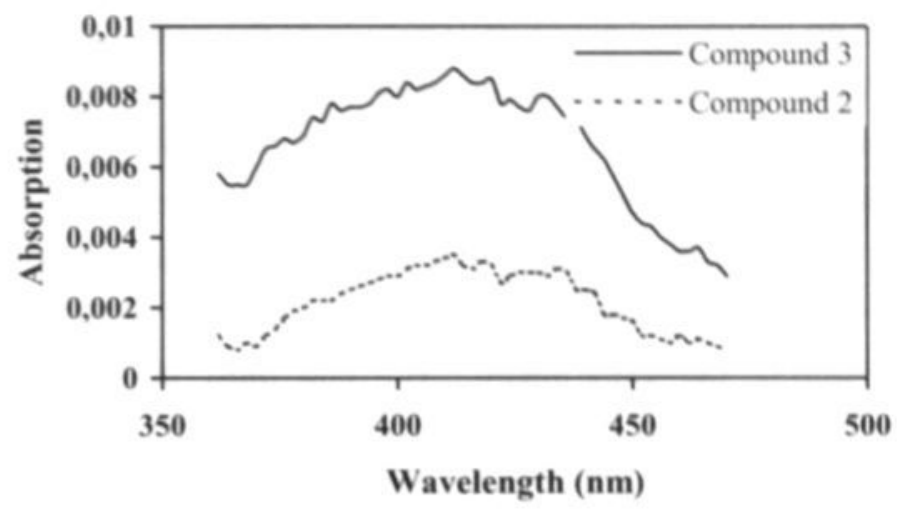

Figure 2. UV absorption spectra of immobilised $\mathbf{2}$ and $\mathbf{3}$ (see text).

\subsubsection{Evaluation of in vitro thrombogenicity}

Thrombin generation experiments: The modified surfaces were subjected to the in vitro thrombin generation assay as developed by Hemker et. al. ${ }^{22}$ Formation of thrombin is a key event in surface-induced blood coagulation. For this reason the thrombin generation assay provides a valuable first impression whether or not immobilisation of $\mathbf{2}$ or $\mathbf{3}$ leads to improved bloodcompatibility. Since the thrombin generation assay was previously described in great detail, we merely summarize essential features: (i) Fresh blood from a healthy donor is used. The donor has not taken aspirin or any other anti-coagulant for at least 1 week prior to blood donation. Platelet-rich plasma (PRP) is mixed with a sodium citrate solution; formation of a complex between $\mathrm{Ca}^{2+}$ in the plasma and citrate anions prevents coagulation prior to the experiment. (ii) The surface is incubated with the "decalcified" PRP and left to stand for $15 \mathrm{~min}$. Then, the PRP is "recalcified" which marks the actual start of the experiment. (iii) Subsamples $(10 \mu \mathrm{L})$ are withdrawn at regular time-intervals (ca $1 \mathrm{~min}$ ), and mixed with a solution of EDTA and chromogenic substrate S 2238 (H.D. phenylalanyl-pipecolyl-arginine $p$-nitroanilide). In the presence of thrombin, this substrate is cleaved into the constituent tripeptide, and p-nitroanilide. The latter compound generates a yellow color which can be conveniently monitored in time by virtue of its extinction $(\mathrm{E})$ at $\lambda=405 \mathrm{~nm}$. The parameter $\mathrm{dE} / \mathrm{dt}$ 
$(\mathrm{mOd} / \mathrm{min})$ provides a measure of the thrombin concentration at the moment of subsampling, i.e. each subsample leads to one data point in the thrombin generation curve. (iv) No thrombin generation is measured immediately after recalcification. After a lag phase (typical duration 2-5 $\mathrm{min}$ ), an explosive increase of the thrombin concentration is noted. At the end of the experiment, the concentration of free thrombin drops to 0 . Particularly in the end phase of the experiment, however, the experimental data also reflect the residual amidolytical activity of a stable long-lived complex between the protein $\alpha_{2}$ macroglobulin $\left(\alpha_{2}-\mathrm{m}\right)$ and thrombin. It is possible to perform an algorithmic correction for this effect, i.e. to estimate the concentration of free thrombin at each moment during the experiment. ${ }^{22}$ (v) The most important parameter abstracted from the thrombin generation curve is the duration of the lag phase, i.e. the time elapsing between the moment of recalcification, and the onset of the explosive increase of [thrombin]. Another parameter is the [thrombin] $]_{\max }$, i.e. the maximum of the concentration of free thrombin reached during the experiment. ( $v i$ ) The thrombin generation test is essentially comparitive, i.e. lag times are always measured for the surface(s) to be investigated and for a set of reference materials simultaneously using the same PRP under identical experimental conditions. In our work, we used polyethylene (PE), a highly thrombogenic material, and polyvinyl chloride (PVC-T), a relative passive material, as controls. PE and PVC-T were obtained as standard reference materials from the organization EUROBIOMAT.

Table I compiles the results of the thrombin generation tests on our polyurethane surfaces with immobilised $\mathbf{2}$ and $\mathbf{3}$, and or a set of reference surfaces.

Table I. Results from the thrombin generation test experiments on polyurethane with immobilised $\mathbf{2}$ or $\mathbf{3}$, and four reference surfaces.

\begin{tabular}{|c|c|c|}
\hline Material & Clotting time & $\begin{array}{l}\text { Max. concentration of free } \\
\text { thrombin }(\mathrm{nM})\end{array}$ \\
\hline $\mathrm{PE}^{1}$ & 395 & 216 \\
\hline PVC-T ${ }^{\prime}$ & 778 & 51 \\
\hline PU, untreated ${ }^{1-3}$ & $538 \pm 29$ & $94 \pm 15$ \\
\hline PU, irradiated without 2 or $3^{1-3}$ & $565 \pm 26$ & $57 \pm 15$ \\
\hline PU with immobilised $2^{2}, 3$ & $1148 \pm 40$ & $39 \pm 4$ \\
\hline PU with immobilised $\mathbf{3}^{2}, \mathbf{3}$ & $1459 \pm 90$ & $73 \pm 4$ \\
\hline
\end{tabular}

Reference Material. ${ }^{2}$ Experiments performed in triplicate. ${ }^{3} \mathrm{PU}=$ medical grade Pellethane D55 , which was used as a transparent foil (thickness $0.40 \mathrm{~mm}$ ), see text. 
Note that four references were chosen: PE, PVC-T, untreated polyurethane foil, and polyurethane foil that was subjected to the entire procedure of washing, solvent evaporation, $\mathrm{UV}$-irradiation, treatment with $\mathrm{Bu}_{4} \mathrm{NF}^{11}$, washings and drying, except that no photoreactive compound ( 2 or 3 ) was used. Experiments with PE and PVC-T were done once since the lag phases and [thrombin $]_{\max }$ values were as usual. All other experiments were done in triplicate. Several conclusions can be drawn from the data in Table I: (i) The lag phases are substantially prolonged upon photo-immobilisation of $\mathbf{2}$ and $\mathbf{3}$. Longest lag phases (ca. $1400 \mathrm{sec}$.) are found for polyurethane with immobilised 3. (ii) The observed prolongation of the clotting time can not be ascribed to UV irradiation and/or treatment with $\mathrm{Bu}_{4} \mathrm{NF}$ and associated washing steps. This is apparent from comparison of untreated and irradiated polyurethane references: these do not show significantly different lag times. (iii) The surfaces obtained after immobilisation of $\mathbf{2}$ and $\mathbf{3}$ are markedly passive; their lag phases have approximately double duration in comparison with PVC-T, which is already known as a relatively passive material.

Several other remarks must be added to the data of Table I. It is seen for the polyurethane control materials that the values for [thrombin $]_{\max }$ do change upon $\mathrm{UV}$ irradiation and/or treatment with $\mathrm{Bu}_{4} \mathrm{NF}$ and subsequent washing steps. The max. thrombin concentrations are in the range 79-109 $\mathrm{nM}$ for the untreated polyurethane, and in the range 43-54 $\mathrm{nM}$ for the irradiated counterpart. We do not have an explanation for these observations. Furthermore, it is seen that while the surface with immobilised $\mathbf{3}$ has a slightly longer lag phase than the surface with immobilised $\mathbf{2}$, the [thrombin] $\max$ of the former surface is approximately 3 -fold higher. In view of our data concerning adherence of platelets to both surfaces (vide infra) it must be expected that the surface with immobilised $\mathbf{3}$ has the best bloodcompatibility.

Adhesion of blood platelets: Three different surfaces were incubated with PRP for $30 \mathrm{~min}$ at $37^{\circ} \mathrm{C}$. These surfaces are: (i) polyurethane (untreated); (ii) polyurethane with immobilised 2; (iii) polyurethane with immobilised $\mathbf{3}$. Subsequently, the surfaces were dried, stained (gold sputtering), and subjected to scanning electron microscopy (SEM). See Experimental Section for details. Figure 3 shows SEM micrographs of the surfaces: polyurethane with immobilised 2 (Figure 3A), and polyurethane with immobilised 3 (Figure 3B). 


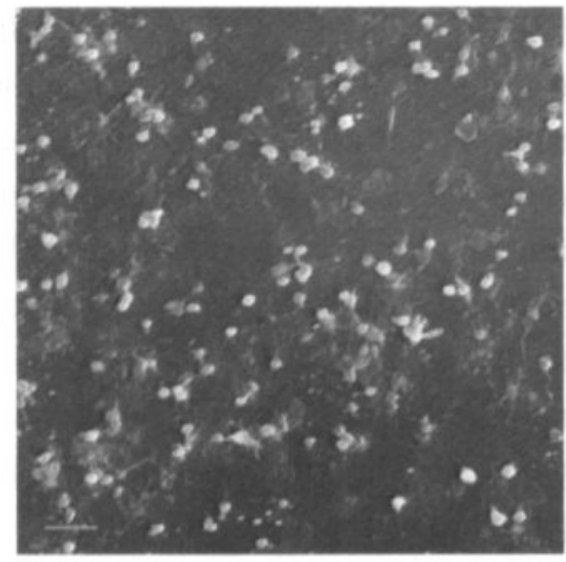

$\mathbf{A}$

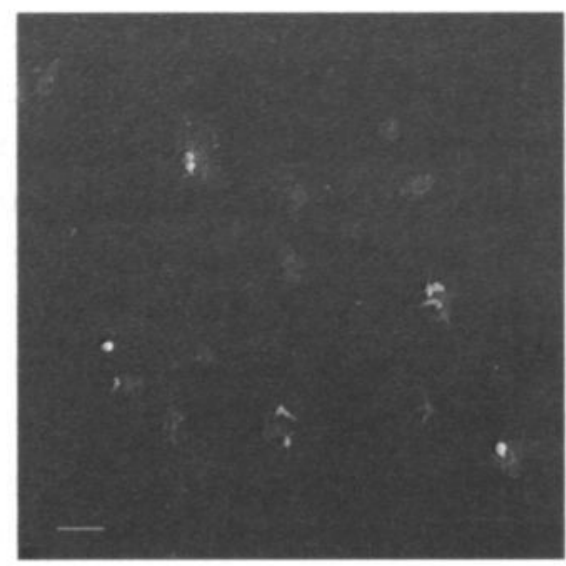

B

Figure 3. SEM micrographs of human blood platelets adhered to the polyurethane foil with immobilised 2 (A) and immobilised 3 (B). Length of bar $=10 \mu \mathrm{m}$.

It is clear that the former surface is covered to a much larger extent than the latter. The SEM micrograph in Figure 3A shows coverage of most of the surface; we recognize spreaded platelets, and clusters consisting of platelets which extend small pseudopods, or platelets of unchanged morphology. In Figure $3 \mathrm{~B}$, it is seen that most of the surface is uncovered; some of the adhered platelets show extensive spreading while others merely show formation of small pseudopods. It is of interest to add that the surface of untreated polyurethane showed almost complete coverage with platelets of different morphology (spreaded, pseudopods; micrograph not shown).

The SEM study of the three different surfaces led to the conclusion that the blood compatibility increases in the order: untreated polyurethane < polyurethane with immobilised $\mathbf{2}<$ polyurethane with immobilised $\mathbf{3}$.

\subsection{Concluding Remarks}

The present results indicate that photo-immobilisation of conjugates $\mathbf{2}$ or $\mathbf{3}$ on polyurethane leads to improved bloodcompatibility in vitro. This conclusion is based on two in vitro assays, i.e. a thrombin generation test, and evaluation of surface blood platelet interactions. Photo-immobilisation of $\mathbf{3}$ leads to better results than photo-immobilisation of 2 . Possibly, this difference can be 
attributed to the fact that $\mathbf{3}$ has a built-in spacer chain between the dipyridamole unit and the photo reactive center (vide supra). Eventually, this spacer chain allows for greater physical separation of dipyridamole and the surface. In the case of photo-immobilised $\mathbf{2}$, the dipyridamole is linked almost directly to the surface. It must be stressed, however, that we do not have conclusive evidence for this assumed effect of the spacer. The experiments on determining the surface-concentration of immobilised dipyridamole indicated a density of 4.9 $\mathrm{nmol} / \mathrm{cm}^{2}$ for immobilised 2, and $14.6 \mathrm{nmol} / \mathrm{cm}^{2}$ for immobilised 3. Future work will be concentrated on improving the efficacy of the immobilisation, and on precise evaluation of the role of the spacer. Incorporation of longer spacers will also be studied.

\subsection{References}

1. N.A. Peppas, and R. Langer, "New challenges in biomaterials," Science, 263, 1715-1720 (1994).

2. See, for instance: F.H. Silver, In: "Biomaterials, medical devices and tissue engineering, an integrated approach," Chapman \& Hall, London-Glasgow-NewYork-Tokyo (1994).

3. R. Luddington, B. Warner, and D.M. Reardon, "Blood coagulation," $\mathrm{Br} . J$. Biomed. Sci., 50, 43-56 (1993).

4. G.H. Engbers and J. Feijen, "Current techniques to improve the blood compatibility of biomaterial surfaces," Int. J. Artif. Org., 14, 199-215 (1991).

5. O. Larm, R. Larsson, and P. Olsson, "A new non-thrombogenic surface prepared by selective covalent binding of heparin via a modified reducing terminal residue," Biomat. Dev. Art. Org., 11, 161-173 (1983).

6. J.H. Chesebro, I.P. Clements, V. Fuster et al., "A platelet-inhibitor-drug trial in coronary-artery bypass operations," N. Engl. J. Med., 307, 73-78 (1982).

7. C.H. Bamford, and K.G. Al-Lamee, "Chemical methods for improving haemo compatibility of synthetic polymers," Clin. Mater., 10, 243-250 (1992).

8. C.H. Bamford, I. Middleton, K.G. Al-Lamee, J. Paparotny, and Y. Satake, "Routes to bioactive hydrophilic polymers," Polym. J., 19, 475-481 (1987).

9. C.H. Bamford, K.G. Al-Lamee, I. Middleton, and R. Can, "Chemical modification of polymers to increase bloodcompatibility," Bull. Soc. Chim. Belg., 99, 919-925 (1990).

10. S. Witkowski, R. Koteswar, H.P. Ramiya, P.V. Haluska, and J. Fried, "Total synthesis of (+)-10, 10-difluorothromboxane A2 and its 9,11 and 15 stereoisomers," J. Am. Chem. Soc., 114, 8464-8472 (1992).

11. E.J. Corey, and A. Venkateswarly, "Protection of hydroxyl groups as tertbutyldimethylsilyl derivates," J. Am. Chem. Soc., 94, 6190-6191 (1972).

12. A.M.P. Koskinen, and L. Munoz, "Intramolecular cyclopropanation: stereospecific synthesis of (E)- and (Z)-1-aminocyclopropane-1-carboxylic acids,"J. Org. Chem., 58, 879-886 (1993). 
13. C.J. Hawker, and M.J. Fréchet, "Unusual macromolecular architectures: The convergent growth approach to dendritic polyesters and novel block copolymers," J. Am. Chem. Soc., 4, 8405-8413 (1992).

14. Hassner, and V. Alexanian, "Direct room temperature esterification of carboxylic acids," Tetrahedron Lett., 46, 4475-4478 (1978).

15. J.S. Moore, and S.I. Stupp, "Room temperature polyesterification," Macromolecules, 23, 65-70 (1990).

16. A. Solladié-Cavallo, and M. Bencheqroun, "Inexpensive reagents for the synthesis of amides from esters and for regioselective opening of epoxides," $J$. Org. Chem., 57, 5831-5833 (1992).

17. D.L. Flynn, R.E. Zelle, and P.A. Grieco, "A mild two-step method for the hydrolysis/methanolysis of secondary amides and lactams," J. Org. Chem., 48, 2424-2426 (1983).

18. V. Kohli, H. Blöcker, and H. Köster, "The triphenylmethyl (trityl) group and its use in nucleotide chemistry," Tetrahedron Lett., 21, 2683-2686 (1980).

19. J. Diago-Mesegauer, and A.L. Palomo-Coll, "A new reagent for activating carboxyl groups; preparation and reactions of $N, N$,-bis[2-oxo-3oxazolidinyl]phosphoro diamidic chloride," Synthesis, 547-551 (1980).

20. P.A.S. Smith, In: "Azides and nitrenes; reactivity and utility," Academic Press, Orlando, Fl, 95-204 (1984).

21. E. Leyva, M.S. Platz, G. Persy, and J. Wirz, "Photochemistry of phenyl azide. The role of singlet and triplet phenylnitrene as transient intermediates," $\mathrm{J}$. Am. Chem. Soc., 108, 3783-3790 (1986).

22. H.C. Hemker, G. Willems, and S. Béguin, "A computer assisted method to obtain the prothrombin activation velocity in whole plasma independent of thrombin decay processes," Thromb. Haemost., 56, 9-17 (1986). 


\section{CHAPTER 3}

Photo-immobilisation of Dipyridamole $\left(\right.$ Persantin $\left.^{\circledR}\right)$ at the Surface of

Polyurethane Biomaterials. Reduction of in vitro Thrombogenicity ${ }^{*}$ 


\subsection{Abstract}

Dipyridamole is a well-known vasodilator and a powerful inhibitor of activation and aggregation of blood platelets. Moreover, dipyridamole is essentially non-toxic. The drug is used extensively in clinical anticoagulation regimens, for example pre and post coronary angioplasty procedures. Recently, we have found that photochemical, covalent coupling of dipyridamole to polyurethane surfaces leads to improved thromboresistance in vitro. This phenomenon was now studied in more detail.

Both qualitative and more quantitative biochemical experiments were performed in order to characterise the in vitro blood compatibility of a set of polyurethane surfaces onto which dipyridamole was immobilised. First, scanning electron microscopy was used to examine morphology of bloodplatelets, which adhered during incubation with platelet rich plasma (PRP). These experiments showed that immobilisation of dipyridamole leads to a clearly decreased number of adherent platelets, and to a largely diminished propensity of the surface to activate adherent platelets. Secondly, an in vitro thrombogenicity assay was run. These experiments showed that the thromboresistance increases with increasing surface density of immobilised dipyridamole. A short spacer chain, separating dipyridamole from the polymer surface, was found to improve the thromboresistance further. Such a spacer chain apparently increases the efficacy of the immobilised drug.

Collectively, the present results further substantiate the idea that dipyridamole retains its inhibitory activity with respect to activation and aggregation of bloodplatelets, when the compound is covalently attached to a polymer surface.

\subsection{Introduction}

The makeup of the natural blood vessel wall is intriguingly sophisticated and complex.' Its structure consists of three layers:

1. The blood-contacting intima, a monolayer of endothelial cells on a basement membrane. 
2. The media, which are composed of smooth muscle cells embedded in an extracellular matrix of collagen, elastin, and mucopolysaccharides.

3. The adventitia, consisting of fibroblast cells which are surrounded by an extracellular matrix of mainly collagen.

In fact, this description of the arterial wall also explains why development of a functional artificial prostheses for blood vessels meets with so many difficulties. Despite numerous attempts to address this problem, the need for a satisfactory small-bore vascular graft (i.d. $<6 \mathrm{~mm}$ ) remains essentially unfulfilled. Most of the complications with vascular grafts are related to the thrombogenicity of the luminal surface of the graft. Differences in compliance between the graft and the host artery are another source of problems. Such differences cause perturbations of the blood flow, which may result in thrombotic phenomena such as anastomotic intimal hyperplasia.

It is widely believed that most of the current complications with vascular grafts are due to thrombus formation as a result of blood - polymer contact. Improvement of the bloodcompatibility of artificial polymer surfaces is therefore a major issue in biomaterials science. ${ }^{2}$ Grossly speaking, two main strategies are being followed:

1. To create surfaces that prevents or suppress unwanted or uncontrolled reactions of the blood (e.g., activation of the blood coagulation cascade, or activation and aggregation of adherent blood platelets).

2. To prepare polymers that are inert or passive with respect to blood reactions.

Strategy 1 is increasingly popular. The underlying theory is that the bloodcompatibility of a material is determined primarily by its surface, rather than by its bulk properties. Through surface modification, biocompatibility can be improved while the physical-mechanical properties of the material remain essentially unchanged. Particularly heparin coatings are frequently used. ${ }^{3}$ It has been shown that heparin retains (most of) its anticoagulant activity after surface immobilisation, which can be through ionic or covalent bonding. ${ }^{4}$ Recent studies by Lindahl et al., ${ }^{5}$ who showed that the blood vessel wall contains substances that are structurally and functionally related to heparin, have led to further acceptance of the concept of immobilisation of the heparin anticoagulant activity. 
The work on surface modification of polyurethanes is aimed specifically at the development of an artificial blood vessel prosthesis which should exhibit minimal thrombogenicity at its luminal surface. The followed approach also fits into strategy 1. First, different agents are selected which find clinical use because of their strong systemic inhibitory effect on activation and aggregation

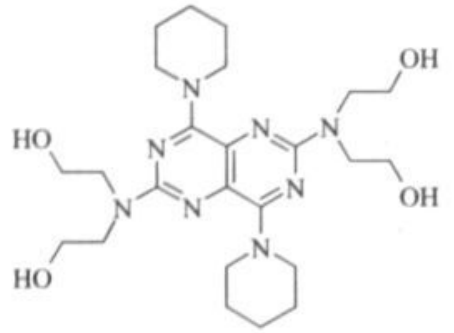

Dipyridamole

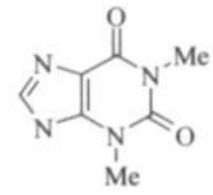

Theophylline

of platelets, for example: theophylline, or dipyridamole (Persantin ${ }^{8}$ ). These compounds are chemically derivatized such that they are linked to a photoreactive moiety, the $p$-azidobenzoyl group. These compounds are adsorbed onto polyurethane sheets, and are subsequently exposed to ultraviolet (UV) light. The resulting photoreaction involves the $p$-azidobenzoyl group, or rather a didehydro-azepine structure generated after photochemical excitation of the $p$-azidobenzoyl group, and a nucleophilic site at the polymer's surface. The consequence of this procedure is that the platelet inhibiting drug becomes exposed at and covalently linked to the polymer's surface. In our previous experiments with theophylline and dipyridamole, in vitro thromboresistance was found to increase substantially as a result of this photochemical surface modification. ${ }^{6,7}$

Here, the results are described which extend on previous work with surfaceimmobilised dipyridamole. ${ }^{7}$ Particularly, the impact of a spacerchain, which separates dipyridamole from the photoreactive moiety is investigated. Such a spacer can be beneficial with regard to the efficacy of the immobilised drug: the longer the spacer, the more the drug can behave as if it were free in solution. A detailed comparative study involving structures $\mathbf{2}$ (no spacer) and $\mathbf{3}$, in which a short spacer chain (-C(O)- $\left.\mathrm{CH}_{2}-\mathrm{CH}_{2}-\mathrm{CH}_{2}-\mathrm{O}-\right)$ is described here. 


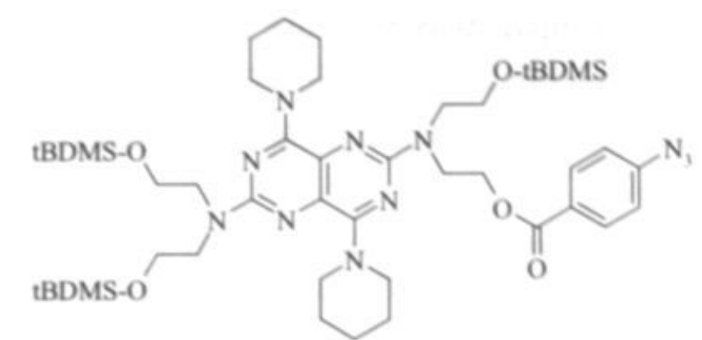

2

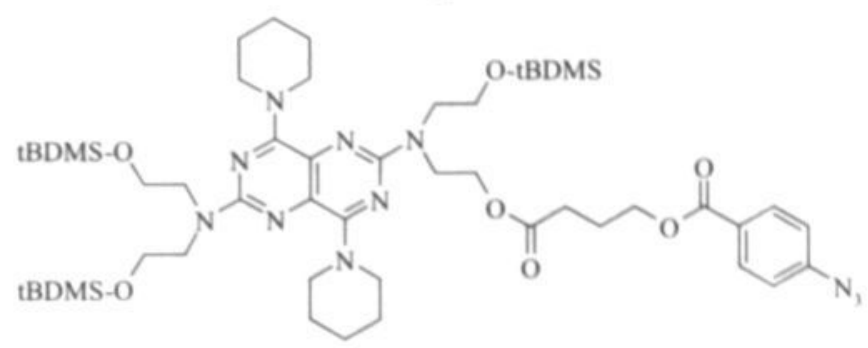

3

\subsection{Materials and Methods}

\subsubsection{Photo-immobilisation}

Photo-immobilisation of $\mathbf{2}$ and $\mathbf{3}$, which were prepared as described previously, was carried out with a commercial polyurethane foil (Pellethane D55 , medical grade, $0.4 \mathrm{~mm}$ thickness $){ }^{6.7}$ A piece of this foil $(30 \times 30 \mathrm{~mm})$ was thoroughly washed with 2-propanol (30 min, ultrasonic), and sprayed with a I $\mathrm{mM}$ solution of $\mathbf{2}$ or $\mathbf{3}$ in 2-propanol. During spraying, the solvent was evaporated continuously by means of a hot-air fan. Spraying was repeated several times. Depending on the number of sprays, polyurethane foils with different surface loadings were obtained. The foils were then irradiated with a Philips HPA 1000 high-power UV light source (Philips Lighting, Eindhoven, The Netherlands). Irradiation lasted $15 \mathrm{~min}$, and the lamp was held $30 \mathrm{~cm}$. above the foil. Subsequently, the foils were thoroughly washed with 2-propanol (30 min, ultrasonic), to remove unreacted $\mathbf{2}$ or $\mathbf{3}$ and possible side-products. The foils were then immersed in a stirred solution of $(\mathrm{n}-\mathrm{Bu})_{4} \mathrm{NF} .3 \mathrm{H}_{2} \mathrm{O}(127$ $\mathrm{mmol}$ ) in $20 \mathrm{~mL}$ of nitromethane. The fluoride reagent is known to effectively cleave the tert-butyldimethylsilyl protective groups. ${ }^{8}$ The foils were then washed successively with 2-propanol (30 min, ultrasonic), and repeatedly with 
water. The surface-treated foils were stored in dry form. Interestingly, the presence of immobilised dipyridamole at the foil's surfaces could be verified easily by means of a low-power UV lamp. The surface-treated foils showed clear fluorescence under the low-power UV lamp, which emits at $274 \mathrm{~nm}$.

\subsubsection{Physico-chemical characterisation}

$U V$-extinction experiments: The UV extinction of dipyridamole provides a convenient means to obtain an estimate of the surface-concentration. Firstly, it was established that the polyurethane dissolves in tetrahydrofuran (THF). A UV extinction spectrum of such a solution shows no absorption at wavelengths $>350 \mathrm{~nm}$. A blank solution was prepared, which contained $99.13 \mathrm{~mm}^{2}$ of the untreated polyurethane in $3.37 \mathrm{~mL}$ of THF. This spectrum was stored in the digital memory of the spectrometer. Secondly, the UV absorption spectrum of dipyridamole was measured. This spectrum showed a local maximum at 408 $\mathrm{nm}$. The molar extinction coëfficient at this wave-length was $4397 \mathrm{~L} \cdot \mathrm{mol}^{-1} \cdot \mathrm{cm}^{-1}$. Thirdly, a known surface-area of a treated foil was dissolved in THF, in such a way that the same polyurethane concentration as in the blank was obtained. Measurement of the extinction at $408 \mathrm{~nm}$ then allowed us to calculate the density of immobilised dipyridamole at the specimen's surface.

Contact angle experiments: Contact angle measurements were performed according to the captive bubble method as described in ref 9. Accuracy of reported values is $\pm 2 \mathrm{deg}$.

\subsubsection{In vitro bloodcompatibility tests}

Adhesion of bloodplatelets: Scanning electron microscopy (SEM) was used to study morphology of blood platelets that adhered to the modified surfaces. Unmodified polyurethane sheets were used as references. The foils were incubated for $30 \mathrm{~min}$. with citrated platelet rich plasma (PRP). Subsequently, the surfaces were rinsed with phosphate buffered saline (PBS), and treated overnight with glutaraldehyde in PBS. The foils were then rinsed with PBS, dehydrated in ethanol, dried by the critical point drying method, and subjected to SEM analysis. A Philips 505 SEM system (Philips, Eindhoven, The Netherlands) was used.

Thrombin generation experiments: The in vitro thrombogenicity tests were performed as described previously. ${ }^{10}$ Briefly, the polymer surfaces were incubated for $15 \mathrm{~min}$. with citrated PRP. Then, blood coagulation was started by the addition of $\mathrm{CaCl}_{2}$. Samples were withdrawn at regular time intervals (ca. 
$1 \mathrm{~min}$.), and assayed for thrombin using the chromogenic substrate S $2238(\mathrm{H}-$ D-phenylalanyl-picolyl-arginine $p$-nitroanilide). ${ }^{11}$ Changes in optical density were recorded at $405 \mathrm{~nm}$ (sample wavelength) and $505 \mathrm{~nm}$ (reference wavelength). Reference curve was constructed from known amounts of thrombin.

\subsection{Results and Discussion}

\subsubsection{Physico-chemical characterisation}

$U V$-extinction experiments: The surface densities of immobilised dipyridamole, as measured via UV-extinction experiments for the different specimens, are compiled in Table 1. Repeated spraying and drying of the polymer surface, prior to UV-irradiation, leads to increased densities of immobilised dipyridamole at the surface. Note that surface densities as high as $45 \mathrm{nmol} / \mathrm{cm}^{2}$ are obtained. In this respect, we observed no differences between conjugates $\mathbf{2}$ and $\mathbf{3}$, i.e. the spacer chain does not appear to have an effect on the efficacy of the photo-immobilisation.

Contact angle measurements: Water contact-angle measurements ${ }^{9}$ showed that the modified surfaces are slightly more hydrophilic than the control (untreated Pellethane D-55 foils). The control exhibited a contact angle of 49.5 deg. The modified surfaces to which dipyridamole was linked directly (no spacer chain, prepared with conjugate 2) showed contact angles of 50.5, 45.9, and $38.2 \mathrm{deg}$. for the surface loadings $10.48,20.43$, and $38.84 \mathrm{nmol} / \mathrm{cm}^{2}$, respectively. The modified surfaces to which dipyridamole is linked via the short spacer chain (prepared with conjugate 3 ) showed contact angles of 48.1, 46.8 , and $40.9 \mathrm{deg}$., respectively for the comparable surface loadings 11.10, 21.05 , and $45.49 \mathrm{nmol} / \mathrm{cm}^{2}$. The hydrophilicity of the modified surfaces is not a particularly strong feature. This is not surprising since dipyridamole is not a very water-soluble compound by itself. Furthermore, it is seen that the spacer chain has no appreciable impact on the surface hydrophilicity. 
Table 1. Results from the UV spectroscopy experiments and the in vitro thrombogenicity test.

\begin{tabular}{llll}
\hline Surface & $\begin{array}{l}\text { Immobilised } \\
\left(\mathrm{nmol} / \mathrm{cm}^{2}\right)\end{array}$ & dipyridamole Lag time (s) & $\begin{array}{l}{[\text { Thrombin }]_{\max }} \\
(\mathrm{nM})\end{array}$ \\
\hline Pellethane D-55 & 0 & 569 & 118 \\
& & & \\
Pellethane D-55 & 11.10 & 878 & 93 \\
treated with 2 & 13.32 & 784 & 88 \\
& 17.49 & 921 & 95 \\
& 21.05 & 945 & 83 \\
& 23.66 & 831 & 79 \\
& 27.05 & 980 & 85 \\
& 30.88 & 813 & 95 \\
& 33.66 & 930 & 112 \\
& 36.04 & 974 & 96 \\
& 45.49 & 1015 & 71 \\
\hline Pellethane D-55 & 10.48 & & \\
treated with 3 & 13.20 & 862 & 99 \\
& 16.10 & 877 & 69 \\
& 17.62 & 953 & 64 \\
& 20.43 & 986 & 79 \\
& 25.35 & 1087 & 70 \\
& 29.85 & 1193 & 80 \\
& 30.35 & 1092 & 68 \\
& 38.84 & 1265 & 49 \\
& 41.92 & 1279 & 54 \\
& & 1250 & 50 \\
\hline
\end{tabular}

\subsubsection{In vitro bloodcompatibility tests}

Adhesion of bloodplatelets: The modified surfaces were first studied with respect to their propensity to adhere and activate bloodplatelets. Activated platelets were found on the control surface (unmodified polyurethane). The adhered platelets (appr. $4000 / \mathrm{mm}^{2}$ ) showed extensive formation of pseudopodia. Far less platelets (appr. $900 / \mathrm{mm}^{2}$ ) appeared to adhere to modified surfaces prepared with conjugate $\mathbf{2}$; most of them were spread. The polyurethane surfaces that were treated with conjugate 3 showed almost no adherence of platelets; the few platelets present merely showed extension of small pseudopodia. 


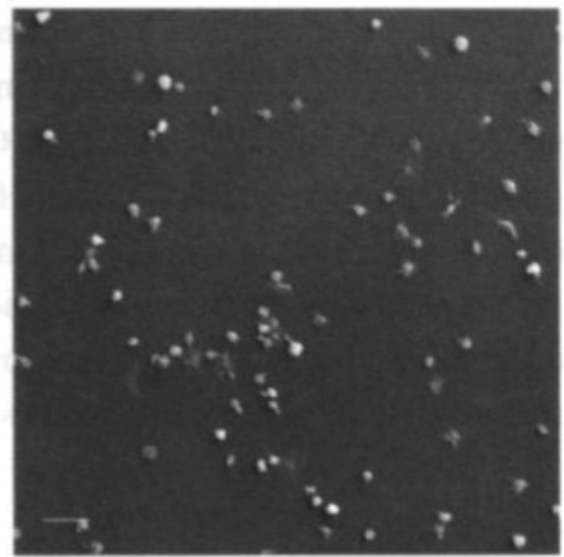

A

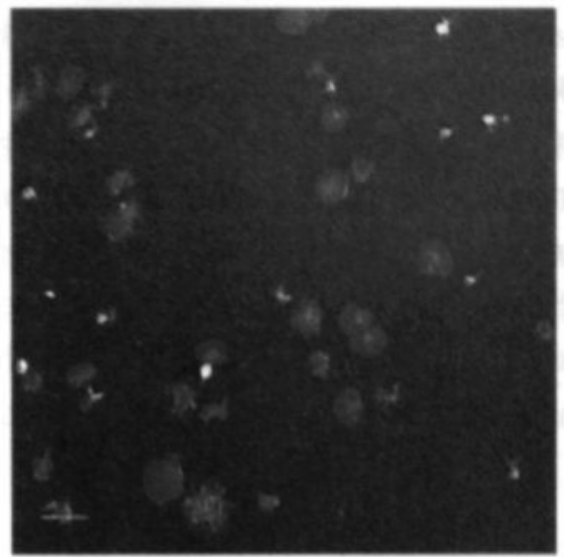

B

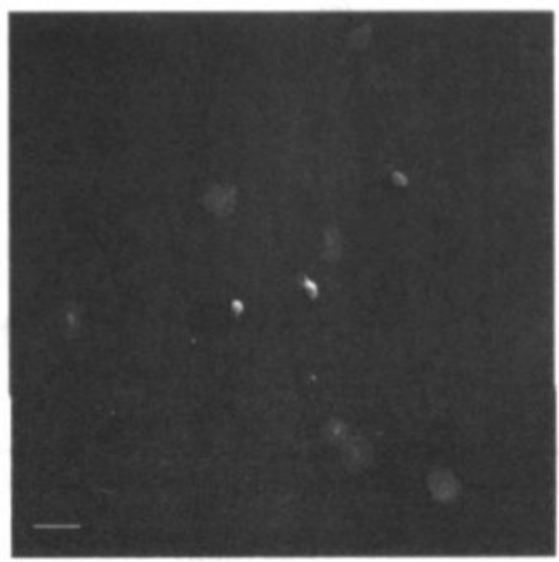

C

Figure 1. Scanning electron micrographs of the control and two modified surfaces after incubation with PRP. A: unmodified polyurethane. B: polyurethane modified with 2 (13.32 nmol/ $\mathrm{cm}^{2}$ immobilised dipyridamole). C: polyurethane modified with $3\left(10.48 \mathrm{nmol} / \mathrm{cm}^{2}\right.$ immobilised dipyridamole). Length of $\mathrm{bar}=10 \mu \mathrm{m}$.

Thrombin generation experiments: All surfaces were subjected to the in vitro thrombin generation assay. ${ }^{10}$ The most important parameter that can be abstracted from a thrombin generation curve is the lag time, i.e. the time elapsing between "recalcification" of the PRP, and the onset of thrombin generation. Another parameter is [thrombin] $]_{\max }$, the maximum concentration of free thrombin reached during the experiment. Table 1 compiles the complete set of results from the thrombin generation assay. 
Surface immobilisation of compound 2 leads, after removal of the tertbutyldimethylsilyl groups, to reduced in vitro thrombogenicity. The lag times are clearly prolonged: 784-1015 s after surface modification, vs. $569 \mathrm{~s}$ for the control surface (untreated Pellethane D-55). Moreover, the values for [thrombin] $]_{\max }$ appear to decrease upon surface modification: 71-112 nM, vs. $118 \mathrm{nM}$ for the control surface. The results obtained after surface modification with 3 and subsequent deprotection show the same trend. Lag times lie in the range $862-1279 \mathrm{~s}$ and [thrombin]max varies from 49 to $99 \mathrm{nM}$. Figure 2 shows

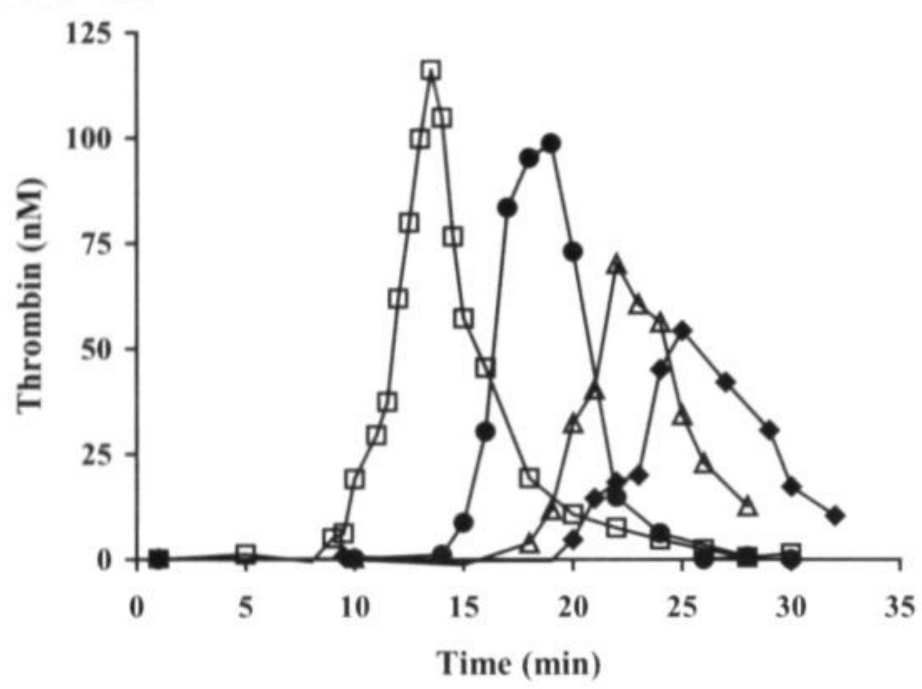

Figure 2. Thrombin generation curves measured for modified surfaces to which dipyridamole is linked via the short spacer chain. The four curves refer to different surface loadings: open squares: blanc, no dipyridamole present; closed circles: 10.48 $\mathrm{nmol} / \mathrm{cm}^{2}$ immobilised dipyridamole; open triangles: $20.43 \mathrm{nmol} / \mathrm{cm}^{2}$ immobilised dipyridamole; closed diamonds: $38.84 \mathrm{nmol} / \mathrm{cm}^{2}$ immobilised dipyridamole. Note that [thrombin $]_{\max }$ decreases, as the lag time for thrombin formation increases with increasing surface density of immobilised dipyridamole.

four thrombin curves which were measured for the modified surfaces to which dipyridamole was linked via the short spacer chain (i.e. conjugate $\mathbf{3}$ was used in the photo-immobilisation). Surface densities are: $0,10.48,20.43$, and 38.84 $\mathrm{nmol} / \mathrm{cm}^{2}$. Figure 3 plots the lag-time data as a function of the surfaceconcentration of immobilised dipyridamole. Closed circles correspond with photo-immobilisation of $\mathbf{2}$ (no spacer), and the open squares relate to photoimmobilisation of $\mathbf{3}$ (short spacer chain). As might be expected, a plateau is 
found in both cases, for high surface concentrations of immobilised dipyridamole $\left(>30 \mathrm{nmol} / \mathrm{cm}^{2}\right)$. Figure 3 clearly demonstrates that the presence of the spacer increases the efficacy of the immobilised dipyridamole. For comparable surface densities, it is consistently seen that the presence of the spacer results in a longer lag time for thrombin generation. Accordingly, the open squares (short spacer chain) show a higher plateau level than the filled circles (no spacer).

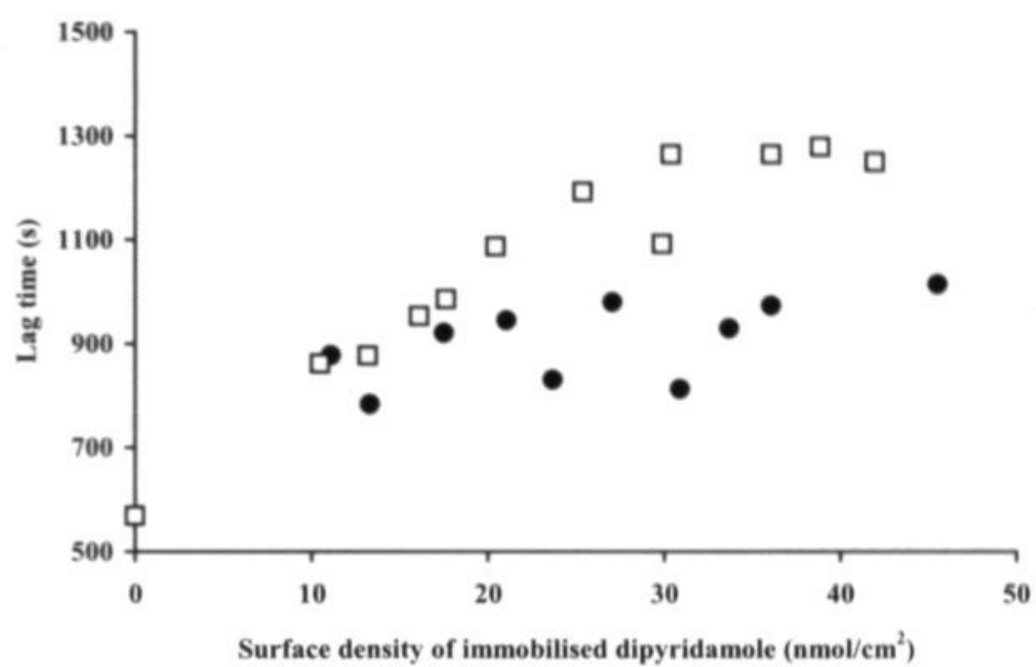

Figure 3. The thrombin generation lag time as function of the surface concentration of immobilised dipyridamole. The closed circles refer to dipyridamole linked directly to the polyurethane surface (no spacer chain, conjugate 2). Open squares relate to dipyridamole linked via the short spacer chain to the polyurethane surface (conjugate 3).

\subsection{Concluding Remarks}

Conjugate molecules $\mathbf{2}$ and $\mathbf{3}$ can both be used for photo-immobilisation of dipyridamole on polyurethane surfaces (Pellethane D-55). The resulting modified surfaces show a decreased propensity to activate adherent blood platelets, and also show a decreased thrombogenicity in vitro. The lag time for thrombin formation, appears to depend on two factors: $(i)$ the surface density of immobilised dipyridamole, and (ii) the absence or presence of a spacer chain, separating the dipyridamole from the polymer surface. The presence of the 
spacer increases the efficacy of the immobilised drug. The latter observation is of considerable interest, since this suggests that the observed reduction of thrombogenicity is not merely a result of changes in the physico-chemical properties of the surface (hydrophilicity, surface energy, etc.). The present results support the idea -previously expressed by Bamford et al. ${ }^{12-14}$, and by ourselves $^{6,7}$ - that dipyridamole which is covalently linked to a polymer macromolecule, retains its platelet inhibiting activity. The underlying mechanism is most probably that dipyridamole is recognized by a putative receptor site on the platelet's exterior membrane. Evidently, such a recognition process would benefit from the presence of a spacer, which allows the dipyridamole, at least to some extent, to move independently of the underlying surface.

\subsection{References}

1. A.C. Guyton, In: "Textbook of Medical Physiology," W.B. Saunders Company, Philadelphia, 149-272 (1995).

2. N.A Peppas and R. Langer, "New challenges in biomaterials," Science, 263, 1715-1720 (1994).

3. G.H. Engbers and J. Feijen, "Current techniques to improve the blood compatibility of biomaterial surfaces," Int J. Artif. Org., 14, 199-215 (1991).

4. O. Larm, R. Larsson, and P. Olsson, In: "Surface Immobilised Heparin. In Heparin: Chemical and Biological properties, clinical applications", Eduard Arnold, London, 597-608 (1989).

5. U. Lindahl, K. Lidholdt, D. Spillmann, and L. Kjellen, "More to "Heparin" than anticoagulation," Thromb. Res., 75, 1-32 (1994).

6. Y.B.J. Aldenhoff and L.H. Koole, "Studies on a new strategy for surface modification of polymeric biomaterials," J. Biomed. Mater. Res., 29, 917-928 (1995).

7. J.M.H. Kuijpens, G.A. Kardaun, R. Blezer, A.P. Pijpers, and L.H. Koole, "Immobilisation of theophylline on medical-grade polyurethane inhibits surfaceinduced activation of blood platelets," J. Amer. Chem. Soc., 117, 8691-8697 (1995).

8. E.J. Corey and A. Venkateswarly, "Protection of Hydroxyl Groups as tertButyldimethylsilyl Derivates," J. Am. Chem. Soc., 94, 6190-6191 (1972).

9. R.N. King, J.D. Andrade, S.M. Ma, D.E. Gregonis, and L.R. Brostrom, "Interfacial Tensions at Acrylic Hydrogel-Water Interfaces," J. Colloid. Interface Sci., 103, 62-75 (1985).

10. T. Lindhout, R. Blezer, C. Maassen, V. Heijnen, and C.P.M. Reutelingsperger, "Procoagulant Surface as an essential parameter for the in vitro evaluation of blood compatibility of polymers," J. Mater. Sci. Mater. Med., 6, 367-372 (1995).

11. H. C. Hemker, In: "Handbook of Synthetic Substrates for the Coagulation and Fibrinolytic System," Martinus Nijhoff, The Hague (1983). 
12. C.H. Bamford, I. Middleton, K.G. Al-Lamee, J. Paparotny, and Y. Satake, "Routes to bioactive hydrophilic polymers," Polym. J., 19, 475-481 (1987).

13. C.H. Bamford, K.G. Al-Lamee, I. Middleton, and R. Can, "Chemical modification of polymers to increase bloodcompatibility," Bull. Soc. Chim. Belg., 99, 919-925 (1990).

14. C.H. Bamford and K.G. Al-Lamee, "Chemical methods for improving haemo compatibility of synthetic polymers," Clin. Mater., 10, 243-250 (1992). 



\section{CHAPTER 4}

Synthesis of a New Photoreactive

Derivative of Dipyridamole and Its Use in the Manufacture of Artificial Surfaces with Low Thrombogenicity* 


\subsection{Abstract}

Photo-immobilisation of dipyridamole (Persantin ${ }^{8}$ ) was accomplished through the use of a new synthetic conjugate molecule, 4. Persantin ${ }^{\otimes}$ is a powerful inhibitor of platelet activation and aggregation, and widely used as a vasodilator. Conjugate $\mathbf{4}$ consists of triply protected dipyridamole (three of the four hydroxyl groups carry a tert. butyl dimethylsilyl protective group), and the photoreactive $p$-azidobenzoyl group. A short hydrophilic spacer chain, derived from triethylene glycol, separates the protected dipyridamole system and the photoreactive group. Compound $\mathbf{4}$ was immobilised on polyurethane sheets (Pellethane D-55) through irradiation with ultraviolet (UV) light, and the protective groups were removed afterwards. The resulting modified polyurethane surfaces were characterised by different physico-chemical techniques: UV extinction, contact angle measurements (captive bubble technique), and Electron spectroscopy for chemical analysis (ESCA). The UV extinction measurements showed the presence of $13 \pm 1 \mathrm{nmol}$ of immobilised dipyridamole per $\mathrm{cm}^{2}$. The contact angle measurements revealed that the modified surface was markedly more hydrophilic than the control (i.e. unmodified polyurethane). ESCA measurements clearly established the presence of immobilised dipyridamole in the outermost layers of the modified surface. This was especially clear from the ESCA spectra recorded at a low take-off angle $\left(\sim 6^{\circ}\right)$. Furthermore, the ESCA spectra showed that the tBDMS protective groups had been quantitatively removed during the deprotection/washing treatment. The in vitro bloodcompatibility of the modified surface was studied with the thrombin generation assay as developed in our group, as well as with scanning electron microscopy. The thrombin generation test produced a lag-time of $1275 \mathrm{sec}$ for the modified surface, as opposed to $569 \mathrm{sec}$ for the control. Scanning electron microscopy showed that far less platelets adhere to the modified surface (appr. $7 \times 10^{3} / \mathrm{mm}^{2}$ ) as compared to the control (appr. $6 \times 10^{2} / \mathrm{mm}^{2}$ ). Taken together, the experimental data reveal that the modified surface has excellent blood compatibility in vitro. It is discussed that the use of conjugate $\mathbf{4}$ leads to simultaneous exposure of dipyridamole at the modified surface and to a marked increase of the surface hydrophilicity, which is likely to hamper adsorption of plasma proteins. 
The combination of these effects is uniquely related to the molecular build-up of $\mathbf{4}$. Conjugate $\mathbf{4}$ will be used in future work, which is aimed at preparing small-caliber polyurethane vascular grafts with a blood compatible lumenal surface.

\subsection{Introduction}

Dipyridamole is a non-toxic drug, which acts as an inhibitor of the activation and aggregation of blood platelets. ${ }^{1,2}$ The drug is also a powerful vasodilator, i.e. a substance which induces widening of the blood vessels after its systemic injection. ${ }^{1.2}$ Dipyridamole, which is marketed as Persantin ${ }^{*}$, is commonly administered to patients before and after percutaneous transluminal coronary angioplasty ("Dottering"), mostly in combination with aspirin. We became interested in dipyridamole in the course of our work, which is aimed at the manufacture of new materials with improved bloodcompatibility. We concentrate both on the preparation and on the testing (in vitro and in vivo) of such materials. ${ }^{3-7}$ Blood clotting as a result of the contact between blood and an artificial surface remains perhaps the most important problem in the development of improved cardiovascular devices.

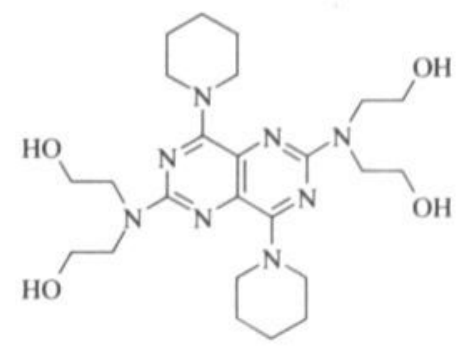

We know, particularly from the pioneering work of Vroman et $\mathrm{al}^{8-10}$ that contact between blood and an artificial surface immediately leads to adsorption of plasma proteins. Adsorbed proteins may be displaced by others, and these processes probably occur within several minutes. Proteins in the adsorbed state adopt a different molecular conformation as compared to the circulating state, and platelets and leukocytes may adhere via receptor sites that match structural patterns of an adsorbate. It has become clear that immunoglobulins, fibronectin 
and fibrinogen have specific significance as adsorbates. ${ }^{11}$ When a platelet is activated through this mechanism, it may in turn trigger other platelets and induce generation of thrombin leading to deposition of fibrin. These events will result in the formation of a thrombus. Recent work by Bamford et al. implied that dipyridamole could play a role in the development of new bloodcompatible materials. ${ }^{12,13}$ Bamford et al. chemically coupled dipyridamole to a series of water-soluble macromolecules, and subsequently showed that the drug retained its platelet-inhibitory activity. In some cases, the drug was even slightly potentiated. As the macromolecular vehicles containing dipyridamole can not cross the platelet's membrane, these experiments revealed -although in an indirect manner- that dipyridamole can exert its function via a putative receptor site on the exterior of the platelet.

Later, it was shown that coupling of dipyridamole onto water insoluble polymers (e.g., the polyurethane Pellethane-D55) markedly contributes to the blood-compatibility of the surface, at least in vitro. ${ }^{3}$ Evidence in support of an inhibitory action of immobilised dipyridamole on contacting platelets has accumulated. The data, taken together, suggest that the platelet inhibition by immobilised dipyridamole counteracts or overrules platelet activation by adsorbed plasma proteins (e.g., fibronectin or fibrinogen).

Immobilisation of dipyridamole onto the surface of water-insoluble polymers was accomplished through a novel photo-immobilisation technique. ${ }^{3-}$ ${ }^{5.14}$ To this end, a series of novel molecules were synthesised, which consist of a triply tBDMS-protected ${ }^{15}$ dipyridamole connected to a $p$-azidobenzoyl group. It could be demonstrated that such conjugate molecules can be covalently coupled to a polyurethane surface via irradiation with ultraviolet (UV) light. ${ }^{14}$ The $p$ azidobenzoyl group loses molecular nitrogen $\left(\mathrm{N}_{2}\right)$ upon UV-irradiation, and this photoreaction generates a highly reactive (electrophilic) didehydroazepine structure. ${ }^{16-18}$ Then, reaction with a nucleophilic site at the polymer surface (e.g. a urethane $\mathrm{NH}$ group) generates a new covalent bond between the conjugate and the polymer surface.

This chapter describes a comprehensive study on a new conjugate molecule, 4, which has the characteristic feature that the (protected) dipyridamole unit is linked to $p$-azidobenzoyl via a short hydrophilic spacer chain. It was decided to prepare and test such a system since we anticipated that a hydrophilic spacer 


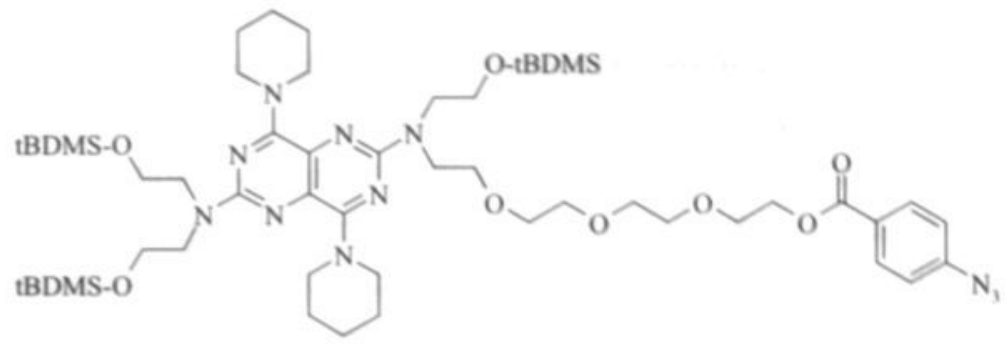

4

chain could facilitate exposure of the deprotected dipyridamole in the aqueous boundary layer at the polymer's surface.

This chapter describes consecutively: (i), synthesis of 4 ; (ii), photoimmobilisation of $\mathbf{4}$ on polyurethane sheets; (iii), deprotection and purification; (iv) physico-chemical characterisation of the modified surfaces (contact angle, ESCA); and ( $v)$, in vitro tests of the bloodcompatibility of modified and unmodified surfaces.

\subsection{Materials and Methods}

\subsubsection{General section}

All solvents and starting materials were of the highest available purity or were purified as specified. Pyridine and dichloromethane were distilled from calcium hydride and stored over Linde $3 \AA$ molecular sieves. Triethylamine was distilled from calcium hydride and stored over potassium hydroxide pellets. Tetrahydrofuran was passed through an alumina column, distilled from calcium hydride, and stored over Linde $3 \AA$ molecular sieves. Methanol was predried with iodine and magnesium turnings, distilled, and stored over Linde $3 \AA$ molecular sieves. Thin layer chromatography was performed on glass plates ( 3 x $10 \mathrm{~cm}$ ) with a fluorescent indicator. Silica gel 60 (particle size 0.063-0.200 $\mathrm{mm}$ ) was used for column chromatography. Mass spectra were run on a Kratos MS $80 \mathrm{RF}$ instrument. ${ }^{1} \mathrm{H} \mathrm{NMR}$ and ${ }^{13} \mathrm{C}$ NMR were recorded at 399.9 and 100.6 $\mathrm{MHz}$ respectively on a Varian Unity-Plus spectrometer, using deuterated chloroform or deuterated methylsulfoxide as the solvent. Tetramethyl silane was used as the internal reference $(\delta=0.00 \mathrm{ppm})$. 


\subsubsection{Synthesis}

Preparation of 1-(2'-O-triphenylmethylethoxy)-2-(2'-hydroxyethoxy)ethane (21): To a stirred solution of triethyleneglycol $(75.09 \mathrm{~g}, 500.00 \mathrm{mmol})$ and 4dimethyl aminopyridine $(0.38 \mathrm{~g}, 3.13 \mathrm{mmol})$ in $125 \mathrm{~mL}$ of anhydrous pyridine was added triphenylmethyl chloride $(17.42 \mathrm{~g}, 63.50 \mathrm{mmol})$ in 10 portions during $3 \mathrm{~h}$. The solution was stirred for $16 \mathrm{~h}$ under exclusion of moisture. Then, pyridine was removed (last traces were removed by coevaporation with toluene). The residue was taken up in dichloromethane and washed with saturated aqueous bicarbonate $(3 \mathrm{x})$ and water $(3 \mathrm{x})$. The organic layer was dried on magnesium sulfate, filtered, and concentrated to dryness under reduced pressure. The crude product was applied to a silica gel column. Elution with 1:1 petroleum ether/ethyl acetate afforded pure $\mathbf{2 1}$ as a viscous oil. $\mathbf{R}_{\mathrm{f}}$ (petroleum ether/ethyl acetate $1: 1)=0.38$. Yield: $20.56 \mathrm{~g}(84 \%) .{ }^{1} \mathrm{H}$ NMR $\left(\mathrm{CDCl}_{3}\right), \delta: 7.50-7.15\left(15 \mathrm{H}, \mathrm{m}, \mathrm{CPh}_{3}\right), 3.66\left(8 \mathrm{H}, \mathrm{m}, \mathrm{OCH}_{2} \mathrm{CH}_{2} \mathrm{O}\right), 3.59(2 \mathrm{H}, \mathrm{t}$, $\left.\mathrm{CH}_{2} \mathrm{OH}\right), 3.24\left(2 \mathrm{H}, \mathrm{t}, \mathrm{CH}_{2} \mathrm{OCPh}_{3}\right), 2.95(1 \mathrm{H}$, broad s, $\mathrm{OH}) ;{ }^{13} \mathrm{C} \mathrm{NMR}\left(\mathrm{CDCl}_{3}\right)$, $\delta: 144.09,128.70,127.80,126.98,86.59,72.60,70.68,63.29,61.69$.

1-(2'-O-triphenylmethylethoxy)-2-(2'-bromoethoxy)ethane (22): A solution of bromine $(12.27 \mathrm{~g}, 76.81 \mathrm{mmol})$ in anhydrous dichloromethane $(60 \mathrm{~mL})$ was added dropwise to a solution of triphenylphosphine $(18.60 \mathrm{~g}, 70.90 \mathrm{mmol})$ in anhydrous dichloromethane $(125 \mathrm{~mL})$. The addition was stopped as the yellowbrown colour of free bromine persisted. Subsequently, anhydrous triethylamine (10.76 g, 106.35 mmol) and a solution of $21(20.19 \mathrm{~g}, 59.08 \mathrm{mmol})$ in $75 \mathrm{~mL}$ of anhydrous dichloromethane were added dropwise. The resulting mixture was stirred for $1 \mathrm{~h}$ under exclusion of moisture. Then, all volatiles were removed under reduced pressure. The residue was taken up in diethyl ether and washed with water. The organic layer was dried on magnesiumsulfate, filtered, and concentrated to dryness under reduced pressure. The crude product was applied to a silica gel column. Elution with dichloromethane afforded 22 as a white solid. $\mathrm{R}_{\mathrm{f}}$ (dichloromethane) $=0.43$. Yield: $23.85 \mathrm{~g}(89 \%)$. ${ }^{1} \mathrm{H}$ NMR $\left(\mathrm{CDCl}_{3}\right), \delta$ : 7.50-7.18 (15H, m, $\left.\mathrm{CPh}_{3}\right), 3.85\left(2 \mathrm{H}, \mathrm{t}, \mathrm{CH}_{2} \mathrm{Br}\right), 3.70\left(6 \mathrm{H}, \mathrm{m}, \mathrm{OCH}_{2} \mathrm{CH}_{2} \mathrm{O}\right), 3.44$ $\left(2 \mathrm{H}, \mathrm{t}, \mathrm{CH}_{2} \mathrm{O}\right), 3.21\left(2 \mathrm{H}, \mathrm{t}, \mathrm{CH}_{2} \mathrm{CPh}_{3}\right) ;{ }^{13} \mathrm{C} \mathrm{NMR}\left(\mathrm{CDCl}_{3}\right), \delta: 144.08,128.69$, $127.74,126.91,86.6,71.28,70.79,70.75,70.66,63.31,30.34$; Mp $57.8^{\circ} \mathrm{C}$.

Compound 24: Sodium hydride $(60 \%, 0.906 \mathrm{~g}, 22.65 \mathrm{mmol})$ was added to a solution of 7 (3.84 g, $4.53 \mathrm{mmol})^{19}$ in $50 \mathrm{~mL}$ of anhydrous tetrahydrofuran. The 
mixture was sonicated under argon for $15 \mathrm{~min}$. Then, compound $22(2.27 \mathrm{~g}$, $4.98 \mathrm{mmol}$ ) was added and the reaction mixture was magnetically stirred for 16 h. The reaction mixture was poured into saturated aqueous ammonium chloride $(150 \mathrm{~mL})$, which was extracted with ethyl acetate. The combined organic layers were dried on magnesiumsulfate, filtered, and concentrated to dryness under reduced pressure. The residue (crude 23) was taken up in $10 \mathrm{~mL}$ of anhydrous dichloromethane and treated with $2 \mathrm{~mL}$ of anhydrous methanol and anhydrous zincbromide $(10.00 \mathrm{~g}, 45.00 \mathrm{mmol})$. This reaction mixture was magnetically stirred for $2 \mathrm{~h}$. The solvents were evaporated under reduced pressure and the residue was taken up in ethyl acetate and washed consecutively with a $0.1 \mathrm{M}$ citric acid, saturated bicarbonate, and brine. The organic layer was dried on magnesiumsulfate, filtered, and concentrated to dryness under reduced pressure. Crude $\mathbf{2 4}$ was applied to a silica gel column. Elution with 1:1 petroleum ether/ ethyl acetate afforded pure $\mathbf{2 4}$ as a yellow viscous oil. Yield: $1.10 \mathrm{~g}(25 \%)$. ' $\mathrm{H}$ NMR $\left(\mathrm{CDCl}_{3}\right), \delta: 4.70-3.80\left(34 \mathrm{H}, \mathrm{m}, \mathrm{CH}_{2}-\mathrm{N}\right.$ and $\left.\mathrm{CH}_{2}-\mathrm{O}\right)$, 1.68-1.62 $\left(12 \mathrm{H}\right.$, broad $\mathrm{s}, \mathrm{CH}_{2}$ of piperidine rings), $0.84(27 \mathrm{H}, \mathrm{s}$, tert. $-\mathrm{Bu}), 0.02$ $\left(18 \mathrm{H}, \mathrm{s}, \mathrm{CH}_{3}-\mathrm{Si}\right)$.

p-Azidobenzoyl chloride: A solution of p-azidobenzoic acid $(7.50 \mathrm{~g}, 45.98$ mmol $)^{21}$ and thionyl chloride $(16.29 \mathrm{~g}, 138.04 \mathrm{mmol})$ in $250 \mathrm{~mL}$ of anhydrous tetrahydrofuran was refluxed for $30 \mathrm{~min}$. All volatiles were removed under reduced pressure (in the hood, stench). The solid residue was recrystallized from hexane to give pure $p$-azidobenzoyl chloride as a yellowish solid. Yield: $6.76 \mathrm{~g}(81 \%)$. ${ }^{1} \mathrm{H}$ NMR $\left(\mathrm{CDCl}_{3}\right), \delta: 8.05(2 \mathrm{H}, \mathrm{d}$, aromatic $\mathrm{H}), 7.05(2 \mathrm{H}, \mathrm{d}$, aromatic $\mathrm{H}$ ); ${ }^{13} \mathrm{C}$ NMR (DMSO-d 6 ): 166.39, 143.87, 131.15, 127.20, 119.34, 119.05 .

Compound 4: Compound $24(1.35 \mathrm{~g}, 1.39 \mathrm{mmol})$ and p-azidobenzoyl chloride $(0.28 \mathrm{~g}, 1.52 \mathrm{mmol})$ were dissolved in $50 \mathrm{~mL}$ of anhydrous pyridine, and the solution was magnetically stirred for $3 \mathrm{~h}$. Then, pyridine was evaporated (last traces were removed by coevaporation with toluene). The residue was taken up in ethyl acetate, and washed with $0.1 \mathrm{M}$ citric acid, saturated bicarbonate, and brine. The organic layer was dried on magnesiumsulfate, filtered, and concentrated to dryness under reduced pressure. The crude product was applied to a silica gel column. Elution with $4: 1$ petroleum ether/ ethyl acetate afforded pure $\mathbf{4}$ as a yellow-brown oil. 
$\mathrm{R}_{\mathrm{f}}$ (petroleum ether/ ethyl acetate $\left.1: 1\right)=0.68$. Yield: $1.12 \mathrm{~g}(72 \%)$. ${ }^{1} \mathrm{H}$ NMR $\left(\mathrm{CDCl}_{3}\right), \delta: 8.02(2 \mathrm{H}, \mathrm{d}$, aromatic $\mathrm{H}), 7.02(2 \mathrm{H}, \mathrm{d}$, aromatic $\mathrm{H}), 4.43(2 \mathrm{H}, \mathrm{t}$, $\left.\mathrm{CH}_{2} \mathrm{C}(\mathrm{O})\right), 4.05-3.48\left(32 \mathrm{H}, \mathrm{m}, \mathrm{CH}_{2}-\mathrm{N}\right.$ and $\left.\mathrm{CH}_{2}-\mathrm{O}\right), 1.65\left(12 \mathrm{H}\right.$, broad s, $\mathrm{CH}_{2}$ of piperidine rings), $0.95\left(27 \mathrm{H}, \mathrm{s}\right.$, tert.-Bu), $0.02\left(18 \mathrm{H}, \mathrm{s}, \mathrm{CH}_{3}-\mathrm{Si}\right) ;{ }^{13} \mathrm{C} \mathrm{NMR}$ $\left(\mathrm{CDCl}_{3}\right), \delta: 160.34,160.28,153.69,132.54,131.51,118,76,70.36,70.49$, 69.76, 69.21, 64.18, 61.48, 51.50, 51.28, 48.82, 48.63, 26.24, 25.94, 25.12, 18.29, -5.32; FABMS: calcd for $\mathrm{C}_{55} \mathrm{H}_{97} \mathrm{~N}_{11} \mathrm{O}_{8} \mathrm{Si}_{3} \mathrm{~m} / z=1224$, obsd $m / z=1225$ $(\mathrm{M}+\mathrm{H})+$.

\subsubsection{Preparation of modified polyurethane surfaces}

Throughout the experiments, a medical grade polyurethane foil (Pellethane D-55) was used. The foil had a smooth surface (as could be verified with scanning electron microscopy) and was transparent; its thickness was $0.4 \mathrm{~mm}$. Compound 4 was dissolved in 2-propanol (concentration $1 \mathrm{mM}$ ), and this solution was sprayed onto several specimens of the polyurethane foil (dimensions $50 \times 50 \mathrm{~mm}$ ). A compressed-air sprayer was used (tube-type, Aldrich Z12,629-2). During spraying, the polymer surface was placed horizontally and consecutively wetted, dried (air föhn), and turned by $90 \mathrm{deg}$. The procedure of wetting, drying, and turning was repeated 20 times. Then, each foil was irradiated for $15 \mathrm{~min}$. with a Philips HPA 1000 high-power ultraviolet lamp (Philips Lightning, Eindhoven, The Netherlands). The distance between the lamp and the foil surface was $30 \mathrm{~cm}$. Technical details on the lamp: nominal power: $930 \mathrm{~W}$, radiation output $\left(\mathrm{mW} / \mathrm{cm}^{2}\right.$, measured at $1.00 \mathrm{~m}$ distance): UV-A: 2500; UV-B: 900; UV-C: 230. After irradiation, each foil was thoroughly washed with 2-propanol, and immersed for $24 \mathrm{~h}$ in a stirred solution of tetrabutylammonium fluoride in nitromethane. ${ }^{22}$ This reagent is known to effectively cleave the tert-butyl dimethylsilyl groups. Each foil was then thoroughly washed with isopropanol and water, and stored in dry form.

\subsubsection{Physico-chemical characterisation}

$U V$-extinction experiments: The UV extinction of dipyridamole provided a convenient means to obtain an estimate of the surface concentration. The UV absorption spectrum of dipyridamole shows a maximum at $\lambda=408 \mathrm{~nm}$. The molar extinction coëfficient at this wavelength is $4397 \mathrm{~L} \cdot \mathrm{mol}^{-1} \cdot \mathrm{cm}^{-1}$. A piece of the unmodified polyurethane $\left(138.79 \mathrm{~mm}^{2}\right)$ was dissolved in tetrahydrofuran $(4.50 \mathrm{~mL})$. The UV extinction spectrum was measured and stored in the digital 
memory of the spectrometer. Then, a similar piece of the modified polyurethane $\left(139.67 \mathrm{~mm}^{2}\right.$ ) was dissolved in $4.53 \mathrm{~mL}$ tetrahydrofuran (same concentration as the blank). The UV extinction was measured at $408 \mathrm{~nm}$ and the density of immobilised dipyridamole coupled to the polyurethane was calculated. ${ }^{3}$

Contact angle experiments: Contact angle measurements were performed according to the captive bubble method. ${ }^{23}$ The contact angle apparatus consists of a travelling microscope with a $40 \mathrm{X}$ eyepiece with fine right angle crosshairs and a long distance objective, a variable intensity light source, and a micrometer-adjustable X-Y stage vertically mounted on an optical bench. The stage contains a Plexiglass box. The polyurethane sheets were held on the underside of a polycarbonate plate with the modified surface exposed. The box was then filled with doubly distilled water and the plate containing the polyurethane sheet was lowered in the box until the polyurethane sheet was completely immersed. A bubble of air with a volume of $\sim 0.1 \mathrm{~mL}$ was positioned underneath the surface and the contact angle was measured.

Electron Spectroscopy for Chemical Analysis (ESCA): For the ESCA experiments, polyurethane sheets were mounted on a standard sample holder and inserted via a separately pumped load lock into a Leybold MAX200 XPS instrument. Sample areas of $4 \times 7 \mathrm{~mm}^{2}$ were analysed. $\mathrm{Mg} \mathrm{Ka}(1253.6 \mathrm{eV})$ radiation of a $\mathrm{Mg} / \mathrm{Al}$ double anode $\mathrm{X}$-ray tube $(13 \mathrm{kV}, 20 \mathrm{~mA})$ was used. The spectrometer was calibrated using $\mathrm{Ag}, \mathrm{Cu}$ and $\mathrm{Au}^{24}$ At the used pass-energy of $48 \mathrm{eV}$, the full width at half maximum for $\mathrm{Ag} 3 \mathrm{~d} 5 / 2$ was $0.95 \mathrm{eV}$. The base pressure in the analysis chamber was well below $1 \times 10^{-9} \mathrm{mbar}$. The instrument was controlled by a HP A400 computer and a Leybold DS100 data system was used for data aquisition and analysis. For the quantitative analysis the spectra were corrected for the analyzer transmission function, and a linear background was substracted. ${ }^{25}$ Sensitivity factors were calculated, using the approach of Nöller et al. ${ }^{26}$ and the Scofield cross-sections. ${ }^{27}$ For energy referencing a C $1 \mathrm{~s}$ binding energy of $285.0 \mathrm{eV}$ for aliphatic carbon was used. ${ }^{28}$ The samples were measured with different take-off angles. Besides the usual angle $\left(90^{\circ}\right)$, the sample holder was rotated in such a way that a take-off angle of $\sim 6^{\circ}$ was obtained. Derivatization of the hydroxyls of the dipyridamole by trifluoroacetic anhydride was achieved by exposing the polyurethane surface to trifluoroacetic anhydride vapour for $5 \mathrm{~min}$ in a sealed vessel. ${ }^{29}$ The polyurethane surface was then removed and dried. 


\subsubsection{Biochemical characterisation}

Thrombin generation experiments: The unmodified and modified surfaces were subjected to the in vitro thrombin generation assay developed by Lindhout et al., ${ }^{30}$ and described extensively in previous work. ${ }^{3,7,31}$ Two reference materials were included in the assay: Polyethylene (PE) which has a high surface thrombogenicity, and polyvinyl chloride (PVC), which is a relatively passive material. Note that the blood was taken from a healthy donor; the blood plasma was anticoagulated with citrate prior to the assay; the addition of calciumchloride marks the actual start of the experiment.

Adhesion of bloodplatelets: Following incubation with platelet rich plasma, the unmodified and modified surfaces were subjected to scanning electron microscopy (SEM) to study the morphology of adhered platelets. The platelets attached to the polyurethane surfaces were fixed with glutaraldehyde. The specimens were then dehydrated with ethanol, subjected to critical-point drying, and sputtered-coated with gold.

\subsection{Results and Discussion}

\subsubsection{Preparation of conjugate molecule 4}

The synthesis route to $\mathbf{4}$ is outlined in Scheme I. The preparation started out with triethylene glycol, which was converted into compound $\mathbf{2 1}$ in the presence of triphenylmethyl chloride. Compound $\mathbf{2 1}$ was then converted into compound 22 in the presence of bromine and triphenylphosphine. Tri-[tert.-butyl dimethylsilyl] dipyridamole (7) was prepared from dipyridamole as described earlier. ${ }^{14}$ Compound 7 was reacted with $\mathbf{2 2}$ in the presence of sodiumhydride. ${ }^{19}$ This reaction afforded compound $\mathbf{2 3}$, which was subsequently treated with zinc bromide in order to cleave the trityl group. ${ }^{20}$ The resulting alcohol, $\mathbf{2 4}$, was esterified through reaction with $p$-azidobenzoyl chloride. This reaction afforded the desired conjugate structure 4 , in $18 \%$ overall yield based on 7.Purity and identity of conjugate $\mathbf{4}$ and all synthetic intermediates were established unequivocally. The chemical synthesis of conjugate compound 4 proceeded smoothly. Figure 1 shows the $400 \mathrm{MHz}$ proton NMR spectrum of $\mathbf{4}$, dissolved in deuterated chloroform. The spectrum clearly reveals the identity and purity of the product. Fast atom bombardment mass spectrometry provided further evidence for the identity of $\mathbf{4}$ (vide supra). 


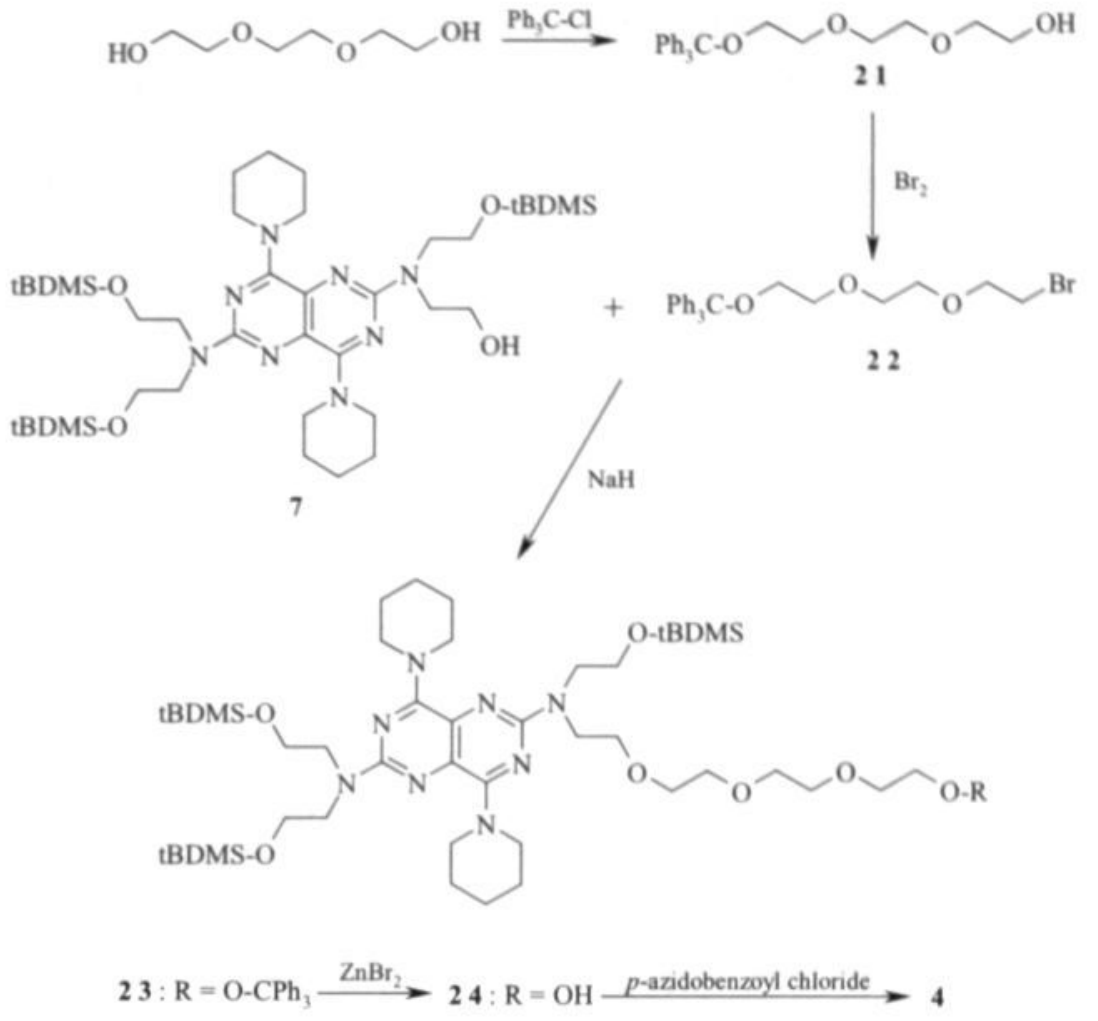

Scheme I. Preparation of compound 4.

\subsubsection{Physico-chemical characterisation}

$U V$-extinction experiments: Measurements of the surface-density of immobilised dipyridamole were performed through UV spectrophotometry. The modified surfaces (dimensions approximately $50 \times 50 \mathrm{~mm}$ ) showed uniform density of immobilised dipyridamole. This was concluded after comparison of different pieces (dimensions $10 \times 15 \mathrm{~mm}$ ), cut out of the foil. All physicochemical and biochemical experiments reported here correspond with a surface density of $13 \pm 1 \mathrm{nmol} / \mathrm{cm}^{2}$ of immobilised dipyridamole. 


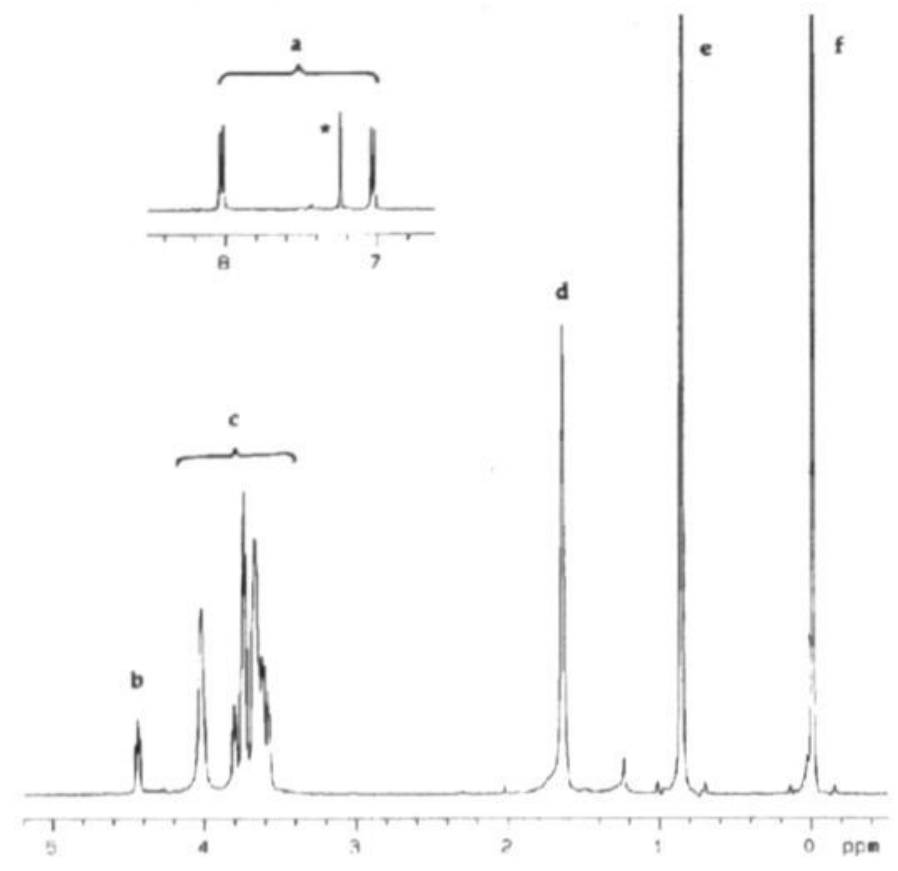

Figure 1. $400 \mathrm{MHz}{ }^{1} \mathrm{H}$ NMR spectrum of 4, dissolved in $\mathrm{CDCl}_{3}$. Spectral parameters: Spectral width: $6000 \mathrm{~Hz}$; number of transients: 8 ; time domain: $32 \mathrm{k}$; size: 64k; Fourier transformation without application of a spectral window. Assignments: a: aromatic protons from the azidobenzoyl group; b: $\mathrm{CH}_{2} \mathrm{C}(\mathrm{O})$; $\mathbf{c}$ : $\mathrm{CH}_{2}-\mathrm{N}$ and $\mathrm{CH}_{2}-\mathrm{O}$; d: $\mathrm{CH}_{2}$ of piperidine rings; e: tert.-butyl; $\mathbf{f}: \mathrm{CH}_{3}-\mathrm{Si}$; ${ }^{*}$ solvent signal $\left(\mathrm{CHCl}_{3}\right)$.

Contact angle experiments: Table 1 compiles the results of the water contact angle measurements on both the unmodified and modified surfaces. The contact angles were measured with the captive-bubble method. Under each surface, five air bubbles $(\sim 0.1 \mathrm{~mL})$ were placed, and height $(\mathbf{h})$ and diameter (d) of the bubbles were measured. The contact angle $\varphi$ was then calculated from the formula: $:^{23}$

$$
\boldsymbol{\varphi}=\cos -1[-1+2 \mathbf{h} / \mathbf{d}]
$$

The data in Table 1 clearly show that the modified surface is more hydrophilic than the unmodified surface. 
ESCA experiments: Furthermore, both surfaces were studied with ESCA. As expected, oxygen, nitrogen and carbon were detected. No contaminations were found on either surfaces. The observed binding energies for the oxygen, nitrogen, and carbon species are in good agreement with those of Beamson and Briggs. $^{28}$

Table 1. Contact Angles Measured with the Captive Bubble Method for the Unmodified and Modified Surface.

\begin{tabular}{cc}
\hline Unmodified surface & Modified surface \\
\hline 49.5 & 19.1 \\
50.6 & 25.3 \\
47.3 & 20.8 \\
51.2 & 22.3 \\
49.8 & 21.5 \\
\hline
\end{tabular}

The spectra were analysed by applying curve deconvolution, using a Gaussian line shape. The $\mathrm{N}$ 1s narrow-scan subspectrum was used to get more detailed information on the nature of the surface. The increase of the $\mathrm{N}$ is signal was not significant, and this inspired us to measure the modified surface also under another take-off angle.

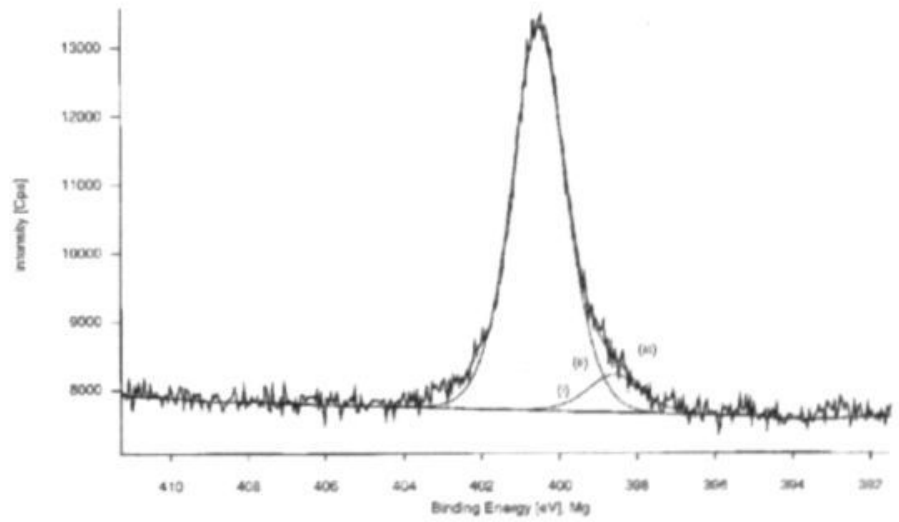

Figure 2. N 1s narrow-scan ESCA spectrum of the modified surface measured at a take-off angle of $90^{\circ}$. The experimental spectrum can be simulated by adding the simulated spectra (i) and (ii). Note that (iii), which equals (i) + (ii) fits the experimental spectrum; (i) corresponds with the aromatic $\mathrm{N}$ of the dipyridamole ring system, and (ii) corresponds with the $\mathrm{N}$ atoms of the polymer urethane groups, and the non-aromatic Ns of dipyridamole. 


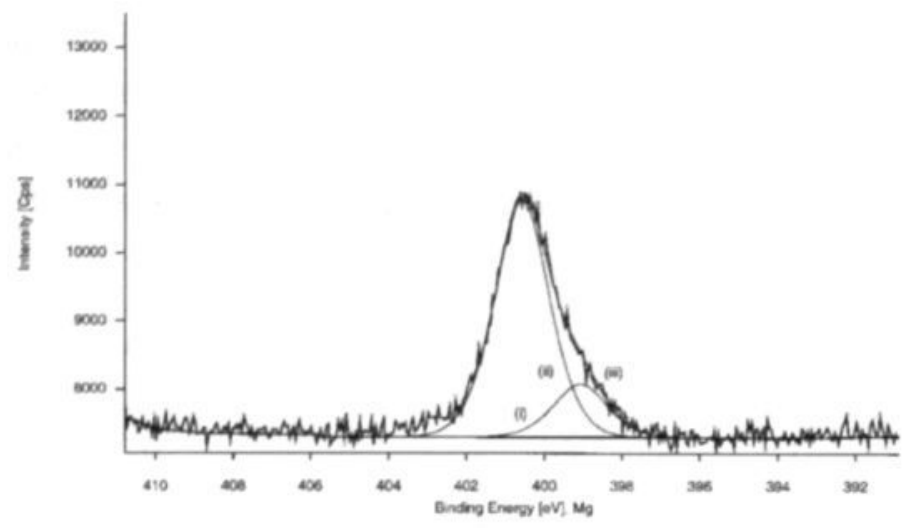

Figure 3. N 1s narrow-scan ESCA spectrum of the modified surface measured at a take-off angle of $\sim 6^{\circ}$. Spectral simulation was accomplished as described in the legend to Figure 2.

This enables one to look more at the outermost layer of the modified surface. The sample holder was rotated in such a way that a take-off angle of $\sim 6^{\circ}$ was obtained. This experiment clearly showed a change in surface chemistry, which could be derived from changes in the peak-shape of the narrow-scan spectra. Figure 2 shows the expansion of the $\mathrm{N} 1 \mathrm{~s}$ narrow-scan spectrum measured at a take-off angle of $90^{\circ}$. Figure 3 shows the expansion of the $\mathrm{N}$ 1s narrow-scan spectrum measured at a take-off angle of $\sim 6^{\circ}$. The $\mathrm{N} 1 \mathrm{~s}$ line is less intense, but broadened, consistent with the presence of another nitrogen functionality in the outermost surface layer (aromatic nitrogen from the dipyridamole). Table 2 gives the atomic $\% \mathrm{C}, \mathrm{N}$, and $\mathrm{O}$, and the elemental ratios $\mathrm{C} / \mathrm{O}$ and $\mathrm{C} / \mathrm{N}$ for the unmodified and the modified surface.

Table 2. Elemental Atomic Percentages and Elemental Ratios Measured by ESCA for the Unmodified and the Modified Surface.

\begin{tabular}{cccc}
\hline Atom & $\begin{array}{c}\text { Unmodified surface } \\
\text { take-off angle } 90^{\circ}\end{array}$ & \multicolumn{2}{c}{$\begin{array}{c}\text { Modified surface } \\
\text { take-off angle } ~\end{array} 6^{\circ}$} \\
\hline$\% \mathrm{C}$ & 80 & 79 & 82 \\
$\% \mathrm{~N}$ & 3.1 & 4.3 & 2.8 \\
$\% \mathrm{O}$ & 17 & 17 & 15 \\
$\mathrm{C} / \mathrm{O}$ & 4.7 & 4.6 & 5.5 \\
$\mathrm{C} / \mathrm{N}$ & 25.8 & 18.4 & 29.3 \\
\hline
\end{tabular}


Another important conclusion that can be drawn from the ESCA spectra of the modified surface is that the $\mathrm{Si}$ protective groups were completely removed in the deprotection/washing steps following the irradiation with ultraviolet light.

The ESCA spectra do not show the very characteristic Si-signals at approximately 102 (Si 2p) and 153 (Si 2s) eV. For this reason, we expected the presence of free hydroxyl groups (three $\mathrm{OH}$-groups for each immobilised dipyridamole) for the modified surface. This expectation could be verified by

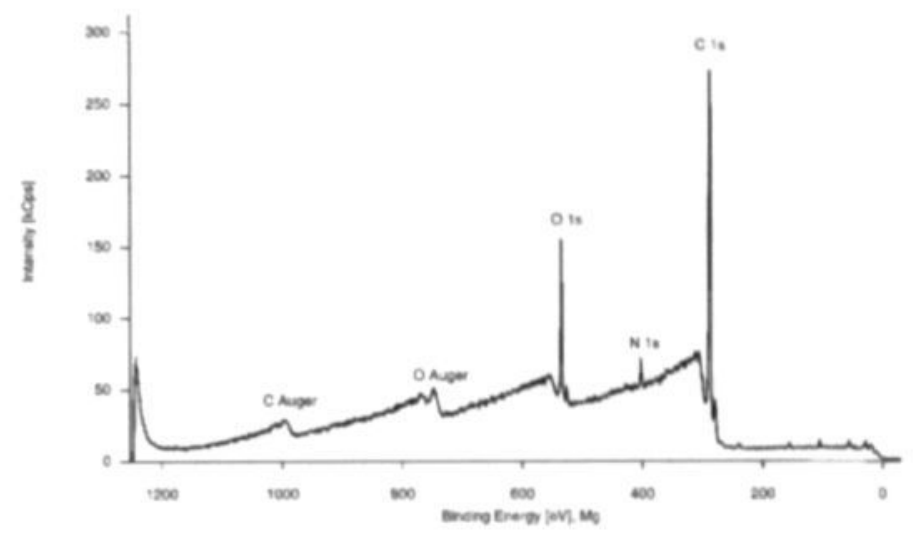

Figure 4. Overall ESCA spectrum of the modified surface measured at a take-off angle of $\sim 6^{\circ}$.

exposure of the modified surface to a vapour of tetrafluoroacetic anhydride in a sealed vessel. The anhydride then reacts with free hydroxyl groups to form the trifluoroacetic ester. This vapour-phase labelling of hydroxyl groups has shown to be very succesful. ${ }^{29}$ The $\mathrm{CF}_{3}$ tag is easily detected since two extra peaks appear in the ESCA spectrum: (i) the F 1s line at approximately $690 \mathrm{eV}$, and (ii) the $\mathrm{F}$ Auger line at approximately $600 \mathrm{eV}$ (Mg Ka radiation; see ref. $28 \mathrm{p}$ 236, and ref. 29). Figure 4 shows the overall ESCA scan of the modified surface (take-off angle of $\sim 6^{\circ}$ ). Figure 5 shows the ESCA scan of the modified surface after its exposure to tetrafluoroacetic anhydride vapour (take-off angle of $\sim 6^{\circ}$ ). This labelling clearly revealed the presence of free hydroxyl groups on the modified surface, which is consistent with the presence of immobilised and fully deprotected dipyridamole. 


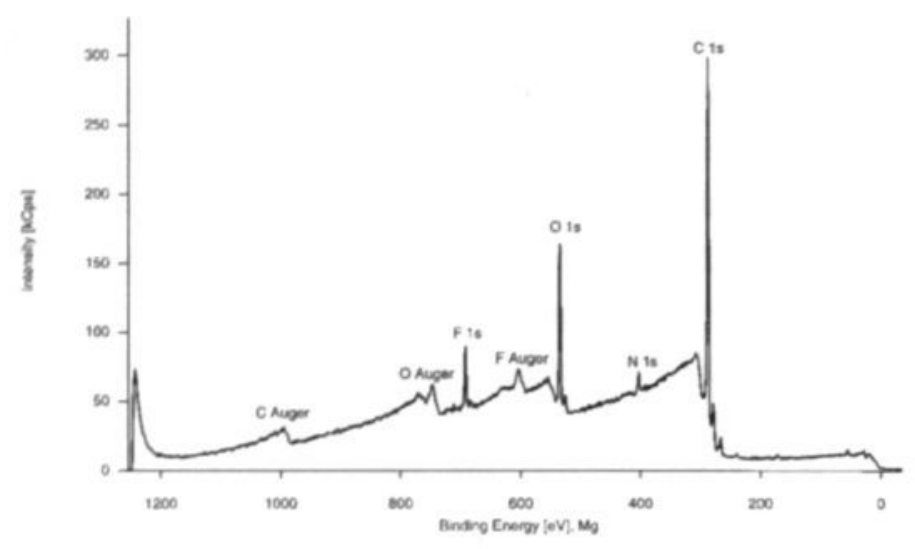

Figure 5. Overall ESCA spectrum of the modified surface exposed to triflouroacetic anhydride vapor measured at a take-off angle of $\sim 6^{\circ}$.

\subsubsection{Biochemical characterisation}

Thrombin generation experiments: The unmodified and modified surfaces were subjected to the in vitro thrombogenicity test developed by Lindhout et al. $^{30}$ Polyethylene (PE), a highly thrombogenic material, polyvinyl chloride (PVC), a relatively passive material, and unmodified polyurethane were used as reference materials. The assay produces a thrombin generation curve for each surface tested. The experiments on the modified surface were performed in duplo. Figure 6 shows the thrombin generation curves for both the unmodified and the modified surfaces, exposed to human platelet-rich blood plasma. Each thrombin generation curve yields two parameters, which are directly related to the thrombogenicity of the material. The first parameter is the lag time, i.e. the time elapsing between the moment of recalcification and the moment on which the free-thrombin concentration starts to increase. The second parameter is the maximal concentration of free-thrombin reached during the experiment. The results of these experiments with all surfaces are compiled in Table 3. It should be noted that the maximum thrombin concentrations were obtained after correction of the experimental thrombin generation curves for the residual amidolytic activity of the thrombin- $\boldsymbol{\alpha}_{2}$-macroglobulin complex according to the method of Hemker et al. ${ }^{32}$ The thrombogenicity of the different surfaces decreases in the following order: $\mathrm{PE}>$ polyurethane $>$ PVC $>$ modified $\mathrm{PU}$. 


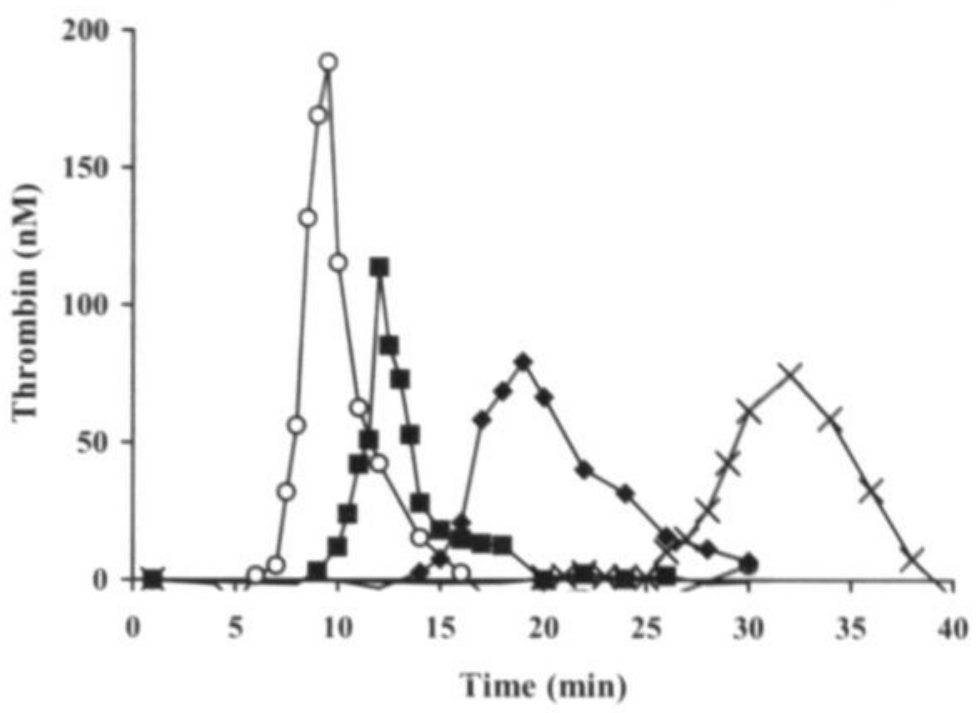

Figure 6. Thrombin generation curves measured for four different surfaces. The thrombin generation curves were corrected for the amidolytical activity of the $\alpha_{2}$ m-thrombin complex. ${ }^{32}$ Assignments: open circles: PE; open squares: Polyurethane; closed diamonds: PVC; cross: Modified polyurethane.

The surface immobilisation of compound 4 leads to a decrease of the thrombogenicity of the polyurethane; the lag time increases from 569 seconds for the unmodified polyurethane to 1267 and $1282 \mathrm{sec}$ (duplo) for the modified surface. The maximum free-thrombin concentration decreases from $85 \mathrm{nM}$ for the unmodified polyurethane to 68 and $75 \mathrm{nM}$ (duplo) for the modified surface.

Table 3. Results of the Thrombin Generation Test.

\begin{tabular}{lcc}
\hline Material & Lag time $(\mathrm{s})$ & [Thrombin $]_{\max }(\mathrm{nM})$ \\
\hline PE & 395 & 169 \\
PVC & 859 & 79 \\
Polyurethane & 569 & 85 \\
Modified polyurethane & $1267 ; 1282$ & $68 ; 75$ \\
\hline
\end{tabular}

Adhesion of bloodplatelets: The unmodified and modified surfaces were further studied with SEM to look at the adherence and activation of platelets on the surfaces. The unmodified surface was covered to a large extent by spreaded platelets, as is shown in Figure 7. From the scanning electron micrographs, a surface density of appr. $7 \times 10^{3}$ platelets per $\mathrm{mm}^{2}$ could be estimated. The 
modified surface showed far less adhered platelets (Figure 8); the scanning electron micrograph indicated a surface density of appr. $6 \times 10^{2}$ platelets per $\mathrm{mm}^{2}$. This implies that the surface modification results in a decrease of platelet adhesion by, roughly, one order of magnitude. This finding is in good agreement with our previous work. ${ }^{3,5}$ It should be noted, however, that spreaded platelets could also be found on the modified surface.

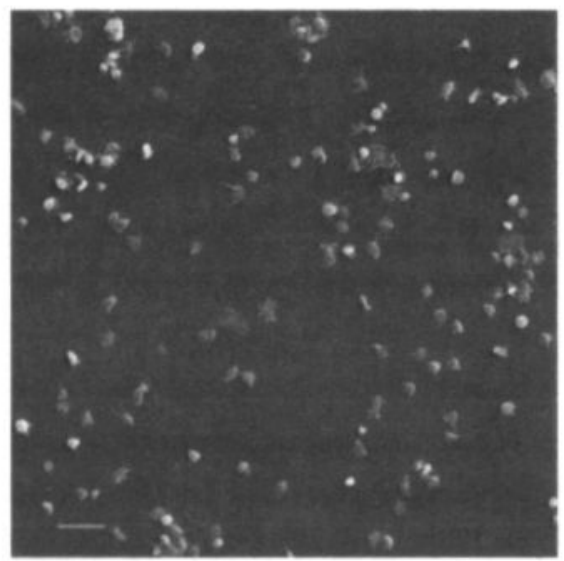

Figure 7. Overview scanning electron micrograph of the unmodified surface after incubation with platelet rich plasma. Length of bar $=10 \mu \mathrm{m}$.

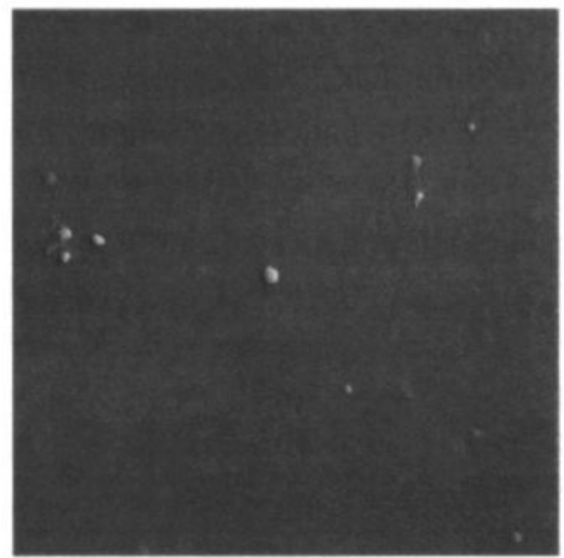

Figure 8. Overview scanning electron micrograph of the modified surface after incubation with platelet rich plasma. Length of $\mathrm{bar}=10 \mu \mathrm{m}$. 


\subsection{Concluding Remarks}

The present results clearly demonstrate that dipyridamole can be immobilised onto polyurethane surfaces through use of conjugate 4. A combination of different physical analytical techniques reveals the presence of fully deprotected dipyridamole in the outermost layer of the modified surface. Furthermore, the modified surface features a markedly increased hydrophilicity, as compared to the control (i.e. unmodified polyurethane). This can be attributed to the short polyethylene glycol spacer chain, which bridges dipyridamole to the polymer surface.

To the best of our knowledge, the present results show for the first time that it is possible to couple a pharmacologically active drug to a polymer surface via a chain of covalent bonds, and to simultaneously achieve a substantial increase of the surface hydrophilicity. This combination of effects holds promise with respect to passivation of artificial surfaces. From the classic work of Vroman and others (vide supra), it is known that contact between blood and an artificial surface first leads to adsorption of plasma proteins, and then to activation of platelets or leukocytes, which recognize one or more specific structural patterns of the proteinaceous adsorbates. A modified surface as studied in our present work interferes with this mechanism at two different stages: $(i)$, the hydrophilic nature of the surface leads to substantial hydration and hence to a diminished affinity for proteins; (ii), the exposure of a platelet inhibitory agent (dipyridamole in our case) suppresses activation of contacting blood platelets.

A quantitative comparison of the modified surfaces based on $\mathbf{4}$, and those to which dipyridamole was coupled either directly or via a short hydrophobic spacer chain was not performed. Nevertheless, the thrombin generation assay suggests that photo-immobilisation of $\mathbf{4}$ leads to the best results. ${ }^{15}$ This idea is reinforced by a comparison of the scanning electron micrographs. Figure 8 (this work) shows that the modified polyurethane surface, prepared with conjugate $\mathbf{4}$, adsorbs far less platelets after exposure to human platelet rich plasma (appr. $6 \mathrm{x}$ $10^{2}$ per $\mathrm{mm}^{2}$ ) as compared to the control (appr. $7 \times 10^{3}$ per $\mathrm{mm}^{2}$ ). Upon use of a short hydrophobic spacer chain (- $\mathrm{C}(\mathrm{O})-\mathrm{CH}_{2}-\mathrm{CH}_{2}-\mathrm{CH}_{2}-\mathrm{O}-$ ), we previously found that platelet adhesion was also markedly suppressed (in comparison with the control). ${ }^{3}$ However, the platelets present on the latter surface showed substantial spreading and formation of pseudopodia. 


\subsection{References}

1. J.A. Oates, A.J.J. Wood, and G.A. Fitzgerald, "Medical intelligence drug therapy dipyridamole," N. Engl. J. Med., 316, 1247-1257 (1987).

2. J.P. Singh, K.J. Rothfuss, T.R. Wiernicki, W.B. Lacefield, W.L. Kurtz, R.F. Brown, K.A. Brune, D. Bailey, and G.P. Dubé, "Dipyridamole directly inhibits vascular smooth muscle cell proliferation in vitro and in vivo: implications in the treatment of restenosis after angioplasty," J. Am Coll. Cardiol., 23, 665-671 (1994).

3. Y.B.J. Aldenhoff and L.H. Koole, "Studies on a new strategy for surface modification of polymeric biomaterials," J. Biomed. Mater. Res., 29, 917-928 (1995).

4. J.M.H. Kuijpens, G.A. Kardaun, R. Blezer, A.P. Pijpers, and L.H. Koole, "Immobilization of theophylline on medical-grade polyurethane inhibits surfaceinduced activation of bloodplatelets," J. Am. Chem. Soc., 117, 8691-8697 (1995).

5. Y.B.J. Aldenhoff, R. Blezer, T. Lindhout, and L.H. Koole, "Photoimmobilization of dipyridamole (Persantin ${ }^{8}$ ) at the surface of polyurethane biomaterials: reduction of in vitro thrombogenicity," Biomaterials, 18, 167-172 (1997).

6. M.A.B. Kruft, A. Benzina, R. Blezer, and L.H. Koole, "Studies on radio-opaque polymeric biomaterials with potential applications to endovascular prostheses," Biomaterials, 17, 1803-1812 (1996).

7. M.A.B. Kruft, A. Benzina, F. Bär, F.H. van der Veen, C.W.M. Bastiaansen, R. Blezer, T. Lindhout, and L.H. Koole, "Studies on two new radiopaque polymeric biomaterials," J. Biomed. Mater. Res., 28, 1259-1266 (1994).

8. L. Vroman and A.L. Adams, "Findings with the recording ellipsometer suggesting rapid exchange of specific plasma proteins at liquid-solid interfaces," Surface Sci., 16, 438-446 (1969).

9. J.L. Brash, "The fate of fibrinogen following adsorption at the blood-biomaterial interface," Ann. New York Acad. Sci., 516, 206-222 (1987).

10. L. Vroman, "The life of an artificial device in contact with blood: Initial events and their effect on its final state," Bull. New York Acad. Med., 64, 352-357 (1988).

11. F. Grinell, "Fibronectin adsorption on material surfaces," Ann. New York Acad. Sci., 516, 280-290 (1987).

12. C.H. Bamford and K.G. Al-Lamee, "Chemical methods for improving haemocompatibility of synthetic polymers," Clin. Mater., 10, 243-250 (1992).

13. C.H. Bamford, K.G. Al-Lamee, I. Middleton, and R.Can, "Chemical modification of polymers to increase blood compatibility," Bull. Soc. Chim. Belg., 99, 919-925 (1990).

14. A.P. van der Heiden and L.H. Koole, "Photochemical coupling of aryl azides to poly(etherurethane) surfaces: Studies with a fluorescent model compound," Macromolecules, 29, 7012-7015 (1996).

15. S. Witkowski, R. Koteswar, H.P. Ramiya, P.V. Haluska, and J. Fried, "Total synthesis of (+)-10, 10-difluorothromboxane A2 and its 9, 11 and 15 stereoisomers," J. Amer. Chem. Soc., 114, 8464-8472 (1992). 
16. E.L. Leyva, M.S. Platz, G. Persy, and J.J. Wirtz, "Photochemistry of phenyl azide: The role of singlet and triplet phenylnitrene as transient intermediates," Am. Chem. Soc., 108, 3783-3790 (1986).

17. Y-Z Li, J.P. Kirby, M.W. George, M. Poliakoff, and G.B. Schuster, "1,2Didehydro azepines from the photolysis of substituted aryl azides: Analysis of their chemical and physical properties by time-resolved spectroscopic methods," J. Am. Chem. Soc., 110, 8092-8098 (1988).

18. P.A.S. Smith, In "Azides and nitrenes; Reactivity and utility," Academic Press, Orlando, $\mathrm{Fl}$ (1984).

19. J.C. Wu, Z. Xi, C. Gioeli, and J. Chattopadhyaya, "Intramolecular cyclizationtrapping of carbon radicals by olefins as means to functionalize 2'- and 3'-carbons in $\beta$-D-nucleosides," Tetrahedron, 47, 2237-2254 (1991).

20. V. Kohli, H. Blöcker, and H. Köster, "The triphenylmethyl (trityl) group and its use in nucleotide chemistry," Tetrahedron Lett., 21, 2683-2686 (1980).

21. H. Bretschneider and H. Rager, "Darstellung aromatischer azido verbindungen nach der Dutt-Wormallschen reaktion," Monatsh. für Chemie, 81, 970-980 (1950).

22. E.J. Corey and A. Venkateswarly, "Protection of hydroxyl groups as tertbutyldimethylsilyl derivatives," J. Amer. Chem. Soc., 94, 6190-6191 (1972).

23. R.N. King, J.D. Andrade, S.M. Ma, D.E. Gregonis, and L.R. Brostrom, "Interfacial tensions at acrylic hydrogel-water interfaces," J. Coll. and Interface Sci., 103, 62-75 (1995).

24. M.P. Seah, "Post-1989 calibration energies for X-ray photoelectron spectrometers and the 1990 Josephson constant," Surf. Interface Anal., 14, 488 (1989).

25. K. Berresheim, M. Mattern-Klosson, and M. Wilmers, "A standard form spectra for quantitative ESCA-analysis,” Fresenius J. Anal. Chem., 341, 121-124 (1991).

26. H.G. Nöller, H.D. Polaschegg, and H. Schillalies, "A step towards quantitative electron spectroscopy measurements by improved electron optics," J. Electron Spectrosc. Relat. Phenom., 5, 705-723 (1974).

27. J.H. Scofield, "Hartree-slater subshell photoionization cross-sections at 1254 and 1487 eV," J. Electron. Spectrosc. Relat. Phenom., 8, 129-137 (1976).

28. G. Beamson and D. Briggs, In: "High resolution XPS of organic polymers," John Wiley \& Sons, Chichester (1992).

29. A.P. Ameen, R.J. Ward, R.D. Short, G. Beamson, and D. Briggs, "A highresolution X-ray photoelectron spectroscopy study of trifluoroacetic anhydride labelling of hydroxyl groups: demonstration of the $\beta$ shift due to - $\mathrm{OC}(\mathrm{O}) \mathrm{CF}_{3}$," Polymer Papers, 34, 1795-1799 (1993).

30. T. Lindhout, D. Baruch, P. Schoen, J. Franssen, and H.C. Hemker, "Thrombin generation and inactivation in the presence of antithrombin III and heparin," Biochemistry, 25, 5962-5970 (1986).

31. T. Lindhout, R. Blezer, C. Maassen, V. Heijnen, and C.P.M. Reutelingsperger, "Platelet procoagulant surface as an essential parameter for the in vitro evaluation of the blood compatibility of polymers," J. Mater. Sci.: Mater. Med, 6, 367-372 (1995).

32. H.C. Hemker, G. Willems, and S. Béguin, "A computer assisted method to obtain the prothrombin activation velocity in whole plasma independent of thrombin decay processes," Thromb. Haemost., 56, 9-17 (1986) 



\section{CHAPTER 5}

\section{Platelet Adhesion Studies on Dipyridamole Coated Polyurethane Surfaces*}

* This chapter is based on: Y.B.J. Aldenhoff, and L.H. Koole, Biomaterials, submitted 


\subsection{Abstract}

Surface modification of polyurethanes (PUs) by covalent attachment of dipyridamole (Persantin ${ }^{8}$ ) is known to reduce adherence of blood platelets upon exposure to human platelet rich plasma (PRP). This effect was investigated in further detail. First platelet adhesion under static conditions was studied with four different biomaterial surfaces: untreated PU, PU immobilised with conjugate molecule 2, PU immobilised with conjugate molecule $\mathbf{4}$, and PU immobilised with conjugate molecule 26. In PU immobilised with $\mathbf{2}$ dipyridamole is directly linked to the surface, in PU immobilised with $\mathbf{4}$ there is a short hydrophilic spacer chain in between the surface and the dipyridamole, while conjugate molecule $\mathbf{2 6}$ is merely the spacer chain. Scanning electron microscopy (SEM) was used to characterise platelet adhesion from human PRP under static conditions, and fluorescence imaging microscopy was used to study platelet adhesion from whole blood under flow. SEM experiments encompassed both density measurements and analysis of the morphology of adherent platelets. In the static experiments the surface immobilised with 4 showed the lowest platelet adherence. No difference between the three modified surfaces emerged from the flow experiments. The surfaces were also incubated with washed blood platelets and labeled with Oregon-Green Annexin V. No capture of Oregon-Green Annexin V was seen, implying that the adhered platelets did not expose any phosphatidyl serine at their exteriour surface.

\subsection{Introduction}

Polyurethanes find widespread use as construction biomaterials for catheters, blood pumps, ' and other medical devices, which are temporarily in contact with the circulation. The physical/mechanical properties of polyurethanes, including their high flexural strength and excellent resistance to flex fatigue, are particularly suitable for these applications. ${ }^{2,5}$ Polyurethanes have, however, one major drawback: they have only moderate bloodcompatibility. Surface-induced thrombus formation poses a significant problem in the development of improved cardiovascular devices, which are based on polyurethanes. 
Previously, it was shown that the drug dipyridamole can be immobilised onto polyurethane surfaces, via a photochemical procedure. ${ }^{6-8}$ Dipyridamole is a well-known non-toxic vasodilator and a powerful inhibitor of platelet activation/ aggregation; its generic name is Persantin ${ }^{* 9,10}$ Two conclusions emerged from the previous work: (i), surface-bound dipyridamole renders the surface significantly less thrombogenic, and (ii), adherence of bloodplatelets is markedly reduced through this surface modification.

This chapter describes the results of an extended study on dipyridamolemodified polyurethane medical grade foils. Three sets of these foils were treated with either, 2, 4,or 26; a fourth set was used as untreated controls. Note that compounds 2, $\mathbf{4}$, and $\mathbf{2 6}$ are conjugate molecules. Molecules $\mathbf{2}$ and $\mathbf{4}$ consist of a protected dipyridamole unit, which is linked to a photoreactive $p$-azidobenzoyl ester $^{11-13}$, either directly, 2, or via a short hydrophilic spacer chain, 4. Compound $\mathbf{2 6}$ served to study the effect of the hydrophilic spacer chain per se.

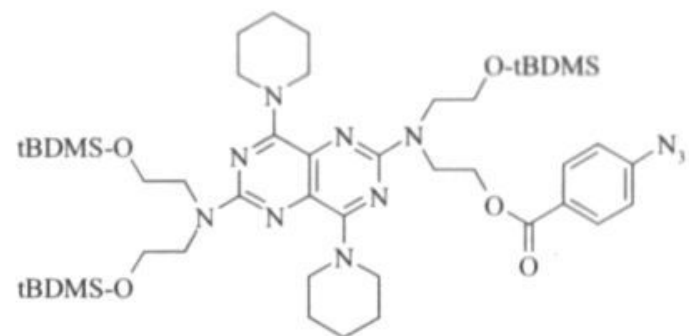

2

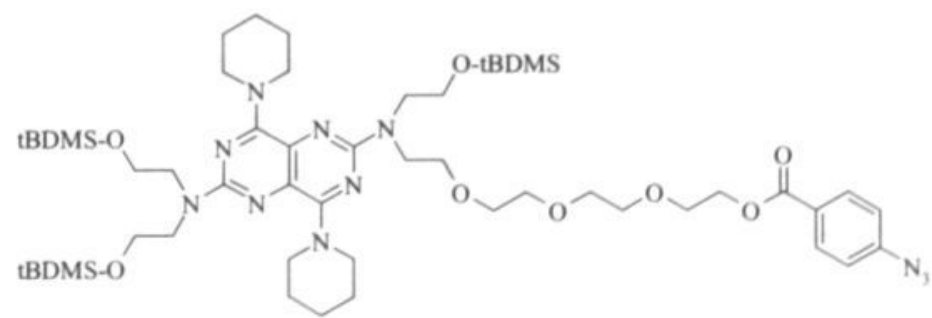

4

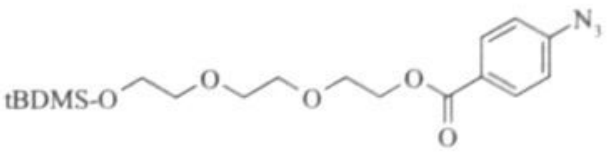


Preparation and physical properties of $\mathbf{2}$ and $\mathbf{4}$ were described previously. The preparation of compound $\mathbf{2 6}$, and the immobilisation of the conjugate molecules onto the polyurethane surfaces are described in this chapter. Each of the four surfaces was incubated with platelet-rich human blood plasma (PRP), for 15,30 or 60 minutes. The density of the adhered bloodplatelets was studied as a function of time. The morphological changes of the adhered bloodplatelets were studied in the static model using PRP. Using whole blood, platelet adhesion was also studied with fluorescent microscopic techniques. ${ }^{14,15}$ In addition, the surfaces were incubated with washed platelets, labeled with Oregon-Green Annexin V, in an attempt to answer the question whether or not the adhered platelets expose phosphatidyl serine at the exteriour plasma membrane. ${ }^{14-17}$

\subsection{Materials and Methods}

\subsubsection{General section}

All solvents and starting materials were of the highest available purity or were purified as specified. $N, N$-dimethylformamide, pyridine and tetrahydrofuran were distilled from calcium hydride and stored over Linde $3 \AA$ molecular sieves. Triethylamine was distilled from calcium hydride and stored over potassium hydroxide pellets. Thin layer chromatography was performed on glass plates $(3 \times 10 \mathrm{~cm})$ with a fluorescent indicator. Silica gel 60 (particle size 0.063-0.200 mm) was used for column chromatography. ${ }^{1} \mathrm{H}$ NMR and ${ }^{13} \mathrm{C}$ NMR were recorded at 399.9 and $100.6 \mathrm{MHz}$, respectively, on a Varian Unity-Plus spectrometer, using deuterated chloroform or deuterated methyl sulfoxide as the solvent. Tetramethylsilane was used at the internal reference $(\delta=0.00 \mathrm{ppm})$. Conjugates $\mathbf{2}$ and $\mathbf{4}$ were prepared as described previously. ${ }^{6,7}$

\subsubsection{Synthesis}

p-Azidobenzoyl chloride: A solution of p-azidobenzoic acid (7.50 g, 45.98 $\mathrm{mmol})^{18}$ and thionyl chloride $(16.29 \mathrm{~g}, 138.04 \mathrm{mmol})$ in $250 \mathrm{~mL}$ of anhydrous tetrahydrofuran was refluxed for $30 \mathrm{~min}$. All volatiles were removed under reduced pressure (in the hood, stench). The solid residue was recrystallized from hexane to give pure $p$-azidobenzoyl chloride as a yellowish solid. Yield: $6.67 \mathrm{~g}(81 \%)$. ' $\mathrm{H}$ NMR $\left(\mathrm{CDCl}_{3}\right), \delta: 8.05(2 \mathrm{H}, \mathrm{d}$, aromatic $\mathrm{H}), 7.05(2 \mathrm{H}, \mathrm{d}$, 
aromatic $\mathrm{H}$ ); ${ }^{13} \mathrm{C}$ NMR (DMSO-d 6 ), $\delta: 166.39,143.87,131.15,127.20,119.34$, 119.05 .

Compound 25: To a magnetically stirred solution of triethylene glycol (33.08 $\mathrm{g}, 220.28 \mathrm{mmol})$ and dimethylamino pyridine $(0.17 \mathrm{~g}, 1.38 \mathrm{mmol})$ in $100 \mathrm{~mL}$ of anhydrous pyridine was added $p$-azidobenzoyl chloride in 10 portions during a time period of 3 hours. The solution was stirred overnight under exclusion of moisture. Then, all volatiles were removed under reduced pressure (last traces of pyridine were coevaporated with toluene). The residue was taken up in dichloromethane and washed with saturated aqueous sodium bicarbonate (three times) and water (three times). The organic layer was dried on magnesium sulfate, filtered, and concentrated to dryness under reduced pressure. The crude product was purified by column chromatography eluting with ethyl acetate to give compound 25 as a viscous oil. Yield: $4.22 \mathrm{~g}(52 \%) ; \mathrm{R}_{\mathrm{f}}$ (ethyl acetate): 0.34 ; ${ }^{1} \mathrm{H}$ NMR $\left(\mathrm{CDCl}_{3}\right), \delta: 8.05(2 \mathrm{H}, \mathrm{d}$, aromatic $\mathrm{H}), 7.05(2 \mathrm{H}$, d, aromatic $\mathrm{H}), 4.42$ $\left(2 \mathrm{H}, \mathrm{t}, \mathrm{CH}_{2}-\mathrm{O}(\mathrm{CO})\right), 3.79\left(2 \mathrm{H}, \mathrm{t}, \mathrm{CH}_{2}-\mathrm{CH}_{2}-\mathrm{O}(\mathrm{CO})\right), 3.64\left(6 \mathrm{H}, \mathrm{m}, \mathrm{CH}_{2}-\mathrm{O}\right), 3.56$ $\left(2 \mathrm{H}, \mathrm{t}, \mathrm{CH}_{2}-\mathrm{O}\right), 2.78(1 \mathrm{H}, \mathrm{t}, \mathrm{OH}) ;{ }^{13} \mathrm{C} \mathrm{NMR}\left(\mathrm{CDCl}_{3}\right), \delta ; 165.21,144.32,131.01$, $126.05,118.31,72.06,70.17,69.85,68.69,63.53,61.20$.

Compound 26: To a solution of compound $25(3.74 \mathrm{~g}, 12.67 \mathrm{mmol})$ in 75 $\mathrm{mL}$ anhydrous dimethyl formamide was added dimethylamino pyridine $(3.09 \mathrm{~g}$, $25.33 \mathrm{mmol})$, anhydrous triethyl amine $(2.56 \mathrm{~g}, 25.33 \mathrm{mmol})$ and tertbutyldimethylsilyl chloride $(3.82 \mathrm{~g}, 25.33 \mathrm{mmol})$. The reaction mixture was magnetically stirred for 1 hour under exclusion of moisture. Then, brine was added and the mixture was extracted with diethyl ether (three times). The diethyl ether layer was washed with saturated aqueous ammonium chloride (three times). The organic layer was dried on magnesium sulfate, filtered and concentrated to dryness under reduced pressure. The crude product was purified by column chromatography eluting with ethyl acetate to give $\mathbf{2 6}$ as a viscous oil. Yield: $5.12 \mathrm{~g}(99 \%) ; \mathrm{R}_{\mathrm{f}}$ (ethyl acetate): $0.69 ;{ }^{1} \mathrm{H} \mathrm{NMR}\left(\mathrm{CDCl}_{3}\right), \delta: 7.98(2 \mathrm{H}, \mathrm{d}$, aromatic $\mathrm{H}), 6.98(2 \mathrm{H}, \mathrm{d}$, aromatic $\mathrm{H}), 4.40\left(2 \mathrm{H}, \mathrm{t}, \mathrm{CH}_{2}-\mathrm{O}(\mathrm{CO})\right), 3.77(2 \mathrm{H}, \mathrm{t}$, $\left.\mathrm{CH}_{2}-\mathrm{CH}_{2}-\mathrm{O}(\mathrm{CO})\right), 3.69$ (2H, t, $\left.\mathrm{CH}_{2}-\mathrm{OtBDMS}\right), 3.62\left(4 \mathrm{H}, \mathrm{m}, \mathrm{CH}_{2}-\mathrm{O}\right), 3.49(2 \mathrm{H}$, t, $\left.\mathrm{CH}_{2}-\mathrm{O}\right), 0.84\left(9 \mathrm{H}, \mathrm{d}, t\right.$-Bu-Si), $0.00(6 \mathrm{H}, \mathrm{d}, \mathrm{Me}-\mathrm{Si}) ;{ }^{13} \mathrm{C} \mathrm{NMR}\left(\mathrm{CDCl}_{3}\right)$, $\delta: 165.41,144.52,131.29,126.43,118.53,72.49,70.54,70.50,68.97,63.99$, $62.51,25.69,25.48,-3.76,-5.50$. 


\subsubsection{Preparation of modified polyurethane surfaces}

Throughout the experiments a medical grade polyurethane foil (Pellethane D-55) was used. The foil is transparent and has a smooth surface, the thickness of the foils is $0.4 \mathrm{~mm}$. Pieces of $5 \times 5 \mathrm{~cm}$ were used. Stock solutions of the conjugate molecules were prepared in isopropanol (concentration $1 \mathrm{mM}$ ). The solution was sprayed (a compressed-air sprayer was used) onto the polyurethane foils 20 times. After each spray the surfaces were dried with a hot-air föhn (to evaporate the isopropanol). Then, the surfaces were irradiated for $15 \mathrm{~min}$, at a distance of $30 \mathrm{~cm}$, with a medium metal halide lamp (Philips HPA 1000 highpower UV lamp), emitting radiation mainly between 300 and $400 \mathrm{~nm}$ (radiation output measured at $1.00 \mathrm{~m}$ distance in $\mu \mathrm{W} / \mathrm{cm}^{2}$ : UV-A: 1000; UV-B: 320 ; UVC: 50$).{ }^{19}$ After irradiation the foils were thoroughly washed with isopropanol (3 x 15 min, ultrasonic) to remove all the unreacted compounds, and immersed into a solution of tetrabutylammonium fluoride $(8.0 \mathrm{~g})$ in nitromethane $(400$ $\mathrm{mL}$ ) to remove the tert-butyldimethylsilyl protecting groups. The surfaces were then washed extensively with isopropanol ( $2 \times 30 \mathrm{~min})$ and water $(2 \times 30 \mathrm{~min})$, dried, and stored in dry form before use.

\subsubsection{Biochemical characterisation}

Adhesion of bloodplatelets in a static model: Fresh blood was taken from a healthy donor who has not been taken aspirin or any other anticoagulant one week prior to blood donation. The whole blood was anticoagulated with citrate $(0.13 \mathrm{mM})$ prior to the experiments. The blood was centrifuged at $250 \mathrm{~g}$ for 15 min at room temperature, and the PRP was decanted. The surfaces were incubated with $0.5 \mathrm{~mL}$ PRP at $37^{\circ} \mathrm{C}$ for 15,30 and 60 minutes. Then, the PRP was removed and the surfaces were washed with PBS-buffer (three times) to remove the non-adhered blood platelets. The adhered blood platelets were fixed with glutaraldehyde. The surfaces were dehydrated with ethanol series, dried on air, and sputter-coated with gold. The surfaces were subjected to scanning electron microscopy (SEM) to study the morphology of the adhered platelets.

Platelet count: For each surface, five rectangular spots were chosen randomly; the dimensions of the spots were $116 \times 91 \mu \mathrm{m}$. Adhered platelets were counted, and the average densities of the adhered platelets per square $\mathrm{mm}$ were calculated from these data. 
Platelet morphology: The adhered platelets on each of the rectangular spots, described above, were examined and classified according to the scheme of Ko et al. ${ }^{20}$

Platelet adhesion under flow: Fresh blood from a healthy donor was used, the blood was heparinized $(5 \mathrm{U} / \mathrm{mL})$, calcein $(2.5 \mu \mathrm{M})$ was added during $45 \mathrm{~min}$. at $37^{\circ} \mathrm{C}$. The surfaces were immersed in HEPES buffer for $30 \mathrm{~min}$. The (whole) blood was run over the surfaces at a shear rate of $100 \mathrm{l} / \mathrm{s}$ (flowrate $200 \mu \mathrm{L} / \mathrm{min}$ ) for $10 \mathrm{~min}$. The experiment was followed by a video system and at several time intervals video-images were stored.

Platelet activation: A suspension of washed platelets was prepared as described previously. ${ }^{15}$ The four different surfaces were incubated with a suspension of $5 \times 10^{7}$ platelets $/ \mathrm{mL}$. Oregon-Green Annexin V was used to detect possible exposure of phosphatidyl serine on the outer surface of activated platelets, according to Briedé et al. ${ }^{15}$

Fluorescence Imaging Microscopic System: A parallel-plate chamber as described by Sakariassen et al was used as the perfusion chamber throughout these experiments. ${ }^{21}$ Positive phase-contrast transmission images were obtained with an inverted microscope using a $100 \mathrm{X}$ quartz oil-immersion objective containing a phase plate. The phase-contrast transmission images were recorded with an infrared camera. For fluorescence imaging, light from a xenon lamp passed a computer controlled excitation and neutral density wheel, and reached the objective of the inverted microscope through an UV-transparent liquid light guide and a dichroic long-pass filter. The emission light passed a computercontrolled emission wheel, and finally reached a low-light level intensified, charge-coupled device camera working at standard video rate. The fluorescence images were digitized and averaged; background images were substracted and stored. 


\subsection{Results and Discussion}

\subsubsection{Preparation of conjugate molecule 26}

The chemical synthesis of conjugate molecule $\mathbf{2 6}$ proceeded smoothly. The synthesis route is outlined in scheme 1. First $p$-azidobenzoic acid was converted

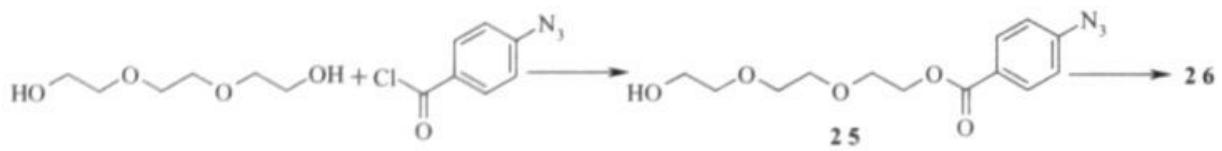

Scheme I. Preparation of compound 26.

in $p$-azidobenzoyl chloride with thionyl chloride. Then, triethylene glycol was reacted with $p$-azidobenzoyl chloride in pyridine. Pure compound 25 was obtained after routine column chromatography on silica gel. In the last step $\mathbf{2 5}$ was reacted with tBDMS-Cl. The target compound $\mathbf{2 6}$ was obtained in pure form after column chromatography. The identity and purity of this compound, a colorless viscous oil, was established by ${ }^{1} \mathrm{H}$ NMR and ${ }^{13} \mathrm{C}$ NMR.

\subsubsection{Preparation of modified polyurethane surfaces}

The photo-immobilisation of all three of the conjugate molecules was succesfull. For the surfaces immobilised with $\mathbf{2}$ and $\mathbf{4}$, the surface density was measured using UV-extinction, as described previously. ${ }^{6.7}$ Surface densities of approximately $20 \mathrm{nmol} / \mathrm{cm}^{2}$ were found for both surfaces. For the surface immobilised with $\mathbf{2 6}$, it was found that the water contact angle decreased as a result of the surface modification. This implies that the surface immobilisation also proceeded with conjugate molecule $\mathbf{2 6}$.

\subsubsection{Biochemical characterisation}

Table 1 compiles the average densities of adhered platelets as a function of time. Figure 1 shows a graphical representation of these data. Figure 2 shows typical scanning electron micrographs of the four different surfaces at 30 minutes incubation. For the polyurethane and the surface immobilised with $\mathbf{2}$ it is clear that the longer the incubation time the more platelets adhere. For conjugate molecule $\mathbf{4}$ and $\mathbf{2 6}$, however, the density of adhered platelets seems to decrease after an incubation time of $30 \mathrm{~min}$. The amount of adhered blood 
Table 1. Amount of bloodplatelets per square $\mathrm{mm}$ and average shape distribution on each of the four different surfaces at different Spread Fully

\begin{tabular}{|c|c|c|c|c|c|c|}
\hline Surface & $\begin{array}{l}\text { Total of } \\
\text { adhered } \\
\text { platelets }\end{array}$ & $\begin{array}{l}\text { Round } \\
\text { (R) }\end{array}$ & $\begin{array}{l}\text { Dendritic } \\
\text { (D) }\end{array}$ & $\begin{array}{l}\text { Spread } \\
\text { Dendritic } \\
\text { (SD) }\end{array}$ & (S) & $\begin{array}{c}\text { Spread } \\
\text { (FS) }\end{array}$ \\
\hline & $\mathrm{mm}^{2}$ & $\%$ & $\%$ & $\%$ & $\%$ & $\%$ \\
\hline PU-15, & $1640 \pm 378$ & 6 & 32 & 22 & 21 & 19 \\
\hline PU-30' & $5420 \pm 1279$ & 8 & 26 & 29 & 24 & 13 \\
\hline PU-60' & $7640 \pm 2912$ & 2 & 20 & 27 & 36 & 15 \\
\hline $2-15^{\prime}$ & $1180 \pm 277$ & 8 & 12 & 9 & 6 & $\begin{array}{l}65 \\
35\end{array}$ \\
\hline $2-30^{\prime}$ & $1920 \pm 753$ & 7 & 29 & 14 & 15 & 35 \\
\hline $2-60$ & $3980 \pm 1482$ & 4 & 25 & 15 & 20 & 36 \\
\hline $4-15^{\prime}$ & $1040 \pm 477$ & 25 & 14 & 1 & 20 & $\begin{array}{l}40 \\
28\end{array}$ \\
\hline $4-30^{\prime}$ & $1540 \pm 483$ & 14 & 21 & 11 & $\begin{array}{l}26 \\
30\end{array}$ & $\begin{array}{l}28 \\
27\end{array}$ \\
\hline $4-60^{\prime}$ & $1340 \pm 607$ & 9 & 28 & 6 & 30 & 27 \\
\hline 26-15 & $2140 \pm 1064$ & 23 & 27 & 12 & $\begin{array}{l}12 \\
22\end{array}$ & $\begin{array}{l}26 \\
22\end{array}$ \\
\hline 26-30' & $2900 \pm 886$ & 6 & 27 & 23 & $\begin{array}{l}22 \\
38\end{array}$ & $\begin{array}{l}22 \\
10\end{array}$ \\
\hline 26- $60^{\prime}$ & $2080 \pm 1291$ & 3 & 17 & 32 & & 10 \\
\hline
\end{tabular}

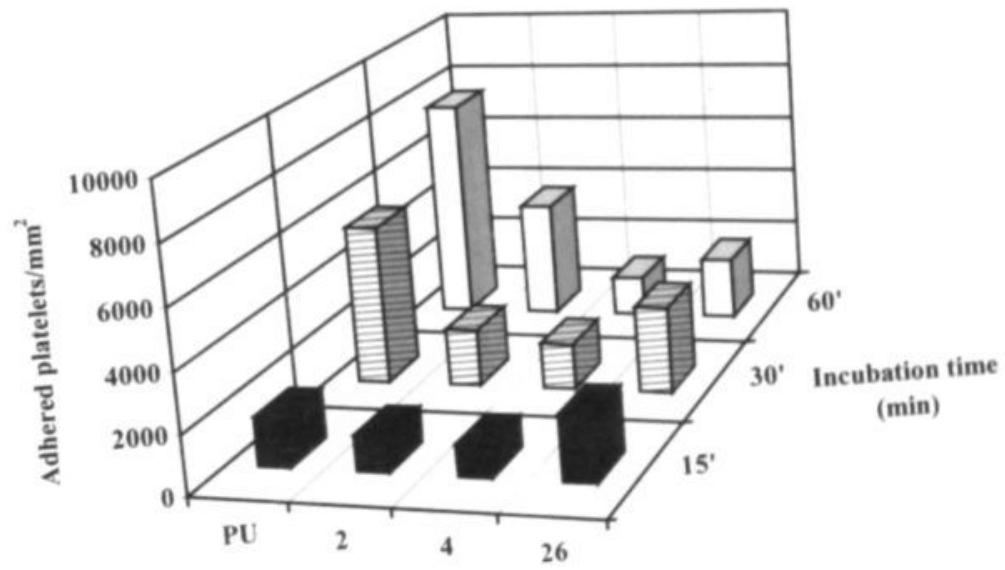

Figure 1. The density of adhered bloodplatelets on each of the four surfaces at different incubation times. 
platelets after 15 minutes increase in the following order: conjugate $\mathbf{4}<$ conjugate $\mathbf{2}<$ unmodified PU < conjugate 26. After 30 minutes the amount of adhered blood platelets increases as follows: conjugate $\mathbf{4}<$ conjugate $\mathbf{2}<$ conjugate $\mathbf{2 6}<$ unmodified PU, and after 60 minutes: conjugate $\mathbf{4}<$ conjugate $\mathbf{2 6}<$ conjugate $\mathbf{2}<$ unmodified PU. These data reveal that unmodified PU attracts most platelets. The surface immobilised with $\mathbf{4}$ shows lowest platelet adhesion, which is in agreement with previous data. ${ }^{8}$ Moreover it is seen that the platelet density for PU modified with $\mathbf{4}$ does not increase with time.

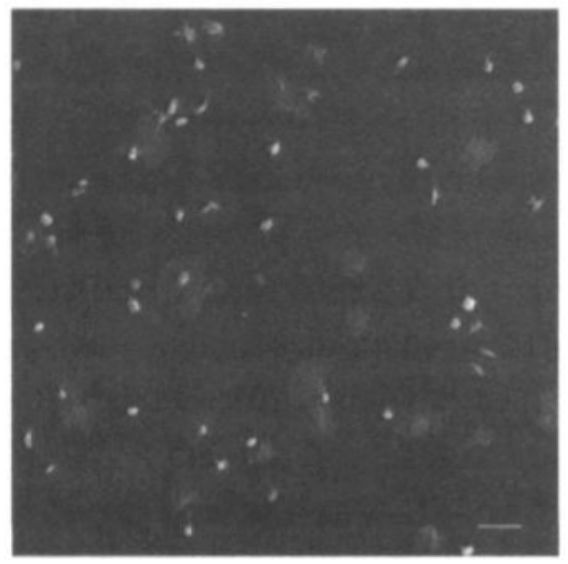

$\mathbf{A}$

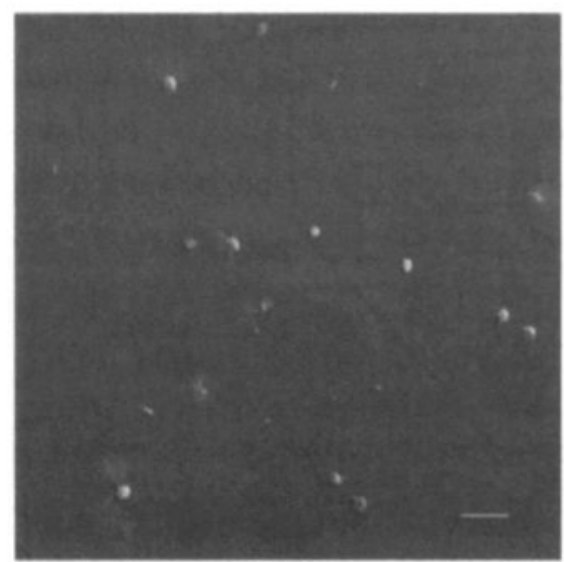

C

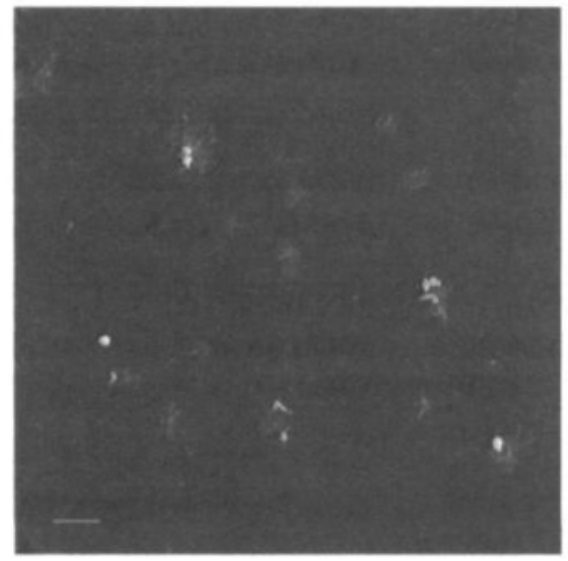

B

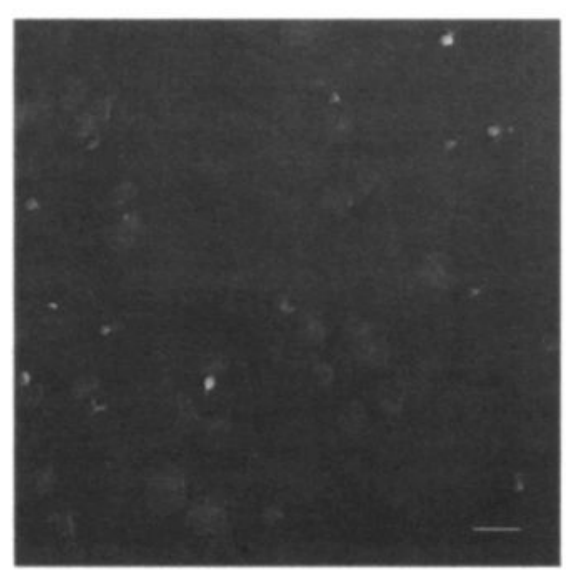

D

Figure 2. Typical scanning electron micrographs of A: unmodified PU; $\mathbf{B}:$ PU modified with 2; C: PU modified with 4; D: PU modified with 26, after an incubation time of 30 minutes. Length of bar $=10 \mu \mathrm{m}$. 
The studies on platelet adhesion from heparinized full blood, under flow, revealed essentially the same trends. Because the platelets are labelled with the fluorescence dye calcein fluoresceine adherence of platelets onto the biomaterial leads to immobilised flourescent acitvity. It is possible to monitor the fluorescent area in the field of view as a function of time. After 10 minutes, the fluorescent area on the untreated PU was $35 \pm 10 \%$. Figure 3 shows the fluorescence image of the unmodified PU. For the three other surfaces, hardly any platelet adhesion was found after 10 minutes. This means that all the three surfaces modifications performed equally well in this test. Overall, the data from the fluorescence experiments under flow, are in line with the results from the SEM experiments.

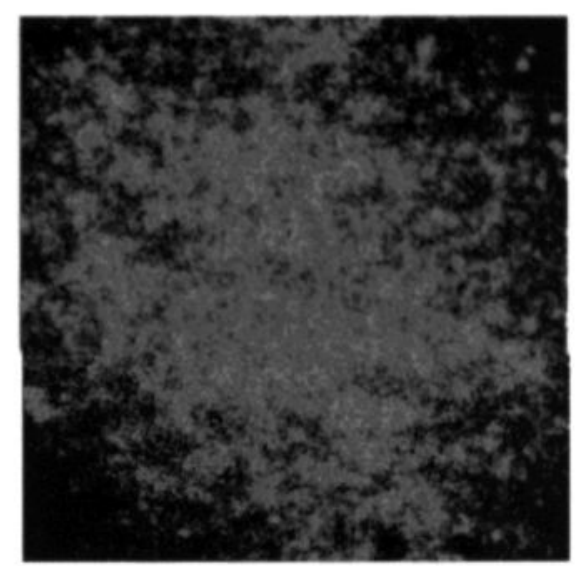

Figure 3. Fluorescence images after a flow time of 10 minutes of unmodified PU.

The SEM micrographs could also be used to study the morphology of the adhered platelets, and also the changes in morphology as a function of incubation time. In order to characterise the morphology of the adhered platelets, we used the same classification in platelet shape as described by Ko et. al. ${ }^{20}$ Five stages of shape changes were distinguished: (1) round or discoid (R), no pseudopodia present, (2) dendritic (D), early pseudopodial, no flattening (3) spread dendritic (SD), one or more pseudopodia flattenend, no hyaloplasm between pseudopodia; (4) spread (S), late pseudopodial, hyaloplasm spreading; and (5) fully spread (FS), hyaloplasm fully spread, no distinct pseudopodia. The 

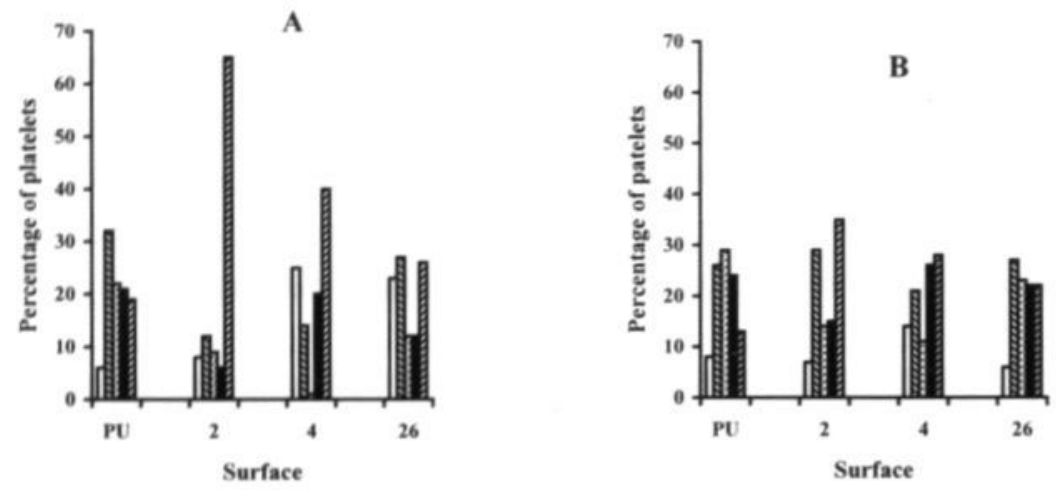

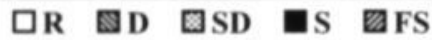

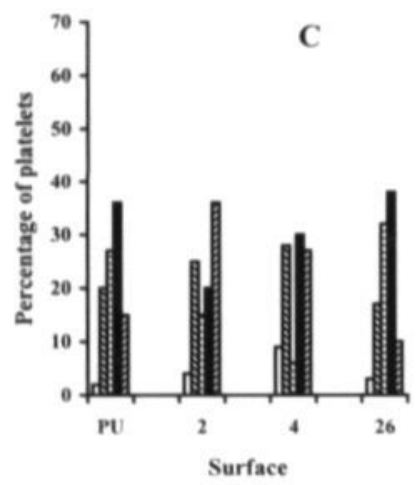

Figure 4. Distribution of the different stadia of the adhered bloodplatelets at an incubation time of A: 15 minutes; B: 30 minutes; C: 60 minutes. Platelet shapes: $\mathbf{R}=$ round $\mathbf{D}=$ dendritic $\mathbf{S D}=$ spread dendritic $\mathbf{S}=$ spread $\mathbf{F S}=$ fully spread.

results of this analysis are compiled in Table 1 and represented graphically in Figures 4A-C. The data show that platelets in the "round" state are most abundant after 15 minutes incubation: their relative contribution decreases gradually with time. Furthermore, it appears that the surfaces that expose dipyridamole at their surface have relatively high numbers of spread and fully spread platelets, already after 15 minutes incubation $(65 \%$ for immobilized $\mathbf{2}$, 
and $40 \%$ for immobilised 4). The latter conclusion made us wonder what was actually happening: ( $i$ ) do the platelets spread because they are activated by the dipyridamole surface, or (ii) do the platelets spread because of a favourable interaction with the surface? In an attempt to discriminate between these two alternatives, a suspension of washed human platelets was mixed with OregonGreen Annexin V. This mixture was used in a FIMS experiment as described above, using the surfaces that were treated with conjugate molecules $\mathbf{2}$ or $\mathbf{4}$. Annexin $\mathrm{V}$ is known to form a complex with phosphatidyl serine, which is exposed on the exteriour plasma membrane of activated platelets. So if the adhered platelets retain the Oregon-Green Annexin V, this implies that the platelets expose phosphatidylserine. After 10 minutes, hardly any Oregon Green label could be detected on both surfaces, which implies that the adherent platelets do not expose phosphatidylserine. ${ }^{16,17}$

\subsection{Concluding Remarks}

The static model, using human PRP, clearly showed that PU immobilised with conjugate molecule $\mathbf{4}$ (dipyridamole immobilised via a short hydrophilic spacer chain) was optimal with respect to suppression of platelet adhesion at all three data points. Platelet adhesion increased with time for PU and PU modified with $\mathbf{2}$ while this was not seen for PU modified with $\mathbf{4}$ and PU modified with 26. The flow experiments, using heparinized full blood, revealed essentially the same trend. After 10 minutes, the fluorescent area on the untreated PU was $35 \pm$ $10 \%$, while there was hardly any fluorescence seen on the three modified surfaces meaning all three surfaces performed equally well in this test.

The morphological changes of the adhered bloodplatelets (using the static model, human PRP) showed no clear trends. Surprisingly, the PU modified with 2 and 4 showed a high numbers of spread and fully spread platelets. This observation leaded to an additional experiment where the surfaces were incubated with a suspension of human washed platelets mixed with OregonGreen Annexin V. Annexin V is known to form a complex with phosphatidyl serine, which will be exposed at the exteriour plasma membrane of an activated blood platelet. After 10 minutes incubation hardly any Oregon Green label could be detected on the dipyridamole coated surfaces, implying that the 
adhered platelets do not expose phosphatidyl serine. We assume, therefore, that the adherent platelets are not activated. We envisage two possible explanations for this phenomenon: $(i)$ either the immobilised dipyridamole molecules are recognized by anchoring molecules on the platelet's surface, (ii) or the immobilised dipyridamole molecules change the physical surface properties of the surface (e.g., wettability, zeta potential, etc.) in such a way that the surface readily accomodates platelets without activating them.

\subsection{References}

1. Coumbe and T.R. Graham, In: "The Pathology of Devices," Springer Verlag, Berlin-Heidelberg (1994).

2. M.D. Lelah and S.L. Cooper, In: "Polyurethanes in medicine," CRC Press, Boca Raton (1986).

3. J.W. Boretos, In: "Biocompatibility of Clinical Implant Materials," CRC Press, Boca Raton (1981).

4. M. Herring, J. Smith, M. Dalsing, J. Glover, R. Compton, K. Etchberger, and T. Zollinger, "Endothelial cell seeding of polytetrafluoroethylene femoral popliteal bypasses: The failure of low-density seeding to improve patency." J. Vasc. Surg., 20, 650-655 (1994).

5. K.M. Müller and G. Dasbach, In: "The Pathology of Devices," Springer Verlag, Berlin-Heidelberg (1994).

6. Y.B.J. Aldenhoff and L.H. Koole, "Studies on a new strategy for surface modification of polymeric biomaterials," J. Biomed. Mater. Res., 28, 917-928 (1995).

7. Y.B.J. Aldenhoff, R. Blezer, T. Lindhout, and L.H. Koole, "Photoimmobilization of dipyridamole (Persantin $^{\circ}$ ) at the surface of polyurethane biomaterials: reduction of in vitro thrombogenicity," Biomaterials, 18, 167-172 (1997).

8. Y.B.J. Aldenhoff, A.P. Pijpers, and L.H. Koole, "Synthesis of a new photoreactive derivative of dipyridamole and its use in the manufacture of artificial surfaces with low thrombogenicity," Bioconjugate Chem., 8, 296-303 (1997).

9. J.A. Oates, A.J.J. Wood, and G.A. Fitzgerald, "Medical intelligence drug therapy dipyridamole," N. Engl. J. Med., 316, 1247-1257 (1987).

10. J.P. Singh, K.J. Rothfuss, T.R. Wiernicki, W.B. Lacefield, W.L. Kurtz, R.F. Brown, K.A. Brune, D. Bailey, and G.P. Dubé, "Dipyridamole directly inhibits vascular smooth muscle cell proliferation in vitro and in vivo: implications in the treatment of restenosis after angioplasty," J. Am. Coll. Cardiol., 23, 665-671 (1994).

11. E.L. Leyva, M.S. Platz, G. Persy, and J.J. Wirtz, "Photochemistry of phenyl azide: the role of singlet and triplet phenylnitrene as transient intermediates," $J$. Am. Chem. Soc., 108, 3783-3790 (1986). 
12. Y-Z. Li, J.P. Kirby, M.W. George, M. Poliakoff, and G.B. Schuster, "1,2didehydroazepines from the photolysis of substituted aryl azides: analysis of their chemical and physical properties by time-resolved spectroscopic methods, " J. Am. Chem. Soc., 110, 8092-8098 (1988).

13. P.A.S. Smith, In: "Azides and nitrenes; reactivity and utility," Academic Press, Orlando (1984).

14. D. Billy, J. Briedé, J.W.M. Heemskerk, H.C. Hemker, and T. Lindhout, "Prothrombin conversion under flow conditions by prothrombinase assembled on adherent platelets," Blood Coagul. and Fibrinolysis., 8, 167-174 (1997).

15. J. Briedé, J.W.M. Heemskerk, H.C. Hemker, and T. Lindhout, "Heterogeneity in microparticle formation and exposure of anionic phospholipids at the plasma membrane of single adherent platelets," Biochim. Biophys. Acta., 1451, 163-172 (1999).

16. M.C. Stuart, E.M. Bevers, P. Comforius, R.F. Zwaal, C.P. Reutelingsperger, and P.M. Frederick, "Ultrastructural detection of surface-exposed phosphatidylserine on activated platelets," Thromb. Hemost., 74, 1145-1151 (1995).

17. M. van Engeland, L.J. Nieland, F.C. Ramaekers, B. Schutte, and C.P. Reutelingsperger, "Annexin V-affinity assay: a review on an apoptosis detection system based on phosphatidylserine experiments," Cytometry, 31, 1-9 (1998).

18. H. Bretschneider, and H. Rager, "Darstellung aromatischer azidoverbindungen nach der Dutt-Wormallschen reaktion," Monatsh. Chem., 8, 970-980 (1950).

19. A.P. van der Heiden, G.M. Willems, T. Lindhout, A.P. Pijpers, and L.H. Koole, "Adsorption of proteins onto poly(ether urethane) with a phosphorylcholine moiety and influence of pre-adsorbed phospholipid," J. Biomed. Mater. Res., 40, 195-203 (1998).

20. T-M. Ko, J-L Lin, and S.L. Cooper, "Surface characterization and platelet adhesion studies of plasma-sulphonated polyethylene," Biomaterials, 14, 657 664 (1993).

21. K.S. Sakariassen, P.A.M.M. Aarts, P.G. de Groot, W.P.M. Houdijk, and J.J. Sixma, "A perfusion chamber developed to investigate platelet interaction in flowing blood with human vessel wall cells, their exttracellular matrix and purified components," J. Lab. Clin. Med., 102, 522-535 (1983). 



\section{CHAPTER 6}

Performance of a polyurethane vascular prosthesis carrying a dipyridamole (Persantin $^{\circledR}$ ) coating on its lumenal surface ${ }^{*}$ and Leo H. Koole, Biomaterials, 18, 167-172 (1997). 


\subsection{Abstract}

A porous polyurethane vascular prosthesis with an internal diameter of $5 \mathrm{~mm}$ was studied. The graft carries a coating of immobilised dipyridamole (Persantin $\left.{ }^{8}\right)$ on the surface of its lumen. Dipyridamole is a potent non-toxic inhibitor of platelet activation/ aggregation, and also a strong inhibitor of vascular smooth muscle cell proliferation. The polyurethane material is also known as Chronoflex ${ }^{\otimes}$, and already finds use as a vascular access graft. The coated vascular graft was studied in vitro (hemocompatibility, interaction with blood platelets and cultured endothelial cells), as well as in two established in vivo models. In the first in vivo study, coated grafts were implanted in goats, as a bypass of the carotid artery (four animals, eight grafts, length of the graft is approximately $12 \mathrm{~cm}$ ). Four uncoated grafts were used as controls in otherwise identical experiments. In the second in vivo experiment, eight sheep were used. Each animal received one coated and one uncoated prosthesis as an interposition graft in the carotid artery (length of the graft is $4 \mathrm{~cm}$ ). The in vitro experiments revealed that the dipyridamole coating has three beneficial effects: (i) reduced thrombogenicity, (ii) reduced adherence of blood platelets, and (iii) accommodation of a confluent monolayer of endothelial cells. The goat experiments showed patency of the coated grafts in three out of the eight cases. The sheep experiments were not useful for the evaluation of the dipyridamole coating, since deterioration of the polyurethane material was observed. The in vivo results indicate that the dipyridamole coating may positively influence the patency rate, probably because the coating promotes the growth of an endothelial cell lining. The sheep data show, however, that the limited stability of the Chronoflex ${ }^{*}$ material precludes its issue for the construction of permanent small-bore vascular grafts.

\subsection{Introduction}

Clinical application of synthetic small-bore arterial prostheses (internal diameter (i.d.) $<6 \mathrm{~mm}$ ) continues to meet with substantial difficulties. ${ }^{1}$ The primary failure modes are thrombus formation in the short term, and intimal hyperplasia (particularly at the anastomoses) in the longer term. Synthetic vascular prostheses are used primarily to substitute rather large peripheral blood 
vessels. In more critical situations, such as in aortocoronary bypass surgery, autologous grafts (particularly the internal mammary artery and the saphenous vein) are clearly superior to their synthetic counterparts.

We are, however, faced with a growing number of patients who lack satisfactory autologous conduit, because of prior removal, disease, or inadequate size. It is for this reason that the search for a truly functional smallbore vascular prosthesis is an active area of research and development. This has led to several interesting approaches: $(i)$, seeding of the lumen of an elastic and compliant polymeric tube with autologous endothelial cells ${ }^{2.3} ;($ ii), application of a haemocompatible coating on the lumen, e.g. through immobilisation of heparin ${ }^{4}$; (iii) coating of the lumen with a biocompatible and biodegradable substance, such as collagen, ${ }^{5}$ albumin, ${ }^{6}$ or poly(ethyleneglycol)/poly(lactic acid) block copolymer (PELA). ${ }^{7.8}$ Such a coating provides a haemocompatible surface directly after the implantation. Ideally, the coating degrades gradually, to be replaced with a lining of endothelial cells; (iv), utilization of novel tissue engineering techniques, in which cells are inoculated onto synthetic biodegradable polymers and cultured in vitro for a period of time. ${ }^{9}$ The cells excrete extracellular matrix proteins which form a three-dimensional structure. The polymer then acts as a scaffold.

Clinically, expanded poly(tetrafluoro ethylene) (ePTFE) is still the most common construction material for small-bore vascular grafts. The material is stable, non-adherent, and chemically inert. For instance, the well-known Permaflow ${ }^{*}$ vascular graft, manufactured by Possis (Minneapolis, MN, USA) is made out of ePTFE. ${ }^{10}$ Perhaps the most important disadvantage of ePTFE is it chemical inertness, which makes surface modification (aiming at improving the biocompatibility) very difficult. It is for this reason that we decided to test a polyurethane vascular graft, which was constructed from the "biodurable" poly(carbonate) polyurethane Chronoflex ${ }^{*}$. The Chronoflex ${ }^{*}$ vascular graft is an elastic, microporous tube with self-healing properties. "Its intended use is for vascular access, for peripheral vascular bypass, and potentially also for aortocoronary bypass surgery.

It has been shown previously, that the drug dipyridamole can be coupled covalently to Pellethane D-55 polyurethane surfaces. The surface modification was found to lead to lower thrombogenicity and less adherence of blood platelets, in vitro..$^{12-14}$ Here, similar results for the immobilisation of dipyridamole to Chronoflex ${ }^{*}$ are described; the surface treatment on the 
lumenal side of the 5-mm internal diameter vascular graft was successful. The dipyridamole treated graft, as well as the untreated controls were tested in vivo, using two different experimental animal models: $(i)$ in goats (six animals): grafts were implanted ( 8 coated and 4 uncoated controls) via two end-to-side anastomoses in the arteria carotis (left and right), length of grafts $12 \mathrm{~cm}$; (ii) in sheep ( 8 animals): grafts were implanted ( 8 coated and 8 uncoated controls) as interposition grafts in the arteria carotis (left and right), length of grafts $4 \mathrm{~cm}$. The goat study was based on previous studies from Maastricht University, in which the carotid artery bypass was used for the study of vascular grafts. ${ }^{15}$ The sheep study was performed in analogy with previous work from the University of New South Wales, Sydney. ${ }^{3}$

Investigating the general utility of the dipyridamole coating procedure was the goal; for this reason two different animal models and two different anastomosis techniques were included in this study.

\subsection{Materials and Methods}

\subsubsection{Immobilisation of dipyridamole onto the lumen of the Chronoflex vascular prosthesis}

This study was conducted with $12 \mathrm{~cm}$ long sections of the Chronoflex ${ }^{8}$ vascular prosthesis (i.d. $5.0 \mathrm{~mm}$, wall thickness $1.0 \mathrm{~mm}$ ). First, each prosthesis was inverted (turned inside-out). Then, a $1 \mathrm{mM}$ solution of conjugate molecule $4^{14}$ in pure isopropanol was sprayed uniformly on the surface. Evaporation of the solvent was accelerated by the use of a hot-air föhn. The prosthesis was then dried in vacuum, and subjected to irradiation ( $30 \mathrm{~min}$, at a distance of $15 \mathrm{~cm}$ ) with ultraviolet light (Philips HPA 1000 high-power UV lamp). The resulting photochemical reaction leads to covalent coupling of the dipyridamole molecules to the polyurethane surface. ${ }^{16}$ The prosthesis was treated with hydrogen chloride ( $1 \%$ solution in ethanol-96, $24 \mathrm{~h}$ ), and washed consecutively with isopropanol and water, followed by re-inversion, repeated washing with isopropanol and water, and drying in vacuo. Subsequently, each prosthesis was packaged, sterilized by ethylene oxide gas, and allowed to degas for at least 7 days prior to use. The presence of dipyridamole on the lumenal surface was obvious from the intense green/blue fluorescence at the prosthesis surface. Dissolution of a $1-\mathrm{cm}$ long piece of the prosthesis in N,N-dimethylformamide, 


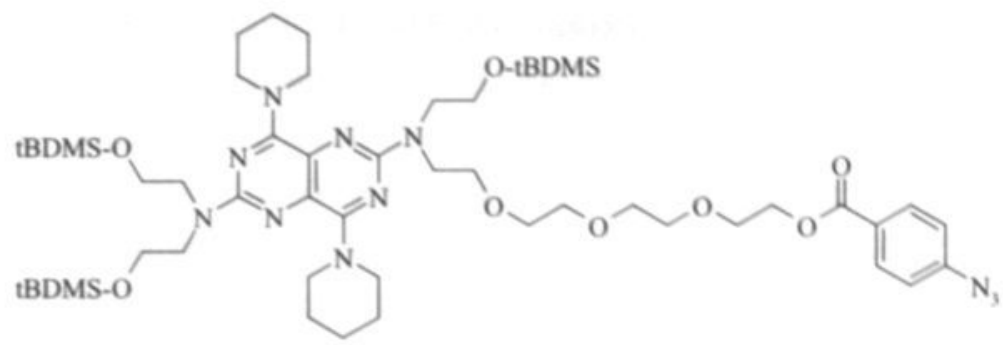

4

and subsequent determination of the UV extinction of the resulting solution (at $408 \mathrm{~nm}$ ), revealed that the density of immobilised dipyridamole was approximately $20 \mathrm{nmol} / \mathrm{cm}^{2}$. Scanning Electron Microscopy (SEM) demonstrated that the surface modification procedure did not affect the morphology (porosity) of the lumen.

\subsubsection{In vitro tests}

Adhesion of bloodplatelets: The adhesion of human blood platelets to the lumen of the vascular prostheses was investigated, using SEM. Prior to the SEM measurements, the surfaces were incubated with human PRP for $30 \mathrm{~min}$ at 37 ${ }^{\circ} \mathrm{C}$, washed, treated with glutaraldehyde (fixation), dehydrated in ethanol series, air-dried, and sputter coated with gold.

Thrombin generation experiments: The grafts were subjected to the in vitro surface-thrombogenicity assay as developed by Hemker et al ${ }^{17}$ and Lindhout et al. ${ }^{18}$ The assay produces a thrombin generation curve for each surface tested. Each thrombin generation curve yields two parameters, which are related to the thrombogenicity of the material. The test was run with both human and goat platelet rich plasma (PRP). This assay is essentially based on the chromogenic substrate H-D-Phenylalanyl-L-pipecolyl-L-arginine-p-nitroanilide dihydro chloride (S-2238, Chromogenix, Sweden), which is cleaved, exclusively by thrombin, in the constituent tripeptide, and p-nitroanilide, which can be monitored spectrophotometrically. ${ }^{19}$ For human blood plasma, the rate of formation of p-nitroanilide can be correlated with the concentration of free thrombin. 
Endothelial Cell Seeding: Ovine endothelial cells (ECs) were harvested and identified according to the procedure described by Poole-Warren et al. ${ }^{3}$ The grafts were cut in such a way that they fitted in a 96 well tissue culture plate. The media used throughout the experiment was McCoy's 5A (M5A; 20\% Fetal Bovine Serum). The samples were incubated with $100 \mathrm{~mL}$ ovine fibronectin (40 $\mathrm{mg} / \mathrm{mL}$ ) at $37^{\circ} \mathrm{C}$ for 1 hour. Following removal of the fibronectin the samples were washed with Dulbecco's phosphate-buffered saline (DPBS). A cell inoculum of $3.3 \times 10^{5}$ cells $/ \mathrm{mL}$ was applied and the microplates were incubated for 1,3 , and 6 days at $37{ }^{\circ} \mathrm{C}$. After the incubation time the medium was discarded and $100 \mathrm{~mL}$ of a XTT labeling (tetrazolium salt (sodium3'-[-1(phenyl-amino-carbonyl)-3,4-tetrazolium]-bis (4-methoxy-6-nitro) benzene sulfonic acid hydrate)) mixture was added to the samples. The microplates were incubated for 2 hours. UV absorbance was measured using a microtiter plate reader (ELISA; absorbance wavelength is $490 \mathrm{~nm}$, reference wavelength is 690 $\mathrm{nm})$.

Furthermore, approximately $4 \mathrm{~cm}$ lengths of the modified and untreated grafts were seeded with ovine ECs. The grafts were coated with $30-40 \mathrm{mg} / \mathrm{mL}$ ovine fibronectin in DPBS for 1 hour at $37^{\circ} \mathrm{C}$. Following removal of the fibronectin solution, grafts were prepared for seeding by insertion of modified injection ports at each end. A cell inoculum of approximately $1.8 \times 10^{6}$ cells $/ \mathrm{mL}$ was applied to the lumen of prepared grafts. Following inoculation tubes were rotated for 1 hour at $15 \mathrm{rph}$ at $37^{\circ} \mathrm{C}$. Non-adherent cells were removed by aspirating the medium and the seeded prostheses transferred to complete M5A media in a sterile $10 \mathrm{~mL}$ polypropylene tube. The grafts were incubated for 5 to 6 days and afterwards prepared for SEM experiments.

\subsubsection{In vivo tests}

Goat studies: Six female goats (mean weight $72 \mathrm{~kg}$ ) were used exclusively for these experiments, according to the protocols approved by the "Experimental Animal Committee of the University of Maastricht". The animals were cared for according to the "Guide for the Care and Use of Laboratory Animals", as published by the National Institutes of Health (NIH publication no. 85-23, revised 1985). The six animals were divided in two groups. Four animals (\# 1 - 4) each received 2 coated prostheses. Sacrifice and harvesting of the vascular grafts was performed after 10 weeks. Two other goats (\# 5 and 6) each received 2 untreated prostheses; these animals were sacrificed after 5 
weeks. All the prostheses used in these experiment had a length of approximately $12 \mathrm{~cm}$, and an internal diameter of $5 \mathrm{~mm}$. The goats were premedicated with atropine $(0.05 \mathrm{mg} / \mathrm{kg}$ body weight), anaesthetized with thiopental sodium (15 mg/kg body weight), intubated and mechanically ventilated $\left(\mathrm{O}_{2}: \mathrm{N}_{2} \mathrm{O}=1: 2\right.$ and halothane $\left.1 \%\right)$. Ampicilline was given just before surgery (1 gram i.v.). A median ventral incision of the neck was made, and both carotids were prepared. After systemic heparinization ( $50 \mathrm{IU} / \mathrm{kg}$ body weight) a proximal end-to-side, prosthesis-to-carotid, anastomosis was performed, using 6-0 prolene. Flow through the carotid artery was blocked between the two anastomoses. The procedure was repeated on the other side. Radiopaque markers were left behind at the anastomoses, for identification of the prostheses during catheterization later on. In each case, the flowing blood pulses through the vascular graft could easily be detected, both visually and by palpation. Another bolus of heparin ( $50 \mathrm{IE} / \mathrm{kg}$ body weight), finadyne ( $1 \mathrm{mg} / \mathrm{kg}$ body weight, im) and ampicilline ( 1 gram i.v.) were given at the time of wound closure. Buprenorfine ( $0.3 \mathrm{mg}$ i.m.) was given postoperatively, to ease the pain. If necessary, this was repeated next day. Once every week, finadyne $(1 \mathrm{mg} / \mathrm{kg}$ body weight, i.m.) was given.

Ten weeks after implantation of the coated vascular prostheses in goats \#1 4 , angiography under total anesthesia was performed. This allowed us to judge the patency of the prostheses. Subsequently, the animals were sacrificed after an euthesate $20 \mathrm{mg}$ iv. bolus injection. The prostheses and the adjacent parts of the carotid arteries were harvested, and fixed in $4 \%$ neutral buffered formalin, followed by dehydration and paraffin embedding. Six-micron thick sections were cut and stained with hematoxylin-eosin (HE) for light microscopic analysis of tissue response, and fluorescent microscopy for examination of the presence of dipyridamole. Material was obtained from the proximal and distal anastomotic ends, and also from the midsection of the explanted vascular prostheses. Essentially the same procedure was followed for the goats \#5 and \#6, which had the untreated (control) vascular prostheses implanted. The only difference with the procedure as described above is, that sacrifice and explant harvesting was performed 5 weeks post implantation (vide supra). 
Sheep studies: This study comprised eight mature crossbred sheep of mean weight $60 \mathrm{~kg}$ (animals \# 7 - 14). Sheep were cared for according to the National Health and Medical Research Council "Code of Practice for the Care and Use of

Animals for Experimental Purposes” (Australian Government Publication Service, 1990). This animal experimentation was approved by the University of New South Wales, Animal Care and Ethics Committee. The animals were acclimatized, operated and treated as described previously. ${ }^{3}$ Each of the eight sheep received one treated and one untreated prostheses, which were implanted as interposition grafts (one in the left and on in the right carotid artery). The prostheses used in these experiments had a length of approximately $4 \mathrm{~cm}$ and an internal diameter of $5 \mathrm{~mm}$. All animals were sacrificed 10 weeks post implantation.

\subsection{Results and Discussion}

\subsubsection{In vitro tests}

Adhesion of bloodplatelets: Adhesion of human platelets to both the untreated and the modified prosthesis surface was studied with SEM, as was described previously. ${ }^{14}$ Many platelets adhere to the untreated surface (appr. 4500 per $\mathrm{mm}^{2}$ ), and the adhered platelets show spreading and formation of pseudopodia. The dipyridamole-coated prosthesis surface appears to attract significantly less platelets (appr. 1000 per $\mathrm{mm}^{2}$ ), which, in addition, appear to retain their discoid shape. These SEM observations are in line with our previous work on dipyridamole-coated polyurethane (Pellethane D-55) sheets. ${ }^{12-14}$

Thrombin generation experiments: Figure 1 shows two representative thrombin generation curves, both for the untreated and dipyridamoleimmobilised graft materials, exposed to human PRP. Note that multiple analyses for thrombin were performed on aliquots of the PRP, at regular time intervals. The two essential parameters which can be abstracted from a thrombin generation curve are: $(i)$ the time elapsing between the start of the experiment (which is the addition of $\mathrm{Ca}^{2+}$ to the citrated PRP at $\mathrm{t}=0$ ) and the moment at which [thrombin] starts to increase, (ii) the maximum concentration of free thrombin, reached during the experiment. ${ }^{17,18}$ Note that free thrombin is first produced via triggering of the coagulation cascade by the foreign surface. Afterwards thrombin is consumed via two different pathways: it complexes with 
$\alpha_{2} \mathrm{~m}$-macroglobulin, and it is neutralized by antithrombin-III. The experimental data are compiled in Table 1. These data show that coagulation of human PRP is somewhat slower than coagulation of goat PRP. Most probably, the goat carotis therefore provides a sensitive model with respect to testing of vascular grafts. It was not possible to assess [thrombin] $]_{\max }$ for the tests with goat PRP, as the kinetic activity of goat thrombin on the cleavage reaction of the chromogenic substrate S2238 is unknown.

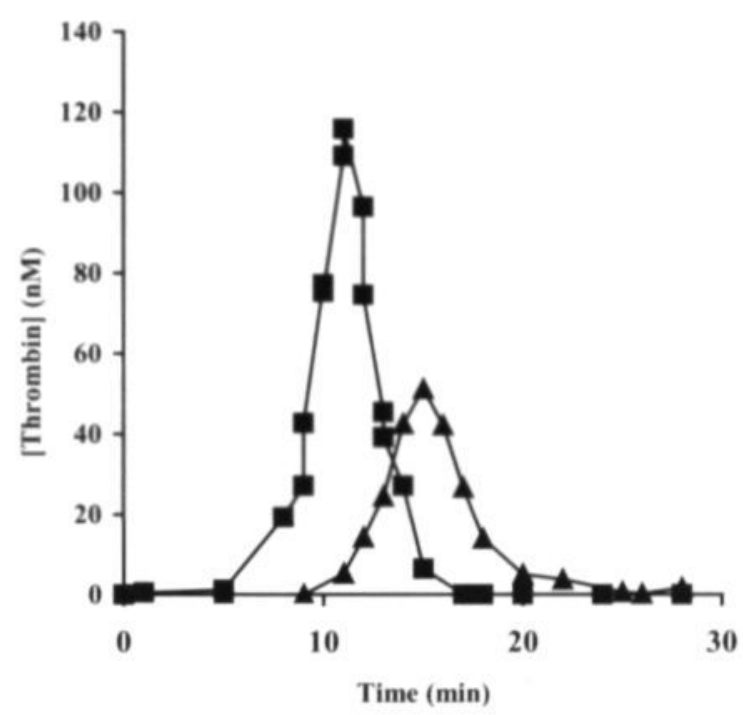

Figure 1. Thrombin generation curves measured for the untreated surface, squares, and the dipyridamole coated surface, triangles.

The data in Table 1 show that the dipyridamole surface modification also leads to decreased thrombogenicity of the prosthesis lumenal surface. These results are in line with our previous work. ${ }^{12-14}$ The average lag times increase from $497 \pm 13 \mathrm{~s}$ to $718 \pm 23 \mathrm{~s}$ (human PRP), or from $290 \pm 18 \mathrm{~s}$ to $418 \pm 23 \mathrm{~s}$ (goat PRP). For human PRP in contact with both surfaces, it is found that [thrombin] $]_{\max }$ drops from approximately $120 \pm 4 \mathrm{nM}$ to approximately $50 \pm 2$ $\mathrm{nM}$ due to the surface modification. 
Endothelial Cell Seeding: Figure 2 shows the proliferation curves measured after seeding of ECs on the non-coated and dipyridamole coated Chronoflex ${ }^{\circ}$ material. The ECs proliferated well on the dipyridamole-coated material; after 6

Table 1. Results of in vitro thrombogenicity tests on the untreated and modified vascular prosthesis.

\begin{tabular}{cccc}
\hline Prosthesis & PRP & Lag time $(\mathrm{s})$ & [Thrombin $]_{\max }(\mathrm{nM})$ \\
\hline Untreated & Human & $497 \pm 13$ & $120 \pm 4$ \\
& Goat & $290 \pm 18$ & --- \\
\hline Modified & Human & $718 \pm 23$ & $51 \pm 2$ \\
& Goat & $418 \pm 23$ & -- \\
\hline
\end{tabular}

days the cell numbers tripled. Proliferation of the ECs was significantly slower on the control material.

The experiments of endothelial seeding onto the 4-cm prosthesis show that the cell coverage of untreated prostheses was poor after 5 days' incubation. Isolated cells were scattered over the seeded surface (assessed by fluorescent microscopy and SEM). Endothelial cells on the dipyridamole-modified surfaces formed monolayers almost completely covering the seeded surface after 5 days.

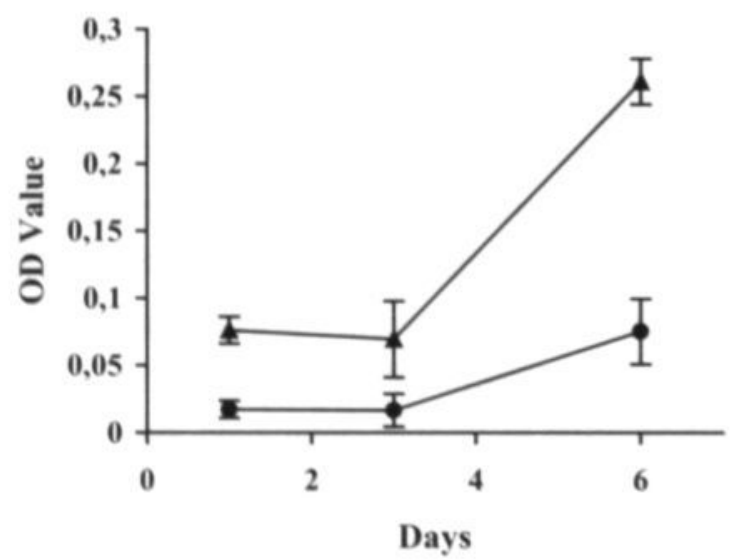

Figure 2. Ovine endothelial cell proliferation curve (cell inoculum $3.3 \times 10^{5}$ cells $/ \mathrm{mL}$ ); triangles: uncoated surface, circles: coated surface. 
Figure 3 shows a comparison of representative SEM micrographs of the dipyridamole-treated and untreated graft surfaces after seeding with ECs, after 5 days incubation.

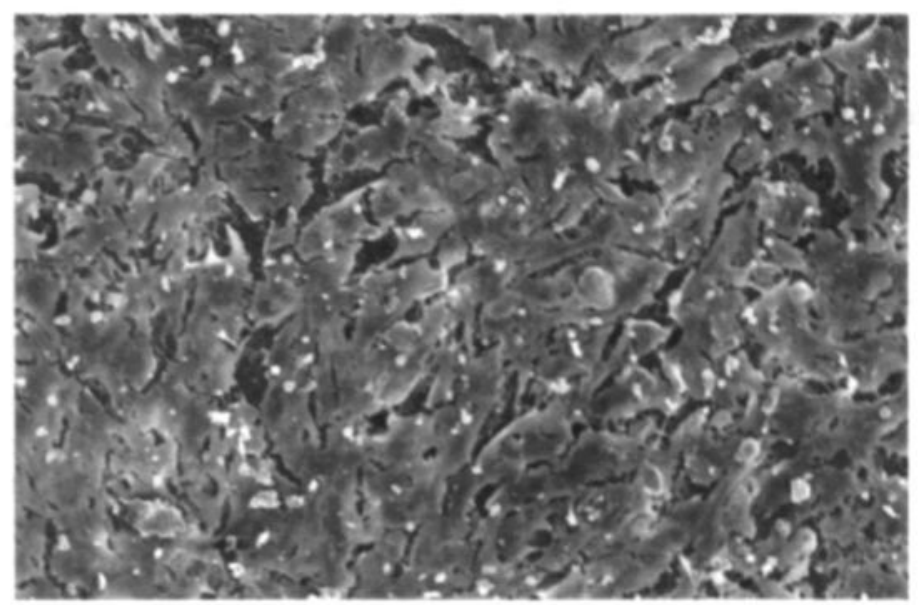

$\mathbf{A}$

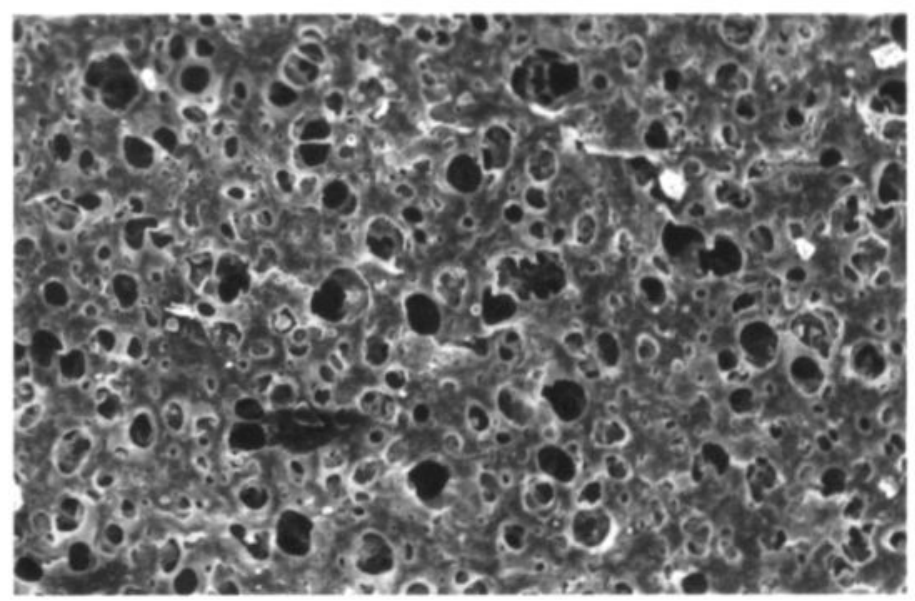

B

Figure 3. Dipyridamole coated polyurethane vascular graft seeded with endothelial cells showing a confluent layer of cells (A). Uncoated seeded polyurethane vascular graft (B). Both images were taken 5 days after incubation. 


\subsubsection{In vivo tests}

Goat studies: Immediately prior to sacrifice, all goats were subjected to angiography in order to evaluate the patency of the grafts. Table 2 compiles the results of these measurements. Three out of the eight modified vascular prostheses were patent, with no observable narrowing of the lumen. Of the

Table 2. Angiographic observations of untreated and modified vascular prostheses.

\begin{tabular}{|c|c|c|c|c|}
\hline Goat \# & $\begin{array}{l}\text { Prostheses } \\
\text { modified }\end{array}$ & $\begin{array}{l}\text { Weeks } \\
\text { implanted }\end{array}$ & Left & Right \\
\hline 1 & yes & 10 & occluded & patent \\
\hline 2 & yes & 10 & patent & patent \\
\hline 3 & yes & 10 & occluded & occluded \\
\hline 4 & yes & 10 & occluded & occluded \\
\hline 5 & no & 5 & half-patent & half-patent \\
\hline 6 & no & 5 & occluded & occluded \\
\hline
\end{tabular}

untreated prostheses, half $(2 / 4)$ were patent with significant narrowing of the lumen. It should be noted that all animals behaved perfectly normal during the entire test period. In those cases where occlusion of the vascular prosthesis had occurred, angiography clearly showed that newly formed collateral blood vessels did take care of the blood supply to the brain. This may indicate that the process of occlusion of the vascular prostheses is rather slow, such that there is enough time for collateral angiogenesis and adaptation. Microscopic sections were taken at six sites of the explants, as indicated in Figure 4. The sections at

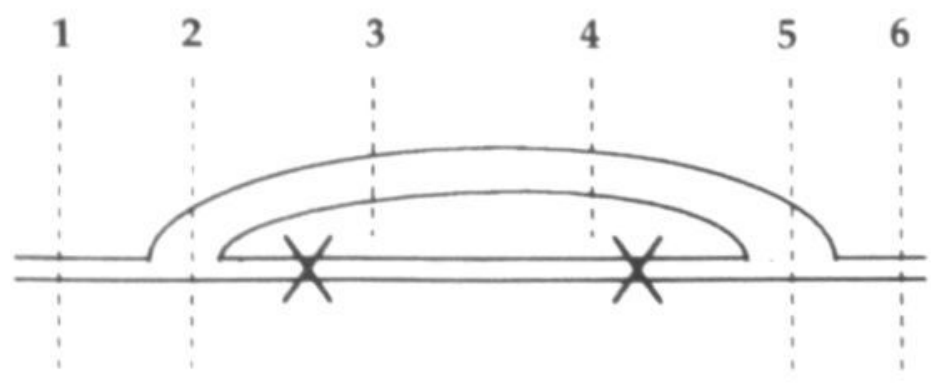

Figure 4. Schematic picture of the bypass of the arteria carotis in our model, showing the six sites where microscopic sections were taken. 
sites 2 and 5 were either longitudinal or transversal (i.e. perpendicular or parallel to the plane of drawing in Figure 4).

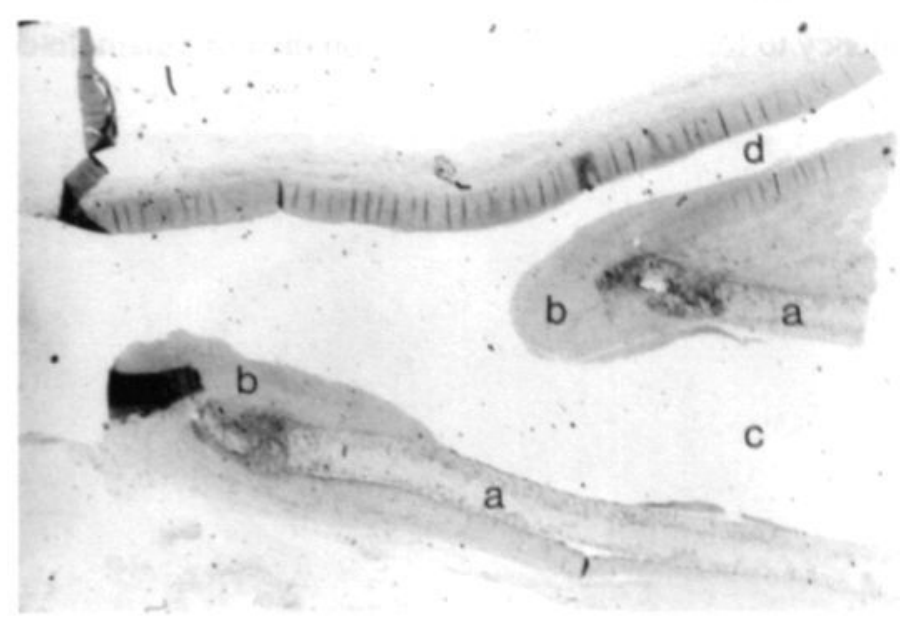

Figure 5. Longitudinal cross-section of the distal anastomosis of one of the dipyridamole coated, patent grafts. Pseudo-intimal structures are practically absent inside the graft lumen. a: vascular prosthesis; $\mathbf{b}$ : neointima; $\mathbf{c}$ : lumen of the graft; d: native artery.

For the eight dipyridamole-coated explants (goats \# $1-4$, left and right), it was observed that extensive formation of neointima had occurred at the anastomotic sites, both at the proximal and distal ends. Relatively thick, wellorganized neointima structures were found at the anastomoses. Our results reconfirm that neointima formation at the anastomoses is of critical importance: if this process proceeds too far, such that the flow is imparted to a too large extent, then occlusion inside the graft is inevitable. An additional problem is that the flow rate is substantially smaller inside the vascular prosthesis than in the adjacent artery, as the lumen of the graft is much wider (i.d. $5 \mathrm{~mm}$ ) than that of the arteria carotis (local i.d. appr. $3 \mathrm{~mm}$ ). Figure 5 shows a longitudinal section of the distal anastomosis of a graft, which showed complete patency (goat \# 2, right). The neointima show a specific architecture of cell and acellular substances, being hypercellular near the lumen, and more fibrocollageneous near the graft. Two remarkable observations were made with the dipyridamolecoated grafts, which were found to be patent,: $(i)$, the thickness of the neointima decreases, going from the anastomoses onward inside the graft, as is clearly visible in Figure 5; (ii) the lumen was found to be covered by a monolayer 
lining of endothelial-like cells. Most of the endothelial-like cells lied directly on the graft surface (Figure 6). Note that this finding correlates with the in vitro experimental data (vide supra), which pointed out that sheep endothelial cells display a tendency to form a monolayer lining on the dipyridamole-coated graft.

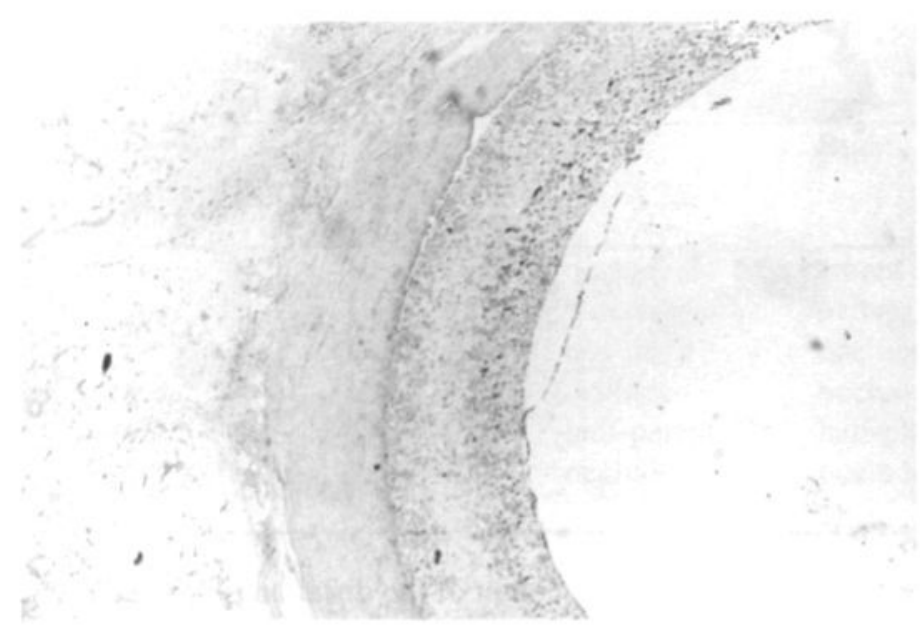

$\mathbf{A}$

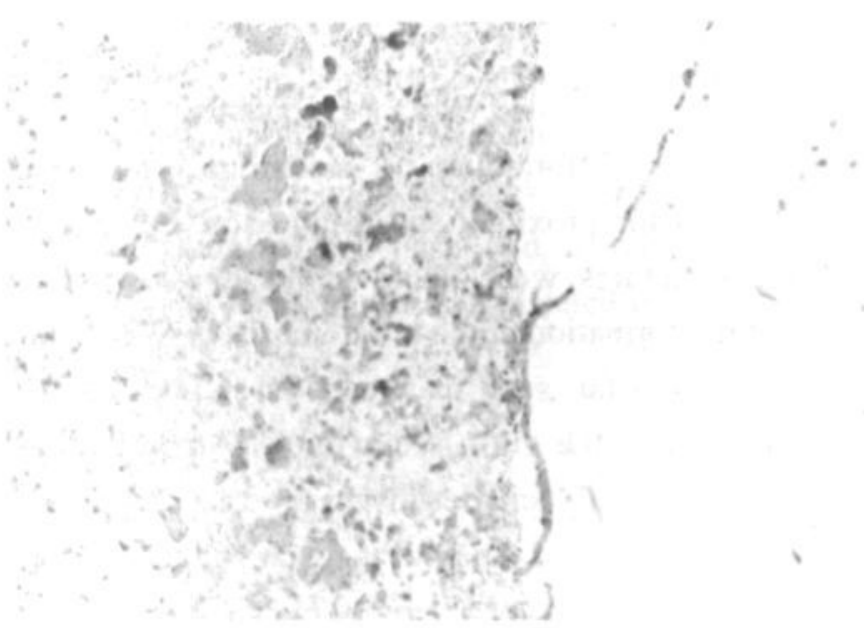

B

Figure 6. Photomicrograph, taken in the midsection of one of the dipyridamole coated, patent grafts. The confluent layer of endothelial-like cells is detached from the graft surface, due to a cutting artifact in the preparation of the section (A). Enlargement of the site where detachment of the endothelial-like cell layer has occurred (B). 
Figure 7 shows a microscopic section of the midsection of a dipyridamolecoated graft, which was found to be occluded (goat \#4, right). The material inside the graft is largely acellular and distinct from the neointima at the anastomotic sites.

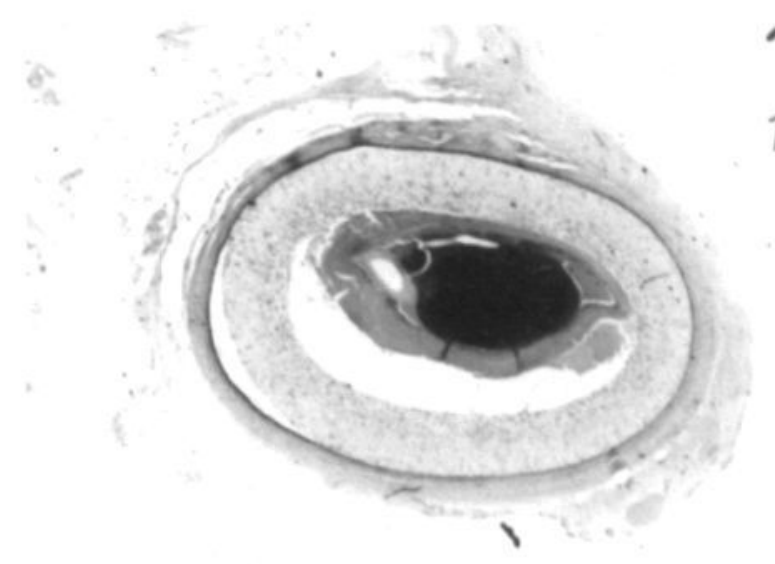

Figure 7. Photomicrograph, taken in the midsection of one of the dipyridamole coated occluded grafts.

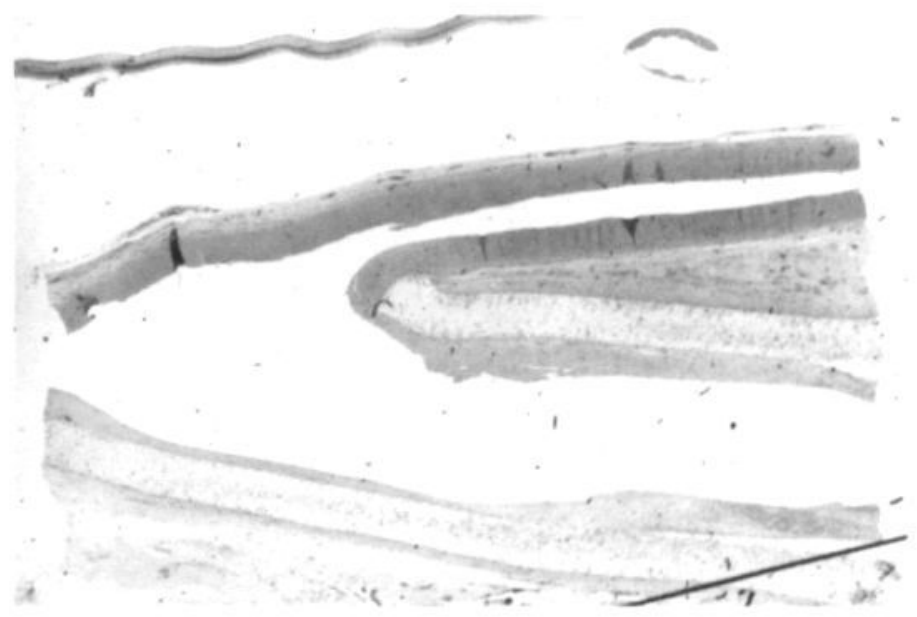

Figure 8. Longitudinal cross-section of the proximal anastomosis of one of the uncoated, half-patent grafts. Note that the pseudo-intimal layer extends into the graft. 
This material is organized thrombus, which -presumably- had formed because the flow through the graft had become very low as a consequence of abundant formation of neointima at the anastomoses (vide supra).

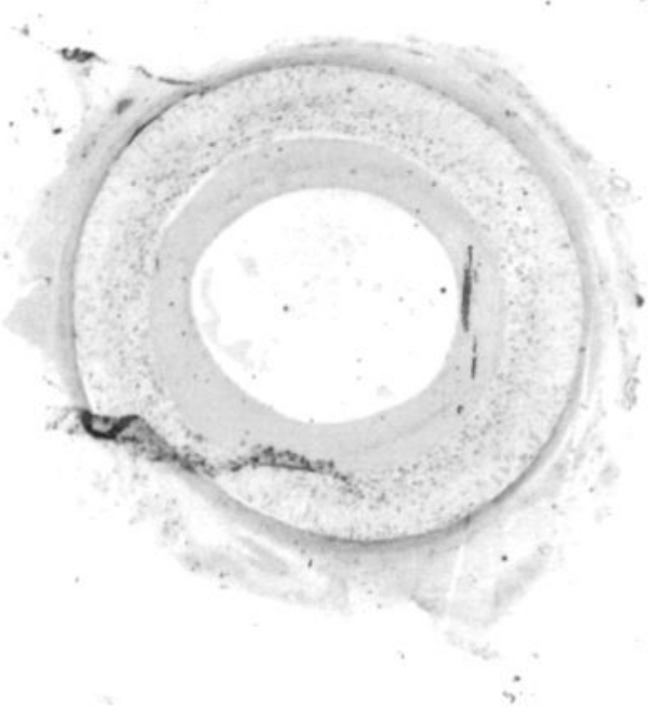

Figure 9. Cross-section, taken in the middle part of one of the untreated, halfpatent grafts.

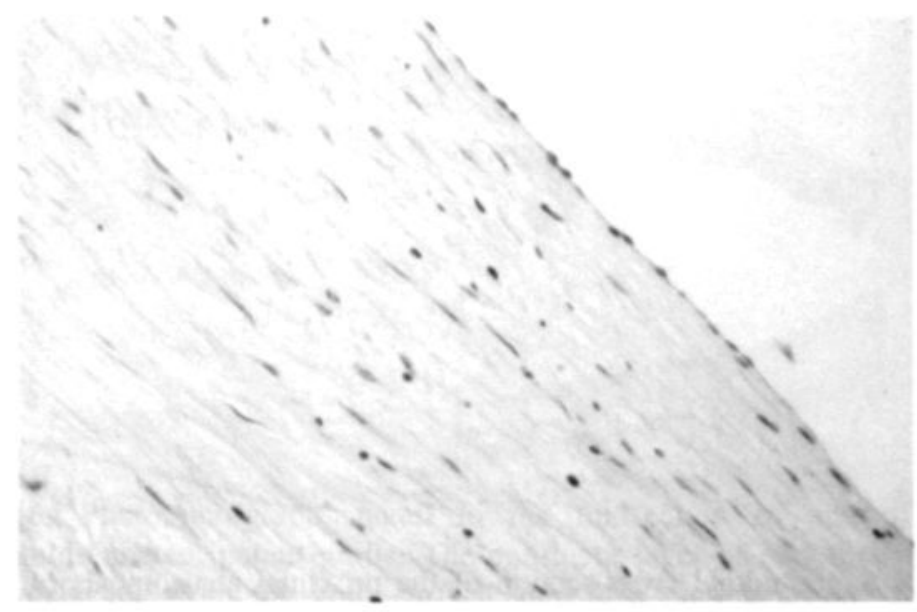

Figure 10. Detail of figure 9, showing the presence of an endothelial-like cell layer on top of the neointima. 
For the four uncoated explants (goats \#5 and 6) different neointima structures were found (Table 2). Figure 8 shows a longitudinal section of the proximal anastomosis of a semi-patent explant (goat \#5, left). Now, it is seen that the neointimal layer extends into the graft, leading to a reduction of its lumen by appr. $50 \%$. The entire lumenal surface of the uncoated grafts appeared to be covered by this neointimal layer, which had a uniform thickness of $800-1000$ $\mathrm{mm}$, and which was covered by a confluent layer of endothelial-like cells. Figure 9 shows a section of the midsection of the half patent explant (goat \#5, right). A detailed micrograph of the neointimal structure, showing that a thin layer of endothelial-like cells constitutes the blood-contacting interface, is shown in Figure 10. The neointimal tissue closely resembles that found at the anastomoses of the dipyridamole-coated grafts (vide supra). Again, it is found that the structure is cellular near the lumen, and fibrocollageneous near the graft surface. The pores in the graft material are filled with acellular, collagen-like material, similar to that observed in dipyridamole-coated grafts.

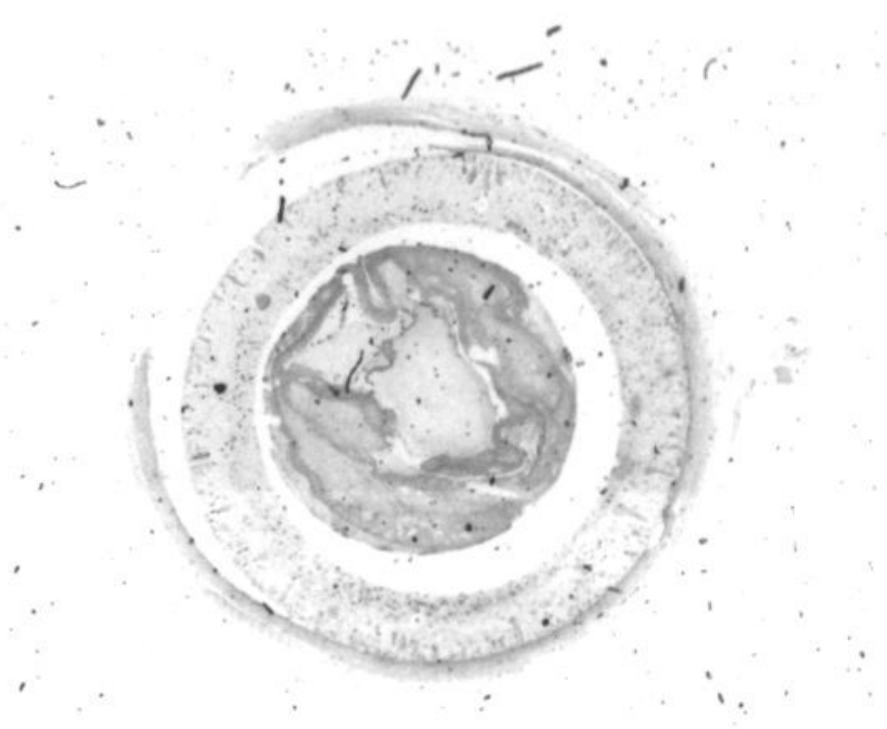

Figure 11. Cross-section, taken in the middle part of an untreated, occluded graft. Neointima, as well as relatively young thrombus are recognized.

Figure 11 shows a section of the midsection of an occluded untreated explant (goat \#6, right). This picture also shows a relatively thick layer of neointima; the residual lumen is closed by relatively fresh thrombus. 


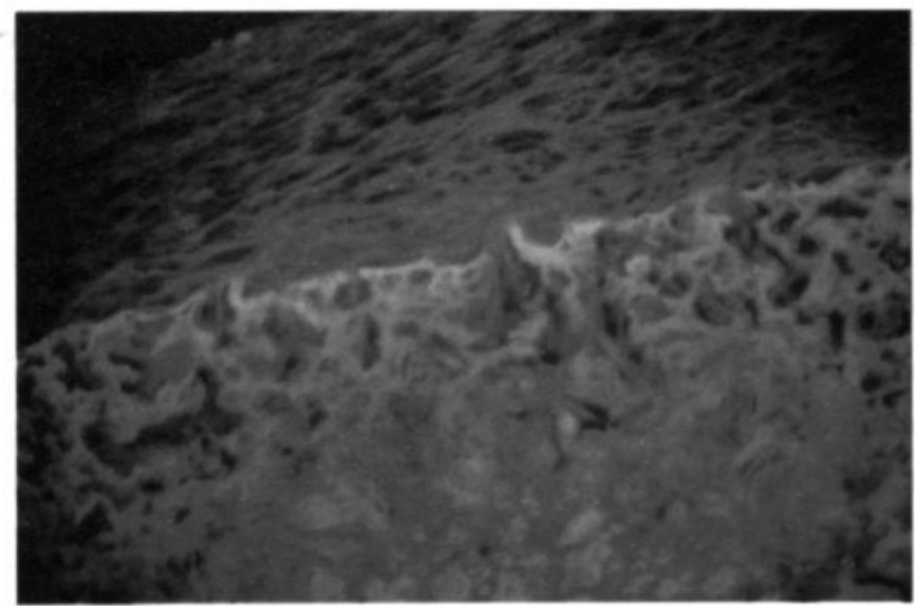

$\mathbf{A}$

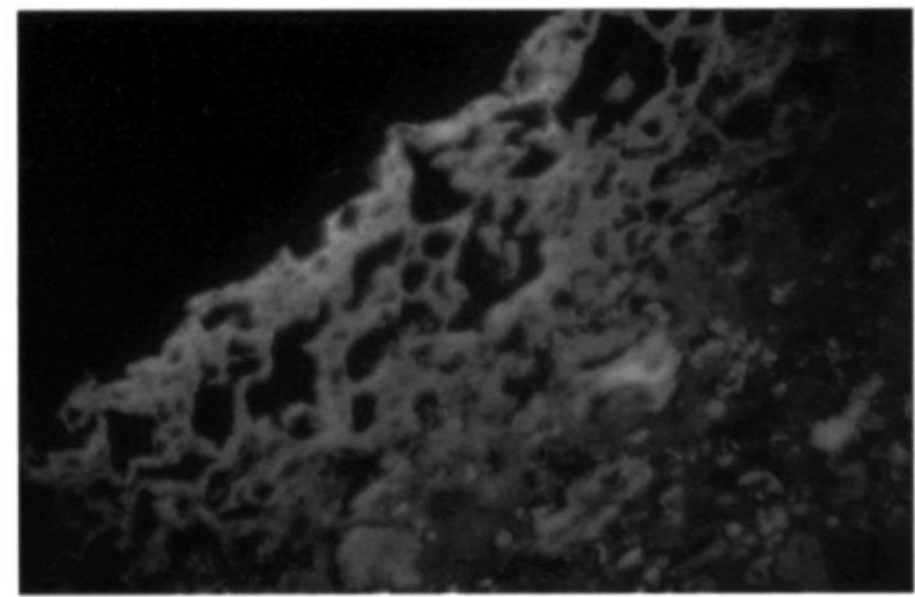

B

Figure 12. Fluorescence photomicrographs of one of the dipyridamole coated, patent graft explants, showing fluorescent immobilised dipyridamole at the interface of the graft material and the neointima, formed at the anastomosis (A), and fluorescent dipyridamole on top of the graft material in the midsection of the graft (B). Apparently, the immobilised dipyridamole promotes the formation of the endothelial cell monolayer directly on top of the modified graft surface. 
An important question is whether the layer of immobilised dipyridamole is stable, or, put in other words: is the dipyridamole still present on the graft lumen after 10 weeks implantation? Figure 12 shows two fluorescence photomicrographs (transversal sections) of an explanted vascular graft (goat\#2, right (patent)). Figure 12A shows an enlargement of the distal anastomosis; intense blue/green fluorescence of immobilised dipyridamole is clearly seen underneath the neointimal layer. Figure 12B shows an enlargement of a section taken at the midsection of this graft. Here, the exposure of immobilised dipyridamole at the lumenal surface is clearly visualized.

Sheep studies: The sheep were sacrificed after 10 weeks implantation; no angiographic measurements were performed. Pieces of the carotid arteries were excised such that approximately $1 \mathrm{~cm}$ of the native artery was preserved on the distal and proximal ends. Vessels were flushed with phosphate buffer ( $\mathrm{PBH})$ and opened longitudinally for macroscopic assessment and photography of the graft lumen. Figure 13 shows the longitudinal section of the graft explanted from sheep \#11. During all observations, grafts were hydrated with cold $\mathrm{PBH}$.

Table 3. Patency of the Implanted Vascular Prostheses in Sheep Model.

\begin{tabular}{ccc}
\hline Sheep \# & Modified & Control \\
& & \\
\hline 7 & Left / occluded & Right / occluded \\
8 & Right / occluded & Left / occluded \\
9 & Left / patent & Right / patent \\
10 & Left / patent & Right / patent \\
11 & Right / patent & Left / patent \\
12 & Right / occluded & Left / occluded \\
13 & Left / patent & Right / occluded \\
14 & Left / occluded & Right / occluded \\
\hline
\end{tabular}

Table 3 compiles the results regarding the patency of the retrieved grafts. Four out of the eight modified grafts were found to be patent. For the control group it was found that three out of the eight grafts were patent. Again, all animals behaved completely normal during the entire test period. We did, however, not verify the possible formation of collateral blood vessels around occluded grafts in the sheep models. 


\section{Chapter 6}

The Chronoflex ${ }^{*}$ material of the grafts which were explanted from the sheep looked very unusual. The grafts showed a tendency to fold (see Figure 13) and were expanded significantly in radial direction. In some cases the internal diameter increased from 5 to approximately $10 \mathrm{~mm}$ in the center of the graft. Furthermore, clear black spots were noted in the material, which points at chemical deterioration. These observations were made for all sheep explants (coated and control).

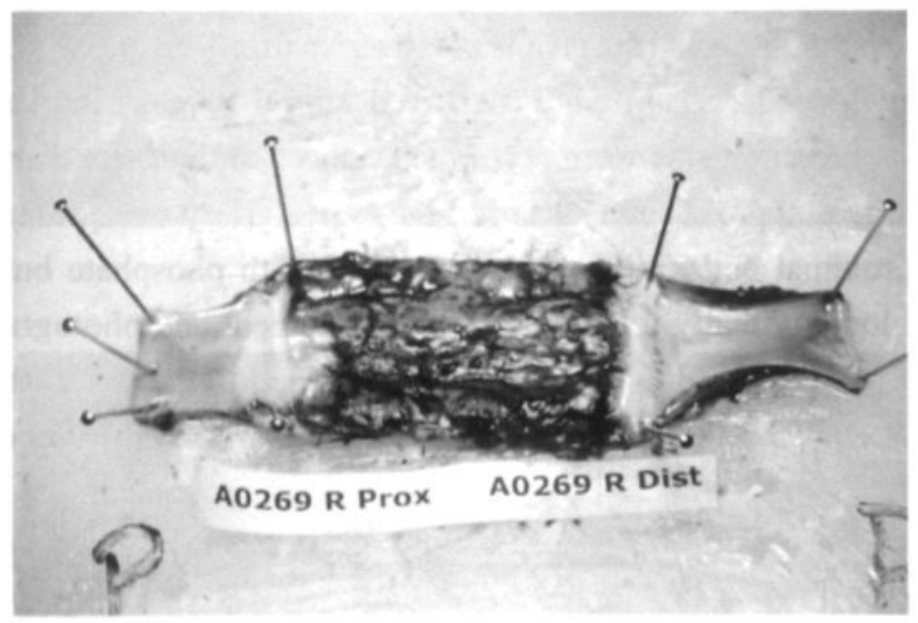

Figure 13. Detailed photograph of the graft, which was, explanted from sheep \#11. The graft was opened longitudinally. The anastomotic stitches are clearly visible. Ingrowth of endothelium towards the inside of the graft occurred, both from the proximal and distal sides. Furthermore it is clear that the graft material lost its cylindrical shape. The material is curved, radially expanded, and shows signs of chemical break-down.

\subsection{Concluding Remarks}

Photo-immobilisation of dipyridamole onto Chronoflex ${ }^{8}$ is technically feasible. The treatment could be carried out on the lumen of the Chronoflex ${ }^{*}$ tube (i.d. $5 \mathrm{~mm}$ ), provided that its length did not exceed $12-15 \mathrm{~cm}$. Taking advantage of the material's elasticity and flexibility, the tube was first inverted by rolling it over a metal rod. The photoreactive dipyridamole-derivative was sprayed onto the surface, and all subsequent steps of the surface treatment could be performed readily. Re-inversion of the tube proceeded smoothly in all cases. 
Biochemical experiments in vitro showed reduced thrombogenicity and less adhesion of blood platelets, after the dipyridamole treatment of Chronoflex ${ }^{*}$. This was analogous to data measured by us previously, for the surface treatment of Pellethane D55 sheets. ${ }^{12-14}$

The results obtained with the goat model do not provide evidence for a benificial effect of the dipyridamole coating in vivo. The patency rate for the coated grafts is $3 / 8$, whereas the untreated controls are partially $(2 / 4)$ or completely $(2 / 4)$ occluded. It is remarkable, however, that the three patent, dipyridamole coated, grafts showed a virtually undisturbed lumen, on which a confluent layer of endothelial-like cells was observed. There was some neointimal hyperplasia at the anastomoses, but the thickness of the neointima decreased rapidly going into the graft; this was observed both at the proximal and at the distal ends.

The results obtained with the sheep model were especially disappointing, since they reveal that the Chronoflex ${ }^{*}$ material lacks structural stability. This implies that Chronoflex ${ }^{*}$ is not a suitable material for this application. Some of the explanted grafts were radially expanded such that the inner diameter was $>1$ $\mathrm{cm}$. There were clear signs of structural breakdown of the polyurethane in most cases. The observations which were made with the sheep model were reminiscent of a recent paper by Guidoin et al., who studied the in vivo performance of the Vascugraft ${ }^{*}$ microporous polyurethane vascular graft in dogs (thoraco abdominal bypass). ${ }^{20}$ This material also lacked sufficient stability. We believe that, the observations which were made with the three patent dipyridamole-coated grafts in the goat model are significant. They show that the dipyridamole coating can accommodate a confluent layer of endothelial-like cells in vivo. This cell growth effect is probably responsible for the observed patency. Future work will be dedicated to the photochemical immobilisation of dipyridamole to a more stable biomaterial, and to reexamine the performance of such small-bore vascular grafts in vitro and in vivo. 


\subsection{References}

1. K-M. Müller and G. Dasback, In: "The Pathology of Devices," Springer Verlag, Berlin-Heidelberg, 273-306 (1994).

2. M. Welch, D. Durrans, H.M.H. Carr, R. Vohra, O.B. Rooney, and M.G. Walker, "Endothelial cell seeding: a review," Ann. Vasc. Surg., 6, 657-666 (1992).

3. L. Poole-Warren, K. Schindhelm, A.R. Graham, P.R. Slowiaczek, and K.R. Noble, "Performance of small diameter synthetic vascular prostheses with confluent autologous endothelial cell linings," J. Biomed. Mat. Res., 30, 221-229 (1996).

4. G.H. Engbers, and J. Feijen, "Current techniques to improve the blood compatibility of biomaterial surfaces,” Int. J. Artif. Organs, 14, 199-215 (1991).

5. V.S. Sottiurai, S. Lim Sue, D.J. Rau, and A.B. Tran, "Comparative analysis of neointima biogenesis in Gelseal coated Dacron knitted graft versus crimped and noncrimped graft,” J. Cardiovasc. Surg., 30, 902-909 (1989).

6. Y. Marois, N. Chakfe, R. Guidoin, R.C. Duhamel, R. Roy, M. Marois, M.W. King, and Y. Douville., "An albumin-coated polyester arterial graft: in vivo assessment of biocompatibility and healing characteristics," Biomaterials, 17, 3 14 (1996).

7. D. Cohn, Z. Elchai, B. Gershon, M. Karck, G. Lazarovici, J. Sela, M. Chandra, G. Marom, and G. Uretzky, "Introducing a selectively biodegradable filament wound arterial prosthesis: a short-term implantation study,” J. Biomed. Mater. Res., 26, 1185-1205 (1992).

8. G. Uretzky, Y. Appelbaum, H. Younes, R. Udassin, P. Nataf, E. Baccioglu, G. Pizof, J.B. Borman, and D. Cohn, "Long-term evaluation of a new selectively biodegradable vascular graft coated with polyethylene oxide-polylactic acid for right ventricular conduit," J. Thoracic Cardiovasc. Surg., 100, 769-780 (1990).

9. S.V. Madihally, J.M. Chupa, L.A. Stepaniak, and H.W.T. Matthew, "Polysaccharide scaffolds for an engineered vascular graft: cell colonization kinetics in vitro," Transactions of the 23-rd Meeting of the Society for Biomaterials, 64 (1997).

10. R.W. Emery, N.L. Mills, F.J. Teijeira, K.V. Arom, P. Baldwin, R.J. Petersen, L.D. Joyce, G.L.B. Grinnan, M.S. Sussman, J.G. Copeland III, J.L. Ochsner, S.W. Boyce, and D.M. Nicoloff, "North American experience with the PermaFlow prosthetic coronary graft,” Ann. Thorac. Surg., 62, 691-696 (1996).

11. A. Edwards, R.J. Carson, S. Bowald, and W.C. Quist, "Development of a microporous compliant small bore vascular graft,” J. Biomater. Appl., 10, 171187 (1995).

12. Y.B.J. Aldenhoff and L.H. Koole, "Studies on a new strategy for surface modification of polymeric biomaterials," J. Biomed. Mater. Res., 29, 917-928 (1995).

13. Y.B.J. Aldenhoff, R. Blezer, T. Lindhout, and L.H. Koole, "Photoimmobilization of dipyridamole (Persantin $(\mathbb{B})$ at the surface of polyurethane biomaterials: reduction of in vitro thrombogenicity," Biomaterials, 18, 167-172 (1997).

14. Y.B.J. Aldenhoff, A.P. Pijpers, and L.H. Koole, "Synthesis of a new photoreactive derivative of dipyridamole and its use in the manufacture of artificial surfaces with low thrombogenicity," Bioconjugate Chem., 8, 296-303 (1997). 
15. M.S. Lemson, M.J.A.P. Daemen, P.J.E.H.M. Kitslaar, and J.H.M. Tordoir, "A new animal model to study intimal hyperplasia in arteriovenous fistulas," J. Surg. Res., 85, 51-58 (1999).

16. A.P. van der Heiden and L.H. Koole, "Photochemical coupling of aryl azides to poly(ether urethane) surfaces: studies with a fluorescent model compound," Macromolecules, 29, 7012-7015 (1996).

17. H.C. Hemker, S. Béguin, and G.M. Willems, "A computer assisted method to obtain prothrombin activation velocity in whole plasma independent of thrombin decay processes," Thromb. Haemost., 56, 9-17 (1986).

18. T. Lindhout, R. Blezer, P. Schoen, G.M. Willems, B. Fouache, M. Verhoeven, M. Hendriks, L. Cahalan, and P.T. Cahalan, "Antithrombin activity of surfacebound heparin studied under flow conditions," J. Biomed. Mater. Res., 29, 12551266 (1995).

19. H.C. Hemker, In: "Handbook of synthetic substrates for the coagulation and fibrinolytic system," Martinus Nijhoff Publishers, Boston-The Hague-DordrechtLancaster (1983).

20. Y. Marois, E. Paris, Z. Zhang, C.J. Doillon, M.W. King, and R.G. Guidoin, "Vascugraft $B$ microporous polyesterurethane arterial prosthesis as a thoracoabdominal bypass in dogs," Biomaterials, 17, 1289-1300 (1996). 



\section{Summary and Concluding Remarks}

Artificial vascular grafts are of great importance in cardiovascular surgery. Nowadays synthetic vascular grafts are used primarily to substitute rather large peripheral blood vessels. Substitution of small-bore blood vessels (i.d. $<5 \mathrm{~mm}$ ) is usually much more difficult. In the most critical situation, coronary bypass surgery, autologous grafts are clearly superior to their synthetic counterparts. There are, however, a growing number of patients who lack satisfactory autologous conduit, because of prior removal, disease, inadequate size in diameter, or inadequate length. The primary failure mode in using synthetic vascular grafts is thrombus formation in the short term and intimal hyperplasia (particularly at the anastomoses) in the long term. The search for functional synthetic small-bore arterial grafts is an active area of research and development. Several interesting approaches have been followed: (i) seeding of an elastic and compliant polymeric tube with endothelial cells; (ii) immobilisation of hemocompatible coatings onto the lumen of a polymeric tube, e.g. immobilisation of heparin; (iii) coating the lumen of a polymeric tube with a biocompatible and biodegradable substance, like collagen, albumin or poly(ethyleneglycol)/poly(lactic acid) block copolymer (PELA); (iv) novel tissue engineering techniques, such as seeding cells onto polymeric biodegradable materials and cultured in vitro for a period of time.

The most common used polymeric biomaterials in the field of artificial blood vessels are: Dacron ${ }^{\circledR}$ and ePTFE. Dacron ${ }^{\star}$ leads to thrombosis and neo-intimal thickening under low-flow conditions meaning that it is not suitable for smallbore arterial grafts. ePTFE is currently the only alternative in small diameter vessel replacement although their biocompatibility and long-term patency is not optimal. Nowadays, polyurethanes (PUs) gain popularity as a potential synthetic vascular reconstructive material. A clear advantage over Dacron ${ }^{(8)}$ is that the physical properties of PU can be tuned accurately by varying the constituents of hard and soft segments in the polymer chain. An advantage over ePTFE is that PUs expose functional groups at their surface whereas ePTFE is chemically inert. An important drawback for PUs is that they have a moderate bloodcompatibility, but the functional groups at their surface can be used in surface modifications aimed at the improvement of the bloodcompatibility. 
This thesis describes a methodology to improve the bloodcompatibility of PUs. The approach is based on a photochemical immobilisation of dipyridamole (Persantin ${ }^{8}$ ), a well-known and safe inhibitor of platelet activation and a vasodilating drug.

Chapter 2 describes the synthesis of two new conjugate molecules consisting of dipyridamole on one hand and an aryl azide (photoreactive group) on the other hand. In compound $\mathbf{2}$ the dipyridamole unit is directly linked to the aryl azide, while a short hydrophobic spacer chain separates the dipyridamole and the aryl azide in compound 3. UV irradiation turns the aryl azide into a very reactive species, which reacts immediately with a nucleophilic group on the polyurethane surface. In this way the dipyridamole is covalently linked to the polyurethane surface. UV extinction experiments showed that a surface density of $4.9 \mathrm{nmol} . \mathrm{cm}^{-2}$ for compound 2 and $14.6 \mathrm{nmol} . \mathrm{cm}^{-2}$ for compound 3 was achieved. The immobilised surfaces and control surfaces were subjected to (i) an in vitro thrombin generation assay and (ii) incubated with human platelet rich plasma (PRP). Both experiments revealed that the immobilisation of the conjugate molecules $\mathbf{2}$ and $\mathbf{3}$ leaded to improved bloodcompatibility in vitro. Immobilisation of $\mathbf{3}$ led to better results. There is no conclusive evidence at this stage that it can be ascribed to the fact that there is a spacer chain between the dipyridamole and the aryl azide or to the difference in surface densities of the immobilised dipyridamole.

The impact of the built-in spacer chain is investigated in Chapter 3. The spacer chain can be beneficial with regard to the efficacy of the immobilised dipyridamole; the longer the spacer chain the more the dipyridamole can behave as if it were free in solution. PU surfaces with different loadings of compounds $\mathbf{2}$ and $\mathbf{3}$ were prepared. The surface densities, which were measured with UV extinction experiments revealed surface densities up to $45 \mathrm{nmol} . \mathrm{cm}^{-2}$. No differences in surface densities between compound $\mathbf{2}$ and $\mathbf{3}$ were observed, i.e. the spacer chain has no effect on the efficacy of the photo-immobilisation. The immobilised surfaces and control surfaces were first incubated with human PRP to study the adherence and morphology of blood platelets. The modified surfaces both showed reduced numbers of adhered blood platelets. An in vitro thrombin generation assay was performed on the modified and control surfaces showing a decreased thrombogenicity in vitro for the modified surfaces. The reduced thrombogenicity appeared to depend on two factors: (i) the surface 
density of the immobilised dipyridamole, and (ii) the absence or presence of the built-in spacer chain. The presence of the spacer chain (compound 3 ) appeared to increase the efficacy of the immobilised dipyridamole.

Chapter 4 describes the synthesis of a new dipyridamole conjugate molecule (compound 4). This molecule consists of the dipyridamole unit and the photochemical unit, separated by a hydrophilic spacer chain. PU surfaces were immobilised with compound $\mathbf{4}$ and characterized by different physicochemical techniques and biochemical techniques. UV extinction measurements showed a surface density of approximately $13 \mathrm{nmol} . \mathrm{cm}^{-2}$. Contact angle measurements revealed that the surfaces immobilised with 4 were more hydrophilic than the control surfaces, which can be related to the incorporation of the hydrophilic spacer chain. ESCA measurements confirmed the presence of dipyridamole in the outermost layer of the polyurethane surface especially at a take-off angle of $\sim 6^{\circ}$. Furthermore, the ESCA experiments established that the tBDMS protective groups had been removed during the deprotection treatment. The in vitro thrombin generation assay showed a decreased thrombogenicity for the PU immobilised with conjugate molecule 4; the lag time increased from 569 sec for the unmodified PU to $1274 \mathrm{sec}$ for the modified PU. The maximum freethrombin concentration decreased from $85 \mathrm{nM}$ for the unmodified PU to $71 \mathrm{nM}$ for the modified surface. The surfaces were studied with scanning electron microscopy (SEM) to look at the adherence and morphology of blood platelets. The immobilised surface showed a decreased number of adhered blood platelets by approximately one order of magnitude.

Chapter $\mathbf{5}$ is a more detailed study of platelet adhesion to four different surfaces: unmodified PU (control surface), PU modified with 2 (dipyridamole linked directly to the PU surface), PU modified with 4 (dipyridamole immobilised via a short hydrophilic spacer chain), and PU modified with $\mathbf{2 6}$ (hydrophilic spacer chain only). First, all four surfaces were incubated with human PRP under static conditions. SEM was used to monitor platelet adhesion as a function of time. Secondly, adhesion of blood platelets under flow, using heparinized human full blood, was studied with fluorescence imaging microscopy. The SEM data, measured after 60 minutes of incubation, showed that the density of adhered blood platelets was the largest for PU (control, 7640 $\left.\pm 2912 \mathrm{~mm}^{-2}\right)$ and the smallest for PU modified with $4\left(1340 \pm 607 \mathrm{~mm}^{-2}\right)$. The data points at 15 and 30 minutes do not allow for clear conclusions; platelet 
adhesion increased with time for PU and PU modified with $\mathbf{2}$ while this was not seen for PU modified with $\mathbf{4}$ and PU modified with 26. It was clear, however, that the surface PU modified with $\mathbf{4}$ was optimal with respect to suppression of platelet adhesion. The flow experiments (heparinized full blood, 10 minutes incubation) revealed essentially the same trend. The control surface (PU) attracted platelets abundantly, while there was almost no residual fluorescence for the three modified surfaces. This technique could not discriminate the three modified surfaces with respect to platelet adhesion. The SEM data were also used to study the morphological changes of the adhered blood platelets. No clear trends were observed, except that the PU modified with $\mathbf{2}$ and PU modified with $\mathbf{4}$ showed high numbers of spread and fully spread platelets. This observation led to an additional experiment where the surfaces were incubated with a suspension of human washed platelets mixed with Oregon-Green annexin $\mathrm{V}$. Annexin $\mathrm{V}$ is known to form a complex with phosphatidyl serine, which will be exposed at the exteriour plasma membrane of an activated blood platelet. Hardly any Oregon Green label could be detected, after 10 minutes incubation and extensive washing, on the dipyridamole coated surfaces, implying that the adhered (fully) spread platelets do not expose phosphatidyl serine.

The surface modification of dipyridamole conjugate molecules was found to lead to lower thrombogenicity and less adhesion of blood platelets in vitro. Chapter 6 describes the modification of a PU small diameter vascular graft (Chronoflex ${ }^{\circledR}$ ) with conjugate molecule 4 . The immobilisation onto the vascular graft was successful and the results of the in vitro experiments (thrombin generation assay and adhesion of blood platelets) were analogous to previous results. Immobilised and untreated grafts were also seeded with ovine endothelial cells (ECs) and incubated for 6 days. The ECs proliferated well on the immobilised grafts, after 6 days the cell numbers had tripled, while on the uncoated grafts the proliferation was significantly slower. The dipyridamole coated grafts, as well as the uncoated grafts, were studied in two established in vivo models. In the first in vivo model the grafts were implanted in goats, as a bypass of the carotid artery ( 8 coated and 4 controls, length of the graft was approximately $12 \mathrm{~cm}$ ). In the second in vivo model the grafts were implanted in sheep, as an interposition graft in the carotid artery ( 4 coated and 4 controls, length of the graft was $4 \mathrm{~cm}$ ). The patency rate for the immobilised graft in the goat model is $3 / 8$, whereas the controls were partially $(2 / 4)$ or completely $(2 / 4)$ 
occluded. The three patent immobilised grafts showed an undisturbed lumen, on which an endothelial-like cell layer was observed. Neointimal hyperplasia was present at the anastomoses but the thickness decreased going into the graft; this was observed both at the proximal and the distal end. The control graft also showed neointimal hyperplasia at the anastomoses but the layer seemed to extend into the graft leading to a reduction of the lumen by approximately $50 \%$. The results of the implantation of the grafts in the sheep model revealed that the Chronoflex ${ }^{\otimes}$ material lacks structural stability. The grafts showed a tendency to fold, expanded significantly in radial direction, and black spots were noted in the material indicating chemical deterioration of the material. The in vivo results indicate that the dipyridamole coating can accommodate a confluent layer of endothelial-like cells, which may be responsible for the patency of the graft. The Chronoflex ${ }^{*}$ material is however not suitable for the construction of permanent small-diameter vascular grafts. 


\section{Samenvatting en Conclusie}

In de cardiovasculaire chirurgie zijn synthetische bloedvaten van belang. Tegenwoordig worden synthetische bloedvaten voornamelijk gebruikt om de grote perifere bloedvaten te vervangen. Vervanging van bloedvaten met een kleine diameter (kleiner dan $5 \mathrm{~mm}$ ) is een stuk ingewikkelder. In de meest kritische situatie (kransslagader bypass operatie) zijn de lichaamseigen bloedvaten superieur ten opzichte van de synthetische bloedvaten. Er is een groeiend aantal patiënten die over geen geschikte bloedvaten beschikken vanwege bv. het eerder verwijderen van bloedvaten of bloedvaten met een ongeschikte diameter of lengte. Bloedstolling op korte termijn en hyperplasie van de intima op lange termijn (vooral bij de aanhechtingsplaatsen) zijn de twee voornaamste problemen die optreden bij het gebruik van synthetische bloedvaten. Het onderzoek naar functionele synthetische bloedvaten met een kleine diameter is daarom een actief onderzoeksgebiedgebied. Een paar interessante benaderingen zijn onderzocht: $(i)$ het zaaien van endotheel cellen (ECs) op een elastische polymere buis; (ii) het immobiliseren van haemocompatible coatings aan de binnenkant van een kunststof buis (bv heparine); (iii) het aanbrengen van een biocompatibele en afbreekbare substantie op het lumen van een polymere buis zoals collageen, albumine of poly(ethyleenglycol)/poly(lactic acid) blok co-polymeer (PELA); (iv) nieuwe tissue engineering technieken zoals bv het zaaien van cellen op een polymere biodegradeerbare materialen die in vitro gekweekt worden gedurende een bepaalde periode.

De meest gebruikte polymere biomaterialen voor de constructie van synthetische bloedvaten zijn: Dacron ${ }^{*}$ en ePTFE. Dacron ${ }^{*}$ is niet geschikt voor synthetische bloedvaten met een kleine diameter omdat het materiaal leidt tot trombose en verdikking van de neo-intima bij een lage bloedstroming. ePTFE is op het moment het enige alternatief alhoewel de biocompatibiliteit en de functionaliteit op de lange termijn niet optimaal zijn. Tegenwoordig winnen polyurethanen (PUs) populariteit als een potentieel synthetisch reconstructie materiaal. Een groot voordeel van PUs ten opzichte van Dacron ${ }^{\star}$ is dat de fysische eigenschappen van PUs aangepast kunnen worden door het variëren van de zachte en harde segmenten in de polymeerketen. Een voordeel ten 
opzichte van ePTFE is dat PUs over functionele groepen beschikken aan het oppervlak, terwijl ePTFE chemisch inert is. Een belangrijk nadeel van PUs is dat het materiaal matig bloedcompatibel is, maar de functionele groepen aan het oppervlak kunnen gebruikt worden voor oppervlakte modificatie leidend tot een verbetering van de bloedcompatibiliteit.

Dit proefschrift beschrijft een methode om de bloedcompatibiliteit van PU te optimaliseren. De benadering is gebaseerd op een fotochemische koppeling van dipyridamole. Dipyridamole is een bekende en veilige remmer van bloedplaatjes activering en een bloedvat verwijdend medicijn.

Hoofdstuk 2 beschrijft de synthese van 2 nieuwe conjugaat verbindingen die dipyridamole aan de ene kant en een aryl azide (foto-reactieve groep) aan de anderen kant bezitten. In verbinding $\mathbf{2}$ is dipyridamole direct aan het aryl azide gekoppeld, terwijl in verbinding $\mathbf{3}$ een korte hydrofobe spacer het dipyridamole en het aryl azide scheidt. UV bestraling verandert het aryl azide in een reactieve verbinding welk meteen met een nucleofiele groep aan het PU oppervlak reageert. Op deze manier wordt dipyridamole covalent gebonden aan het PU. Uit UV extinctie experimenten werd berekend dat een oppervlaktedichtheid van 4.9 nmol. $\mathrm{cm}^{-2}$ voor verbinding 2 en $14.6 \mathrm{nmol} . \mathrm{cm}^{-2}$ voor verbinding 3 werd bereikt. De geïmmobiliseerde en controle oppervlakken werden onderworpen aan een in vitro trombine generatie test en geïncubeerd met menselijk plaatjes rijk plasma (PRP). Beide experimenten toonden aan dat de immobilisatie van de beide conjugaat moleculen tot een verbeterde bloedcompatibiliteit in vitro leidde. Immobilisatie van verbinding 3 leidde tot de beste resultaten. Er is geen afdoende bewijs op dit punt dat deze verbetering is toe te schrijven aan het feit dat in verbinding 3 een spacer aanwezig is of aan het verschil in oppervlaktedichtheid van de behandelde oppervlakken.

Het effect van de ingebouwde spacer is verder onderzocht in Hoofdstuk 3. De spacer kan nuttig zijn ten aanzien van de doeltreffendheid van de geïmmobiliseerde dipyridamole; des te langer de spacer des te meer kan het dipyridamole zich gedragen alsof het vrij in oplossing is. PU oppervlakken met diverse oppervlaktedichtheden van verbinding $\mathbf{2}$ en $\mathbf{3}$ werden bereid. UV extinctie experimenten lieten zien dat oppervaktedichtheden tot $45 \mathrm{nmol} . \mathrm{cm}^{-2}$ konden worden bereikt. Er werden geen verschillen waargenomen tussen verbinding 2 en 3, d.w.z. de spacer verstoort de foto-immobilisatie niet. De behandelde en onbehandelde (controle) oppervlakken werden eerst geïncubeerd met PRP om de adhesie en morfologie van de bloedplaatjes te bestuderen. De 
beide behandelde oppervlakken toonden een verlaagd aantal vastgehechte bloedplaatjes. De in vitro trombine generatie test toonde een verminderde trombogeniciteit voor beide behandelde oppervlakken. De verminderde trombogeniciteit bleek afhankelijk te zijn van twee factoren: (i) de oppervlaktedichtheid van het geïmmobiliseerde dipyridamole en (ii) de aan- of afwezigheid van de ingebouwde spacer. De aanwezigheid van de ingebouwde spacer (verbinding 3) bleek de effectiviteit van het geïmmobiliseerde dipyridamole te bevorderen.

Hoofdstuk 4 beschrijft de synthese van een nieuw conjugaat molecuul (verbinding 4). Deze verbinding bestaat uit dipyridamole en het aryl azide gescheiden door een korte hydrofiele spacer. PU oppervlakken werden behandeld met verbinding $\mathbf{4}$ en gekarakteriseerd met verschillende fysischchemische en biochemische technieken. UV extinctie experimenten toonden een oppervlaktedichtheid van ongeveer $13 \mathrm{nmol} . \mathrm{cm}^{-2}$ aan. Uit contacthoek metingen bleek dat de oppervlakken behandeld met $\mathbf{4}$ meer hyrofiel waren dan de controle oppervlakken, wat gerelateerd kon worden aan de ingebouwde hydrofiele spacer. Elektronen Spectroscopie voor Chemische Analyse (ESCA) experimenten bevestigden de aanwezigheid van het dipyridamole aan de buitenste laag van het PU oppervlak, vooral onder een hoek van $\sim 6^{\circ}$. Bovendien kon worden aangetoond dat de tBDMS beschermgroepen kwantitatief verwijderd waren gedurende de deprotectie behandeling. De in vitro trombine generatie test toonde een verlaagde trombogeniciteit voor het geïmmobiliseerde oppervlak; de bloedstollingtijd nam toe van 569 seconden voor het controle oppervlak tot 1274 seconden voor het behandelde PU. De adhesie en morfologie van de aangehechte bloedplaatjes op de behandelde en onbehandelde PUs werden bekeken met scanning elektronen microscopie (SEM). PU geïmmobiliseerd met verbinding $\mathbf{4}$ gaf een verminderd aantal bloedplaatjes te zien.

Hoofdstuk 5 is een meer gedetailleerde studie van bloedplaatjes adhesie op vier verschillende oppervlakken: onbehandelde PU (controle), PU behandeld met verbinding $\mathbf{2}$ (dipyridamole direct gebonden aan PU), PU behandeld met $\mathbf{4}$ (dipyridamole verbonden via hydrofiele spacer), en PU behandeld met $\mathbf{2 6}$ (hydrofiele spacer). Ten eerste werden alle oppervlakken geïncubeerd met PRP onder statische condities. SEM werd gebruikt om de plaatjesadhesie als functie van de tijd te bestuderen. Ten tweede werd de plaatjesadhesie bekeken onder stromingscondities (gehepariniseerd vol bloed) met fluorescentie microscopie. 
De SEM data, gemeten na 60 minuten incubatie, toonden de meeste bloedplaatjes voor het onbehandeld PU $\left(7640 \pm 2912 \mathrm{~mm}^{-2}\right)$ en de minste bloedplaatjes voor PU geïmmobiliseerd met verbinding $4\left(1340 \pm 607 \mathrm{~mm}^{-2}\right)$. De data bij 15 en 30 minuten leidden niet tot verdere conclusies: plaatjes adhesie nam toe met de tijd voor PU (controle) en het oppervlak behandeld met $\mathbf{2}$ terwijl dit niet het geval was voor het oppervlakken behandeld met $\mathbf{4}$ en $\mathbf{2 6}$. Het was echter wel duidelijk dat PU behandeld met $\mathbf{4}$ optimaal was ten aanzien van de onderdrukking van bloedplaatjesadhesie. De experimenten onder stromingscondities (gehepariniseerd vol bloed, 10 minuten) lieten bijna dezelfde resultaten zien. Het controle oppervlak trok overvloedig bloedplaatjes aan terwijl bijna geen fluorescentie te zien was voor de drie geïmmobiliseerde oppervlakken. Deze techniek kon echter geen onderscheid maken tussen de drie behandelde oppervlakken ten aanzien van bloedplaatjesadhesie. De SEM data werden ook gebruikt om de morfologie van de gehechte bloedplaatjes te bestuderen. Geen duidelijke tendens werd waargenomen, behalve dat PU behandeld met $\mathbf{2}$ en $\mathbf{4}$ relatief veel gespreide en volledig gespreide bloedplaatjes bezat. Deze observatie leidde tot een extra experiment waarbij de oppervlakken behandeld met $\mathbf{2}$ en $\mathbf{4}$ werden geïncubeerd met een mengsel van gewassen bloedplaatjes met Oregon-Green Annexin V. Het is bekend dat Annexin V een complex vormt met phosphatidyl-serine. Phosphatidyl-serine is aanwezig aan de buitenkant van de plasma membraan van een geactiveerd bloedplaatje. Na 10 minuten incubatie en zorgvuldig wassen kon er geen Oregon-Green worden gedetecteerd op de dipyridamole geïmmobiliseerde oppervlakken wat aanduidt dat er geen phophatidyl-serine aanwezig was aan de buitenkant van de plasma membraan.

De oppervlakte modificatie van dipyridamole conjugaat moleculen leidt tot een verlaagde trombogeniciteit en minder adhesie van bloedplaatjes in vitro. Hoofdstuk 6 beschrijft de modificatie van een PU synthetisch bloedvat met een kleine diameter $\left(\right.$ Chronoflex $^{2}$ ) met verbinding 4. De immobilisatie op het synthetisch bloedvat was succesvol en de in vitro resultaten (trombine generatie en adhesie van bloedplaatjes) waren analoog aan eerdere resultaten. De onbehandelde en behandelde bloedvaten werden gezaaid met ECs (schaap) en zes dagen geïncubeerd. De ECs vermenigvuldigden zich zeer goed op het behandelde materiaal, na zes dagen waren er drie maal zo veel cellen aanwezig, terwijl op het controle materiaal de vermenigvuldiging significant lager was. De geïmmobiliseerde en controle materialen werden verder onderzocht in twee in 
vivo modellen. In het eerste in vivo model werden de PU bloedvaten in geiten als een bypass van de halsslagader ( 8 behandelde en 4 controles, lengte ongeveer $12 \mathrm{~cm}$ ). In het tweede in vivo model werden de PU bloedvaten geïmplanteerd in schapen als een tussenstuk van de halsslagader ( 4 behandelde en 4 controles; lengte $4 \mathrm{~cm}$ ). In het eerste model (geit) waren 3 van de 8 behandelde bloedvaten $100 \%$ open terwijl de controles gedeeltelijk ( 2 van de 4 ) of helemaal dicht (2 van de vier) zaten. De 3 opengebleven behandelde bloedvaten toonden een ongestoord lumen waar een laag endotheel-achtige cellen te zien was. Bij de aanhechtingsplaatsen was een dikke laag neo-intima aanwezig maar deze laag werd dunner verder in het bloedvat. Dit fenomeen werd zowel bij de proximale als bij de distale aanhechtingsplaats geobserveerd. Ook bij de controles was een dikke laag neo-intima aanwezig maar hier werd de laag dikker verder in het bloedvat, wat uiteindelijk leidde tot een reductie van het lumen van ongeveer $50 \%$. De implantaties bij de schapen lieten zien dat het Chronoflex materiaal structureel niet stabiel is. De bloedvaten hadden de neiging om te knikken, waren significant verwijd, en er werden zwarte plekken geconstateerd in het materiaal wat wijst op ontleding van het materiaal. De in vivo resultaten laten zien dat dipyridamole kan helpen om een confluente laag van endotheel-achtige cellen te bevorderen, deze cellen zijn belangrijk met betrekking tot de doorgankelijkheid van het kunst-bloedvat. Het Chronoflex materiaal is echter niet geschikt voor de constructie van permanente synthetische bloedvaten met een kleine diameter. 


\section{Publications}

\section{List of publications related to this work:}

1. Y.B.J. Aldenhoff, J.M.H. Kuijpens, and L.H. Koole, "Studies on a new photochemical method for surface modification of polymeric biomaterials," Transactions of the VII Colloquium on Biomaterials, Aachen, Germany (1993).

2. Y.B.J. Aldenhoff and L.H. Koole, "Studies on an new strategy for surface modification of polymeric biomaterials," J. Biomed. Mater. Res., 29, 917-928 (1995).

3. Y.B.J. Aldenhoff and L.H. Koole, "Photo-immobilization of dipyridamole decreases thrombogenicity of polyurethane surfaces," Transactions of the Fifth World Biomaterials Congress, 16, Toronto, Canada (1996).

4. L.H. Koole, Y.B.J. Aldenhoff, J. ter Woorst, and F.H. van der Veen, "Studies on a small-bore vascular graft with a hemocomapatible lumenal coating," Transactions of the $X^{\text {th }}$ Colloquium on Biomaterials, Aachen, Germany (1997).

5. Y.B.J. Aldenhoff, R. Blezer, T. Lindhout, and L.H. Koole, "Photo-immobilization of dipyridamole (Persantin ${ }^{2}$ ) at the surface of polyurethane biomaterials: reduction of in vitro thrombogenicity," Biomaterials, 18, 167-172 (1997).

6. Y.B.J. Aldenhoff, A.P. Pijpers, and L.H. Koole, "Synthesis of an new photoreactive derivative of dipyridamole and its use in the manufacture of artificial surfaces with low thrombogenicity," Bioconjugate Chemistry, 8, 296-303 (1997).

7. Y.B.J. Aldenhoff, J. Briedé, T. Lindhout, and L.H. Koole, "Blood platelets in contact with polyurethane exposing immobilised dipyridamole at their surface," Transactions of the Sixth World Biomaterials Congress, 932, Kamuela, Hawaii (2000).

8. Y.B.J. Aldenhoff, F.H. van der Veen, J. ter Woorst, J. Habets, L.A. Poole-Warren, and L.H. Koole, "Performance of a polyurethane vascular prosthesis carrying a dipyridamole (Persantin ${ }^{8}$ ) coating on its lumenal surface," J. Biomed. Mater. Res., 54, 224-233 (2001).

9. Y.B.J. Aldenhoff, J. Briedé, T. Lindhout, and L.H. Koole, "Platelet studies on dipyridamole coated polyurethane surfaces," Biomaterials, submitted.

\section{List of publications not related to this work:}

10. Y.B.J. Aldenhoff, M.J.P.G. van Kroonenburgh, S.V.M. Zimny, P.P.C.A. Menheere, and L.H. Koole, “A new amphiphilic host molecule for ${ }^{99 m}$ Tc. Specific imaging of the hepatobiliary system in an rabbit model," J. Chem. Soc., Chem. Commun., 15, 451-453 (1995). 
11. Y.B.J. Aldenhoff, M.J.P.G. van Kroonenburgh, and L.H. Koole, "Preparation, characterization and radiolabeling of a new amphiphilic derivative of DTPA, "Nucl. Med. Biol., 23, 653-656 (1996).

12. L.H. Koole, M.A.B. Kruft, Y.B.J. Aldenhoff, N.E. van 't Oost, M.J.P.G. van Kroonenburgh, and F.H. van der Veen, "Sustained local drug delivery from a radiopaque implanted reservoir," Nature Biotechnology, 16, 172-176 (1998).

13. L.H. Koole, M.A.B. Kruft, Y.B.J. Aldenhoff, N.E. van 't Oost, M.J.P.G. van Kroonenburgh, and F.H. van der Veen, "Sustained local drug delivery from a radiopaque implanted reservoir," Transactions of the $24^{\text {th }}$ Annual Meeting for the Society of Biomaterials, 279, San Diego, California, USA (1998).

14. L.H. Koole, M.A.B. Kruft, Y.B.J. Aldenhoff, N.E. van 't Oost, M.J.P.G. van Kroonenburgh, and F.H. van der Veen, "Sustained local drug delivery from a radiopaque implanted reservoir," Transactions of the XII th Aachen Colloquium on Biomaterials, Aachen, Germany (1999).

15. A. Boyde, P.G.T. Howell, Y.B.J. Aldenhoff, G.M.R. Wetzels, and L.H. Koole, "Utility of novel iodinated polymer series for standardising the backscattered electron signal from bone at the biomaterials surface," Transactions of the Sixth World Biomaterials Congress, 607, Kamuela, Hawaii (2000).

16. L.H. Koole, Y.B.J. Aldenhoff, and J-J. Boelens, "Magnetic microimaging in biomaterials science," Transactions of the Sixth World Biomaterials Congress, 686, Kamuela, Hawaii (2000).

17. Y.B.J. Aldenhoff, M.A.B. Kruft, A.P. Pijpers, F.H. van der Veen, R. Kuijer, and L.H. Koole, "Stability of radiopaque iodine-containing biomaterials," Transactions of the Sixth World Biomaterials Congress, 900, Kamuela, Hawaii (2000).

18. L.H. Koole, Y.B.J. Aldenhoff, and M.J. Bruining, "Swelling of synthetic hydrogels studied by magnetic resonance microimaging," Transactions of the Sixth World Biomaterials Congress, 932, Kamuela, Hawaii (2000).

19. Y.B.J. Aldenhoff, M.A.B. Kruft, A.P. Pijpers, F.H. van der Veen, S.K. Bulstra, and L.H. Koole, "Stability of radiopaque iodine-containing biomaterials," Biomaterials, accepted.

20. M.J. Bruining, Y.B.J. Aldenhoff, and L.H. Koole, "NMR microimaging as a versatile tool for studying water-uptake and decomposition of hydrophilic and degradable biomaterials," Biomacromolecules, submitted.

21. J.J. Boelens, Y.B.J. Aldenhoff, and L.H. Koole, "Nuclear magnetic resonance (NMR) microimaging as a tool for studying biocompatibility of biomaterials in the living mouse," manuscript in preparation. 


\section{Curriculum vitae}

Yvette Aldenhoff werd op 16 april 1969 geboren te Budel-Schoot. In 1988 behaalde zij het HAVO diploma aan het Bisschoppelijk College Schöndeln te Roermond. Hetzelfde jaar werd begonnen aan de Hoger Laboratorium Onderwijs te Sittard, met als afstudeerrichting Organische Chemie. Haar stage en afstuderen werden uitgevoerd aan de Universiteit Maastricht, bij het Biomaterials and Polymer Research Institute Maastricht Eindhoven (nu: Centre for Biomaterials Research). Het diploma werd behaald in september 1993.

Van oktober 1993 tot en met oktober 1998 heeft zij, parttime, gewerkt in het Academisch Ziekenhuis Maastricht, bij de afdeling Nucleaire Geneeskunde. Daar heeft zij onderzoek heeft verricht naar het ontwikkelen van nieuwe gastmoleculen die door de bloed-hersen barriere heen kunnen gaan. In maart 1994 kwam zij, tevens parttime, in dienst bij de Universiteit Maastricht, vakgroep Biochemie, om het hier beschreven onderzoek te gaan verrichten. Vanaf oktober 1994 werd het onderzoek voortgezet bij Biomat B.V., gevestigd binnen de Universiteit Maastricht. In september 1997 is zij afgereisd naar Australië waar zij 3 maanden gewerkt heeft aan de University of New South Wales in Sydney. In oktober 1998 is haar parttime contract omgezet in een fulltime contract bij Biomat B.V. alwaar zij nog steeds werkzaam is. 



\section{Dankwoord}

Tja, het dankwoord, één van de leukste maar ook de moeilijkste dingen om te schrijven. Het leukste is natuurlijk om mensen te laten weten hoezeer je ze waardeert en hoe dankbaar dat je ze bent, maar het moeilijkste is om dat goed onder woorden te brengen. Dan schuilt er tevens ook nog het gevaar dat je mensen vergeet. Ik begin dan ook maar om iedereen die een bijdrage heeft geleverd aan dit proefschrift te bedanken, maar ik wil toch een aantal mensen met naam noemen.

Veel heb ik te danken aan Leo Koole. Leo, jij bent de voornaamste drijfveer geweest achter de realisatie van dit proefschrift. Je wist mij er toch van te overtuigen dat ik deze klus kon klaren, en zoals je zelf altijd zegt: "Ik heb graag gelijk", ik moet je nu dan ook gelijk geven. Ik wil je dan ook bedanken dat jij mij de gelegenheid hebt gegeven om dit te realiseren, voor alle begeleiding -ook al was je vaak nergens te vinden of had je geen tijd- en vooral voor het vertrouwen dat je in mij hebt gesteld.

Mijn huidige en voormalige collega's van zowel het Instituut Biomaterialen als van Biomat BV wil ik graag bedanken voor de leuke samenwerking. Er zijn er toch een paar waar ik iets meer woorden aan kwijt wil.

Marc-Anton Kruft: De eerste vier jaar dat wij samen gewerkt hebben was geweldig. Jij heb altijd in de realisatie van dit proefschrift geloofd, en ondanks dat je al dik vijf jaar bij ons weg bent, mis ik je nog regelmatig in Maastricht. Je bent een goede vriend en een geweldige steunpilaar, merci bien.

Monique Bruining: We hebben in het begin erg aan elkaar moeten wennen maar uiteindelijk zijn we erg naar elkaar toe gegroeid. We hebben veel nuttige, en ook niet zo nuttige discussies gevoerd, samen heerlijke "choclat-pie" gegeten, en ook buiten het werk om veel plezier gehad. Je was een fantastische collega en ik hoop dat je op je nieuwe werkplek veel (werk)plezier zult hebben. Pas een beetje op jezelf, stress niet te veel en heel veel geluk met de toekomstige kleine.

Menno Knetsch: Je bent nog niet zo lang bij de biomaterialen groep, maar je hebt de eerste maanden al heel wat met me te stellen gehad (zal in de toekomst niet veel veranderen ben ik bang). Vooral met betrekking tot dit proefschrift heb $\mathrm{ik}$ je (voor mijn gevoel) vaak om advies gevraagd en je was nooit te beroerd om 
te helpen. Jij vond het allemaal vanzelfsprekend maar toch ben ik erg blij met de hulp die ik van je gehad heb.

Alle medewerkers en promovendi van de vakgroep Biochemie: Ook al zitten jullie twee verdiepingen hoger en is het daardoor moeilijk om een hecht contact te hebben, wil ik jullie danken voor de prettige werksfeer en de gezellige vakgroepuitjes. In het bijzonder wil ik Theo Lindhout, Ron Blezer $\dagger$, Jacco Briedé en Simone Wielders danken voor de hulp die ik van jullie heb gekregen voor het uitvoeren van de biochemische experimenten en de kennis die ik van jullie heb meegekregen.

Trees Camphuisen: Jij was (en bent nog steeds) een heerlijk rustpunt. Het is te veel om op te noemen waar ik je voor zou moeten bedanken dus ik doe het maar kort en krachtig: Bedankt schat!

Eric van der Veen, Jo Habets en Joost ter Woorst: Jullie inbreng in het realiseren van hoofdstuk 6 was fantastisch. Het was altijd weer een groot feest om met jullie samen te werken.

Veel dank ben in ook verschuldigd aan Paul Pijpers (DSM Research) voor de ESCA metingen die hij heeft uitgevoerd. Jouw enorme kennis op dit gebied en het geduld dat jij kon opbrengen om mij in deze materie een beetje thuis te brengen bewonder ik ten zeerste.

Many thanks for all the people that work on the lab of Biomedical Engineering at the University of New South Wales, Sydney. In particularly I want to thank Laura Poole-Warren; you made it possible that I could work at your lab for three months. You learned me all I had to know about endothelial cells and also showed me how real Aussis live. It was a once in a lifetime experience, thanks again.

Financial support from the EUREKA program (via the Dutch Ministry of Economic Affairs) is gratefully acknowledged.

I am most grateful to CardioTech Ltd. (Chesire, UK) for the generous gift of a number of Chronoflex ${ }^{*}$ porous polyurethane vascular grafts.

Pap en mam bedankt dat jullie mij de gelegenheid hebben gegeven te studeren en het vertrouwen dat jullie altijd in mij gehad hebben, en nog steeds hebben. Ik heb nooit de gemakkelijkste weg gekozen (en doe dat tegenwoordig nog niet) maar jullie hebben mij altijd gesteund in de keuzes die ik maakte. Dit is dan ook voor jullie: You are the best, I love you !!! 
Jos, mijn grote broer: ik vind het geweldig dat jij er nu wel bij kunt zijn. Je hebt al zo veel dingen moeten missen, wat voor beide partijen niet leuk was. Daarom ben ik ook zo blij dat je nu wel naast me kan staan.

En tenslotte blijven er nog twee mensen over: Jay, je bent nu nog zo klein en het meeste werk was al verricht voordat jij geboren werd. Jij trapte er lustig op los in mijn buik toen ik dit proefschrift aan het schrijven was, en hebt heel wat uurtjes met pappa moeten doorbrengen toen ik alles aan het afronden was. En dan tenslotte, Lieve Marc, altijd optimistisch en het volste vertrouwen dat dit werkje ook wel geklaard zou worden. Je hebt heel wat met mij moeten doorstaan (en nog steeds) maar dat kon, en kan, bij jou de pret niet drukken. Je bent een fantastische man en een hele lieve vader. 
